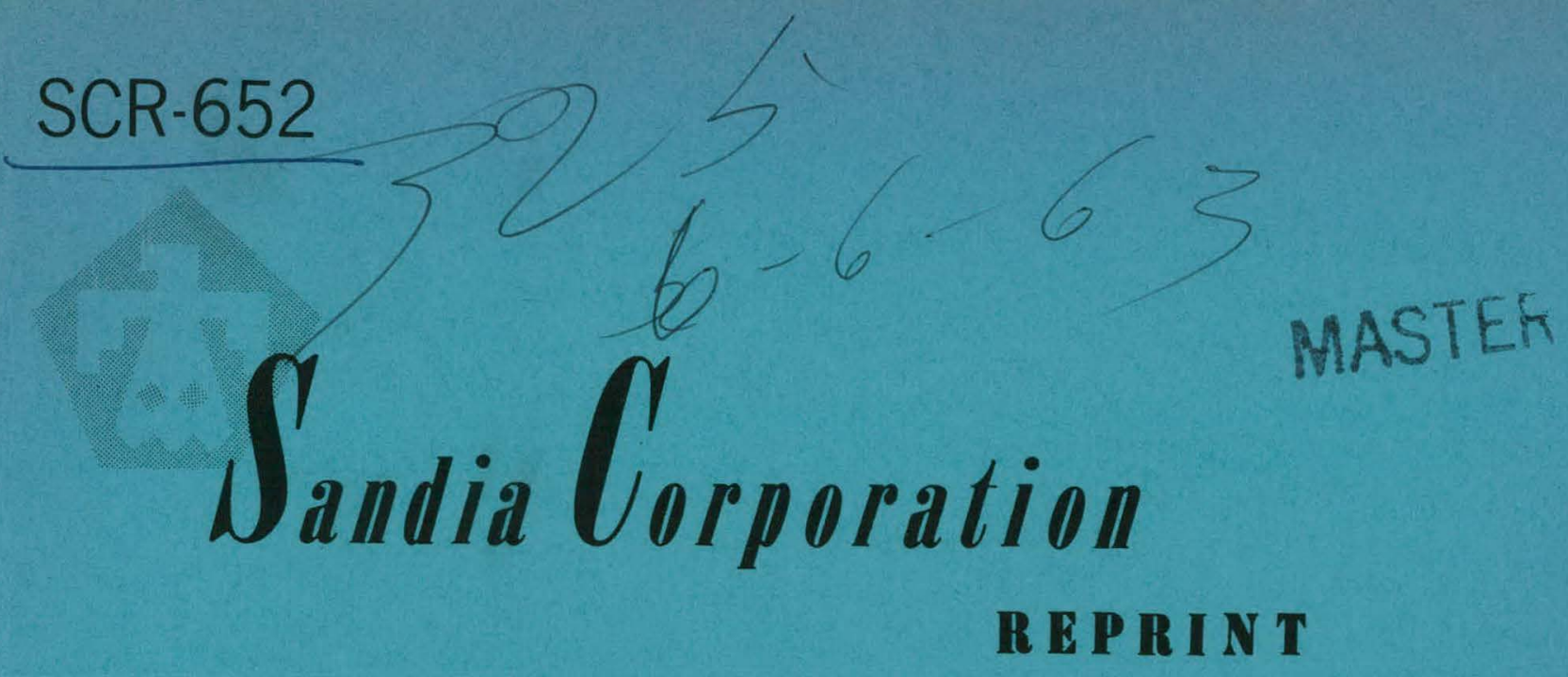

\title{
CONFERENCE ON \\ CLEAN ROOM SPECIFICATIONS
}

Held at Sandia Laboratory,

Albuquerque, New Mexico

April 9 and 10, 1963

May 1963 


\section{DISCLAIMER}

This report was prepared as an account of work sponsored by an agency of the United States Government. Neither the United States Government nor any agency Thereof, nor any of their employees, makes any warranty, express or implied, or assumes any legal liability or responsibility for the accuracy, completeness, or usefulness of any information, apparatus, product, or process disclosed, or represents that its use would not infringe privately owned rights. Reference herein to any specific commercial product, process, or service by trade name, trademark, manufacturer, or otherwise does not necessarily constitute or imply its endorsement, recommendation, or favoring by the United States Government or any agency thereof. The views and opinions of authors expressed herein do not necessarily state or reflect those of the United States Government or any agency thereof. 


\section{DISCLAIMER}

Portions of this document may be illegible in electronic image products. Images are produced from the best available original document. 


\section{Issued by \\ Sandia Corporation, a prime contractor to the United States Atomic Energy Commission}

Issued by Sandia Corporation,

a prime contractor to the

United States Atomic Energy Commission

\section{LEGAL NOTICE}

This report was prepared as an account of Government sponsored work. Neither the United States, nor the Commission, nor any person acting on behalf of the Commission:

A. Makes any warranty or representation, expressed or implied, with respect to the accuracy, completeness, or usefulness of the information contained in this report, or that the use of any information, apparatus, method, or process disclosed in this report may not infringe privately owned rights; or

B. Assumes any liabilities with respect to the use of, or for damages resulting from the use of any information, apparatus, method, or process disclosed in this report.

As used in the above, "person acting on behalf of the Commission" includes any employee or contractor of the Commission, or employee of such contractor, to the extent that such employee or contractor of the Commission, or employee of such contractor prepares, disseminates, or provides access to, any information pursuant to his employment or contract with the Commission, or his employment with such contractor.

Printed in USA. Price $\$ 2.50$. Available from the Office of Technical Services, Department of Commerce, Washington 25, D.C. 
CONFERENCE ON

CLEAN ROOM SPECIFICATIONS

April 9 and 10, 1963

Held at

Sandia Corporation

Albuquerque, New Mexico 


\section{CO-SPONSORS}

US Atomic Energy Commission, Albuquerque Operations Office Field Command Defense Atomic Support Agency

Sandia Corporation 


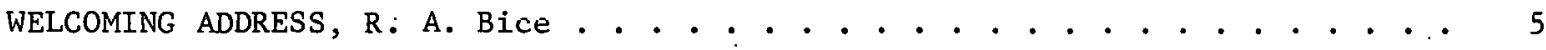

OPENING ADDRESS, L. A. Hopkins . . . . . . . . . . . . . . . . . . . . . 7

FIRST DAY - Morning Session

Need for a Uniform Specification, T. R. Casberg . . . . . . . . . . . . 11

General Aspects of Contamination Control, J. G. King . . . . . . . . 15

Cleanliness Versus Need, A. Lieberman . . . . . . . . . . . . . . . . . 17

Contamination Control - Cleaning and Verification, C. F. Bild . . . . 25

FIRST DAY - Afternoon Session

Introductory Remarks, Colonel I. R. Perkin . . . . . . . . . . . . . 35

Air Force Revised Technical Order 00-25-203, Lt. P. R. Austin . . . . 37

Navy Specifications and Factlities, F. C. Shadewald . . . . . . . . . 53

U.S. Army MIL-STD-1246(MI), J. W. Hodges . . . . . . . . . . . . . . . 55

Summary, Colonel I. R. Perkin . . . . . . . . . . . . . . . . 59

EVENING ADDRESS - The Medical Use of Clean Rooms, W. R. Lovelace II . . . . . 61

SECOND DAY - Morning Session

Introductory Remarks, J. F. Cully . . . . . . . . . . . . . . . . . . 71

State of the Art (Contamination Contro1) and Laminar Air-Flow

Concept, W. J. Whitfield . . . . . . . . . . . . . . . . . 73

Laminar Air Cross-Flow Room, F. L. Flinn and J. Gosma . . . . . . . . 87

Clean Bench, Stewart W. 'l'immerman . . . . . . . . . . . . . . . . . 97

Adaptability of Laminar Air Flow for Contamination Control,

R. C. Marsh . . . . . . . . . . . ... . . . . . . 101

SECOND DAY - Afternoon Session

Introductory Remarks, Colonel Charles E. Fay, Jr . . . . . . . . . . . 115

Special Sandia-Prepared Proposal, D. W. Ballard . . . . . . . . . . . 117 


\title{
WELCOMING ADDRESS
}

\author{
R. A. Bice \\ Sandia Corporation
}

Gentlemen, I'd like to welcome you this morning to this Conference on Clean Room Specifications, which is being sponsored by the Albuquerque Operations Branch of the Atomic Energy Commission, Field Command Defense Atomic Support Agency, and Sandia Corporation.

I thought it might be interesting and useful to you if I talked a few minutes on the interrelationship of the agencies in New Mexico and in Livermore, California, which are connected with the development of nuclear weapons. The Albuquerque Operations Branch of the Atomic Energy Commission has the responsibility for the development and the production of nuclear weapons, and it carries out a major portion of this responsibility through a number of prime contracts with various industrial concerns in the U.S., including the General Electric Company, Dow Chemical, Monsanto, American Car and Foundry, and so on. As one of these prime contractors, Sandia Corporation is responsible for ordnance research and development work, dealing with the nonnuclear portions of these weapons. The nuclear and physics portions are developed by Los Alamos Scientific Laboratories and by the Livermore branch of the Lawrence Radiation Laboratories. We feel very Fortunde in that we also liave a close working relationship with the various branches of the Armed Services. The Defense Atomic Support Agency, which runs Sandia Base, is a tri-Service organization. Among its important responsibilities are those of carrying on liaison with the development laboratories during the development phase of weapons, facilitating the transition between the development and field use by training the field troops in handing weapons, providing logistic support, and being responsible for the national stockpile sites. The Kirtland Field complex includes an Air Force agency and a Navy establishment. These two groups are responsible for fitting weapons into aircraft and making weapons and carriers compatible.

The development work in clean rooms that has gone on at Sandia appeared to be of such major interest throughout industry and government that it appeared to be in the national interest to establish a set of standards useful in the expensive installations necessary for controlling environment for very precise types of work, not only in atomic energy work, but across the whole defense establishment and its contractors. We are certainly hoping that out of this conference can come a method for the development of a standard that can be useful to all of us.

I'1l now turn the conference over to Mr. L. A. Hopkins, who is your Chairman for this morning session. 


\title{
OPENING ADDRESS
}

\author{
L. A. Hopkins \\ Sandia Corporation
}

Gentlemen, we in the atomic energy and atomic weapons business believe that the reliability of an atomic weapon can be expressed as a function of the design, the quality of manufacture, and the passage of time as the weapon is in stockpile. Our requirement for clean assembly facilities stems from these latter two factors. Our over-all objective is to design and build a high quality weapon which can remain in stockpile for up to 10 years and work the very first time it is called upon to work, although we certainly hope we never have to use our weapons. Further, we would like to design and build a weapon with such high quality and such minimum degradation in stockpile that the care of it by the Military will be held to an absolute minimum. We do not require the Military to make any last minute tests or any last minute adjustments before the weapon is used.

We have as one of the main safety devices in a good number of our weapons a small integrating accelerometer. It consists of a tube and a little piston, and, as this device is subjected to an acceleration field, the piston moves down the tube metering the air, thus providing the integration function. The clearances between the cylinder and the tube are measured in millionths of an inch, and obviously any micron-size particles would be ruinous. Even more important, this piston closes a pair of normally opened contacts when a certain velocity change is applied. These contacts stay open during the entire stockpile life of the weapon, up to 10 years. We expect these contacts to close with a low contact resistance after the long storage. So perhaps even more important than the precision of this gadget is the importance of keeping these contacts clean during manufacture. These then are two requirements which Sandia has for clean rooms. In some of our devices the contact pressures are measured in a few grams. In these cases it is extremely important that there be no contamination whatsoever on the contact, and we cannot, in this particular case, depend upon the wiping action of the contact to get low contact resistance.

Sandia has several million dollars invested around the country at our various contractors in "brick and mortar, stainless-steel wall-type"clean rooms, clean rooms built into the facility so that they cannot be moved. In our business, technology changes very rapidly, and we find it necessary to move from one contractor to another as the technology changes. About three years ago, Sandia established an advanced manufacturing development group of about 20 people to examine general manufacturing problems. They were free to take their time to come up with solutions to general manufacturing problems. One of the first things they looked at was the fact that we had many millions of dollars invested in permanent clean rooms. The specific project they undertook was to develop a portable clean room that could be moved from one supplier to another. They looked at the problem in its fundamentals, and Willis Whitfield came up with the laminar flow principle. We have applied this principle at several of our contractors and it has worked out quite successfully.

Since Sandia Corporation is a nonprofit organization entirely financed by AEC funds, we feel that it is important that anything that we come up with be made available to the rest of the government agencies and to their important contractors. Consequently, we decided to bring this group together so that they can have the advantages accruing from the taxpayer's dollar.

I'd like to introduce Mr. Tom Casberg, from the Office of Assistant Secretary of Defense, who will talk about the need for a uniform specification. 
FIRST DAY

Morning Session 


\title{
NEED FOR A UNIFORM SPECIFICATION
}

\author{
T. R. Casberg \\ Office of Assistant Secretary of Defense
}

\begin{abstract}
When it was first suggested that a talk be given at this conference on the need for a uniform approach to clean rooms, I quickly agreed, because I feel strongly that such an approach is essential. Then it was suggested that I should give this talk, and it forced me. to arrange my thoughts on this subject. After a brief analysis it occurred to me that such a talk was really not needed. If it is true that everyone recognizes this need then why try to argue people into recognizing the need? I sought an answer to this seemingly easy question. One evening when I came home I was suddenly confronted with the rather violent answer. I walked into the house and my three daughters ran up to me and said, "Daddy, it just isn't fair; we have already done it once this week." I was puzzled, but the situation soon made sense. I have a habit when I am working on something of keeping it in mind by writing one or two key words on a piece of paper and leaving it on my desk. My wife had found one piece of paper and, being thoroughly indoctrinated in the uniform approach, had taken the uniform approach. The words on the piece of paper were "clean rooms." They had done just that; they had cleaned their bedrooms for the second time that week. Here, to me rather obviously, was, a large segment of my answer.
\end{abstract}

I think everyone agrees on the need for uniform specifications or a uniform approach, but does everyone agree on the monning of "uniform"? Does everyone agree on the meaning of "clean room"? What is a clean room? You know the answer to that one of course, or do you? Listen to the definition of a clean room that I have here. It is a definition which one of the Services uses.

"The clean room shall consist of a complete enclosure in which windows and doors are tight fitting. The air supplied to these rooms shall be clean. A mechanical filter may be used if necessary to obtain the same amount of cleanliness as one could expect in a normal business office. Walls may be constructed of standard structural materials and shall be painted to minimize dirt pickup and facilitate cleaning. Personnel working continuously in such areas shall wear clean coverall or smocks without pockets, buttons, or badges and similar items. In those cases where dirt may be brought in from the outside, preventative measures such as shoe covers shall be employed. In general the room shall be free of dirt and debris and shall be maintained in a condition comparable to that which is normally expected in a business office or home."

You say that isn't a clean room? Here is another definition used by a large organization:

"A clean room is an enclosed space in which the physical environment is defined and contaminating matter is controlled in size and quantity."

I don't mean to ridicule this definition, but I can think of an enclosed space in which the physical environment is defined as "hot," the contaminating matter is of uniform small size, and the quantity is proportional to the incoming product, and the area I am thinking of cannot be called a clean room because it is a boiler room of a hand-fired coal plant. 
We do need a uniform specification on clean rooms, but first we need a uniform definition. We need uniformity in what we are talking about; we need to know what we are talking about. It is going to be very difficult to prepare a uniform specification without agreeing on what we are attempting to specify. We now have gray rooms, white rooms, some superclean rooms, and recently I saw in a technical journal where one organization had achieved a technical breakthrough and now there is an ultraclean white room.

We need a uniform specification for clean rooms that everyone can understand so that we will not confuse each other, so that manufacturers of military products will not be confused, so that suppliers and manufacturers of clean rooms and clean room equipment will not be confused. It is all too easy to specify a facility in such a way that others have difficulty understanding what is wanted. I'd like to use a personal illustration of this. I am a Texan, and as you know, everything in Texas is the biggest and the best. I happen to be the tallest midget from Hidalgo County in Texas. When people ask me how tall I am, I quite often tell them I am 5 feet 19 inches. This often rattles people, who walk back to their group and say, "I don't understand; I thought the fellow was at least 6 feet." I have used this gag to at least three professional engineeriling soclecles, all, aflur the rueting was over, at least two or three professional engineers would come up to me and say, "That was a real clever gag, but are you really be feel 9 ?" If I slaxled uut by telling you that professional engineers don't know how many inches there are in a foot, you wouldn't have believed me. The involved story demonstrates that you can specify something in such a manner that the reader or listener doesn't understand. Here's another example of what I am talking about. Two years ago, a branch of one of our military departments formally advertised for bids for a clean room. Six hids were received. and in addition to the bid, there was a statemenl from each prospective contractor saying in essence, "Here is our price for what we thluk you want. We don't really understand what you want, but, if we do understand what you want, we don't think you need it." This so confused the agency that they voided all of the bids, took suggestions from these six prospective contractors, rewrote the specifications, reissued the invitation to bid, and, when this project was finally awarded, the clean room that was built was over $\$ 50,000$ less than the original one specified.

As you know, this is a now field, and total knowledge is spread thin aiul is hard to get at. Recently. I was reviewing a request for a rather small facility called a clean room. I phoned a program officer and asked him to contact the installation involved and see if they had read the Air Force Tech Order. The program officer immediately told me this wasn't necessary since lliere was no requirement for them to read the Air Force Tech Order; they weren't in the Air Force. The same project included a requirement for "high efficiency filtration." I asked him what was meant by this. He assured me they needed a filter with at leasl a 20-percent efficiency. Don't smile. I might be talking about an isolated branch of your organization.

At the request of the Sandia Corporation (which has done a magnificent job in arranging this conference and deserves the thanks of everyone), I canvassed military requirements to determine the extent of interest in clean rooms. I started by going through all the areas that I know about, and, after exhausting this, I turned to a random look at the classified section of the Department of Defense phone book. I came across one element of one military department which indicated that it was a standards branch. I called this group and asked them about their interest in clean rooms. The fellow who answered the phone was nut overiy enthusiastic about clean rooms. He indicated that really chey were rather overrated and that they were simply air-conditioned rooms with a system that filtered out "dusty microns." You can imagine my relief when he told me that his organization had no requirement for a clean room.

We need a uniform specification because it will contain inputs from all groups and all users of clean rooms. The uniform specification should contain the sum total of all current knowledge in this rapidly advancing specialized field. When I reported to the commanding officer of a Navy engineering group in 1944, I noticed sitting on the corner of his desk a large, solid black, 15-inch cube. A small bakelite nameplate at the bottom, so small that you had to bend over to read it, said "Paper Weight, Mk 1 Mod 1." I picked up this cube and found that it was made of balsawood. Maybe your specification for your clean room is only Mk 1 Mod 1 ; maybe you have gone a step further than this; maybe you have gone to Mk 1 Mod 2 , or 
maybe Mod 3. I feel that if we take the combined knowledge of everyone we can very easily come up with a Mk 3 or even maybe a Mk 4 unit. We need a uniform specification on clean rooms to lower costs. By giving a supplier basic guide lines, ones that he knows will be the same for all government agencies, for all government contracts, for all government projects, he will know what is expected. He will be able to concentrate on a few problems and not hundreds of problems. He can pass on to us cost reductions and improvements achieved from a degree of standardization. We can benefit from competition because we can compare cost of like features and like facilities. Manufacturers of products for the government can keep costs down because they will build one clean room and not a new one every time they get a new spec or a new requirement. We need a uniform specification for clean rooms to achieve uniform results. After all, a clean room is simply a tool to obtain the final product. In many cases, clean room products not only represent very large sums of money but actually the security of the United States itself. A uniform standard can assure a uniform high quality in development, manufacturing, receiving, inspection, storage, handling, and utilization.

I see a few frowns. I hope some of these will change when I say that we don't desire uniform specifications to force clean rooms down to a price, but rather to force them up to a high quality. Don't punch your neighbor and say that that big Texan fxom the Pentagon has a five-sided brain; don't say he wants to put everybody in one standard clean room even if it won't do the job; this isn't so at al1. What I am trying to say can be illustrated by an analogy. According to the March 25 th issue of the Automotive News there are 336 models of standard American automobiles available in 1963, not inctuding motor options. Ford alone has 51 models. Somewhere between the 100-horsepower Falcon and the 425-horsepower Thunderbird, there should be a standard production model which will serve your specific needs very well. All I am trying to suggest is that we don't need the three-wheel, two-cycle, V-4, custom-built job with the pink vinyl top.

A uniform specification for clean rooms doesn't mean one clean room for all purposes. It simply means one uniform approach which will provide better clean rooms at a substantially lower over-all cost. 
GENERAL ASPECTS OF CONTAMINATION CONTROL

\author{
J. G. King \\ Sandia Corporation
}

\begin{abstract}
- There are few absolutes in science. At best, there are some convenient theoretical limits such as absolute zero, the speed of light, or an absolute vacuum. Even though we use. these in our calculations, we cannot reach them in practice. In design form, a component is perfectly clean and (theoretically) operates perfectly. When the design is translated into hardware, however, there is no such thing as absolute cleanliness, and troubles begin to mount. The very best that we can do is to recognize that contamination problems always exist and try to control conditions so that the problems are minimized.
\end{abstract}

By definition, contamination is any foreign material that renders something unfit for use. For our purpose, "rendering unfit for use" may have a wide range of meaning, from the outright stopping of function to the lowering of reliability by a fraction of a percentage point. Contamination control, therefore, can be defined as the removal (and protection against reintroduction) of foreign material to a degree which is acceptable in terms of its effects on the item being produced.

For purposes of discussion, we have arbitrarily divided contamination control into four general areas. These areas are all interrelated but may be considered separately. These definitions are chronological in the same sense that design concept, production, inspection, and packaging are chronological. The general areas of contamination control are:

1. Cleanliness Versus Need -- This area is concerned with how clean the component needs to be. Hundreds of parameters enter into this decision. There is a great need for definitive information which would permit prediction of requirements. At the present time, the approach is strictly empirical or, even worse, based solely on opinion.

2. The "Second General Area of Contamination Control is Cleaning -- This area is concerned with the removal of foreign material which may be solid, liquid, gaseous, film, particulate, hydrophillic, hydrophobic, hard, soft, soluble, insoluble, and so forth. Cleaning methods are usually specific, but many times we treat them as being universal.

3. The Third Area is the Verification of Cleanliness -- Very few methods exist for verification in production. We are generally limited to what we can see either directly (with or without magnification) or indirectly, by observation of water-break or similar tests. We have no commercial test equipment calibrated in "clean units."

4. The Fourth Area is Environmental Protection -- This area can be defined simply as the protection of the item from recontamination after it is cleaned to the desired degree. In general, this area deals with the period from.cleaning to final packaging.

Each of the first three areas needs much work to bring it out of the "art" stage to the point where orderly, scientific decisions can be made based upon the component operational and quality requirements. Because of the lack of knowledge in these areas, we are forced into expensive empirical decisions. Errors may be made in either direction. We risk excessive rejects when parts are not clean enough, or we needlessly overprocess and overbuild facilities. 
The fourth area, that of environmental protection, -is really the subject of this conference, even though the next two speakers will give brief surveys of the first three areas. Environmental protection includes providing air of the proper cleanliness, developing proper handling procedures to prevent direct transfer of contamination, controliling both processing and testing, and providing a final enclosure or package which is a permanent barrier to contamination.

Current knowledge and equipment are available to control airborne contamination to any desired degree. In fact, it is quite easy to provide an atmosphere cleaner by far than any known requirement. I would like to emphasize that developments made recently have so changed the entire contamination control picture that the ultimate cleanliness of a component or assembly is now a direct result of cleaning, processing, and handling. In other words, it is now possible to provide such facilities that airborne contamination is no longer a problem. For this reason we believe that the time has now arrived to categorize and standardize clean facilities. 


\title{
CLEANLINESS VERSUS NEED
}

\author{
A. Lieberman
}

Armour Research Foundation

Basically, the need for cleanliness and cleanliness itself can be understood as three definitions. The first is the need for device cleanliness; the second definition is that of cleanliness itself; the third definition is a group definition aimed at defining Lhe problems involved in attaining a practical level of cleanliness.

The need for cleanliness is based upon the operational requirements of precise devices. Such devices include electronic, mechanical, hydraulic, pneumatic assemblies, subassemblies, and individual components. The scope covers the cntire range of manufactured objects, and each device must operate correctly within narrow ranges of performance and with extreme reliability as has been pointed out just previously. Operation according to these specifications often requires that the component subassembly or device be free and clean of contaminants because contamination may interfere with the motion of components of a device. It is immaterial whether the interference affects the rate of motion or the energy required to produce the motion. The motion can be sliding or rolling; it can be uniform or intermittent; it can be any combination. Contamination may affect the position requirements of timers, switching devices, and so forth. Contaminants also interfere with energy transmission when mechanical or fluid energy transmission is consideren This in turn can affect the flow rate of fluids and the pressure capability of fluid systems. 'l'he meclinism with whirh contaminants interfere with required operation, are many and varied. Dimensional changes can result frum wear: and friction effects over an adequate period of time. These minute changes can result in subcomponent degradation due to galling, seizing, blockage, or slipstick phenomena in moving devices.

Catastrophic failure can also occur when increased friction causes local heating which then can result in thermal expansion and subsequent seizure. In high-speed devices structural failure usually occurs; in low-speed devices welding sometimes happens. In electrical systems, arcing across heated conductive materials which were not conductive before they were heated is a potential outcome.

The fusion of particulates or of gaseous contamination into the surface of a component is sometimes responsible for the formation of a compound or alloy whose physical properties differ from those of the substrate. Some years back there was a problem known as the brown polymer formation. This is one very familiar example of such an effect due to gaseous contamination. Localized failure of the substrate due to change in tensile strength, creep rate, brittleness or conductivity is a common occurrence when this happens.

A device which is to operate correctly cannot tolerate any of these phenomena. This means that the device must be clean or at least the unavoidable contaminants must not produce harmful effects. This, in essence, is the definition of cleanliness itself. Bluntly stated, cleanliness is "just short of the amount of dirt that causes the problem."

Unfortunately the amount of dirt which causes the problem can vary from device to device and from requirement to requirement. In addition, the type of dirt which is harmful also varies, but the major criterion is still the ability to cause damage. This means that any material to be considered as a contaminant must be in a defined and harmful physical location and must have physical properties that result in damage. The dandruff on our coat collars is not a contaminant 
until it gets into the components which can be harmed. Even gaseous materials cause problems. In the case of metals, acid vapors produce metal salts which can cause damage in other locations and, in addition, by virtue of their formation, can cause local weaknesses. The organic vapor in noble metal reaction products of course covers the brown polymer situation. Particles which are present in sizes too small to cause any physical damage cannot be considered as contamination until or unless they diffuse or otherwise travel to a location where their size is critical or if they aglomerate into a larger particle. Potential contaminants may be present in systems whose materials are hard and/or tough enough to destroy the particle without damage to the system. In this case, although the particle is present in quantities that would normally be harmful in other systems, it is not a contaminant but is just a particle that is about to be rejected by a tough system.

Figure 1 shows the type of material which can be a problem. This is an electron micrograph of material which was collected in a laboratory atmosphere. This material was deposited by a low efficiency electrostatic precipitator so that the aglomerates would not be harmed. The material was then shadow-casted with germanium and the electron microscope was used to obtain a photograph. As you notice, we shadow-casted in two directions. The aglomerate in the upper center is a little better than a micron in length. It is composed of particles which are themselves only a few tenths of a micron in diameter. Normally these particles would not be a problem but because of their aglomeration they will causc difficulty. Toward the lower left is a droplet which also contains smaller particles. This again could he a problem but does not neccssarily have to be.

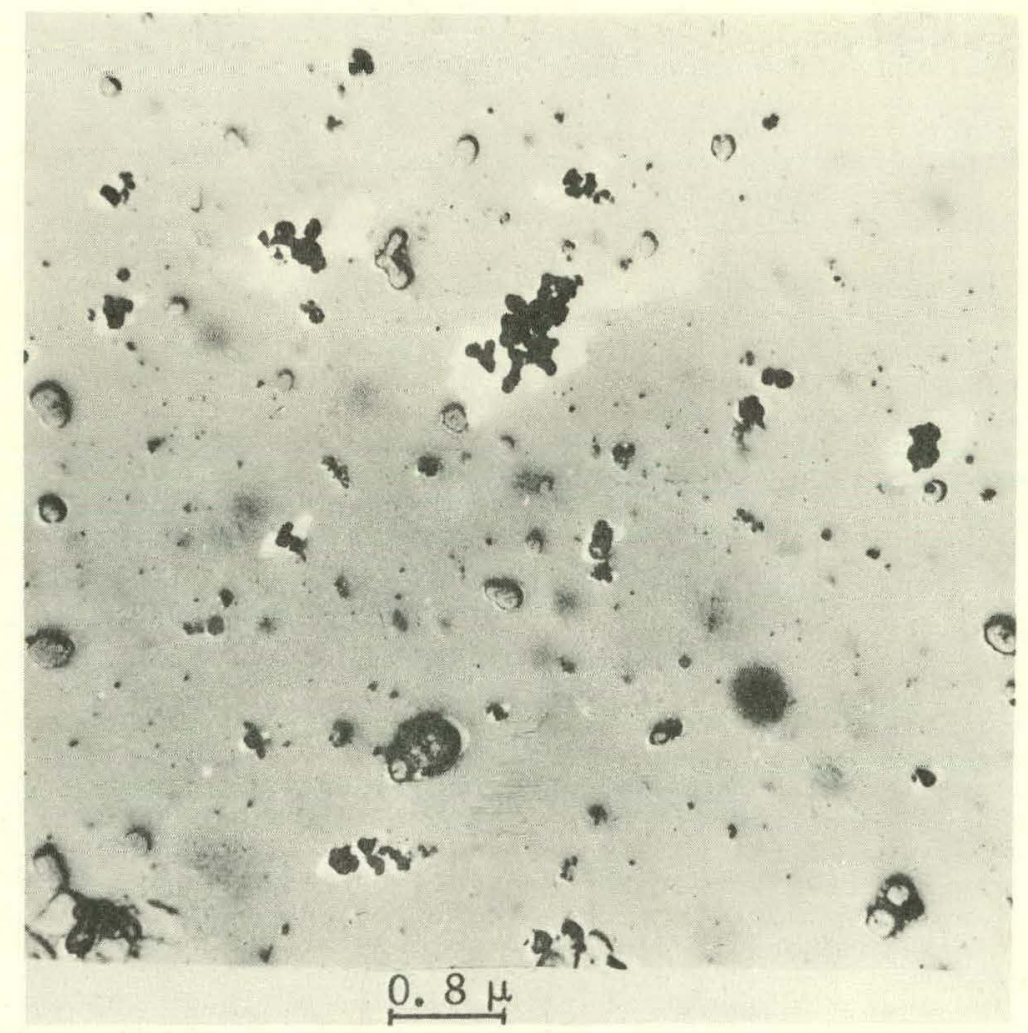

Figure 1

Figure 2 is a selected sample of dust collected from a building ventilation system. The particle on the right is approximately 100 microns in diameter. Again, particles which would not cause problems individually might do so when aglomerated. 


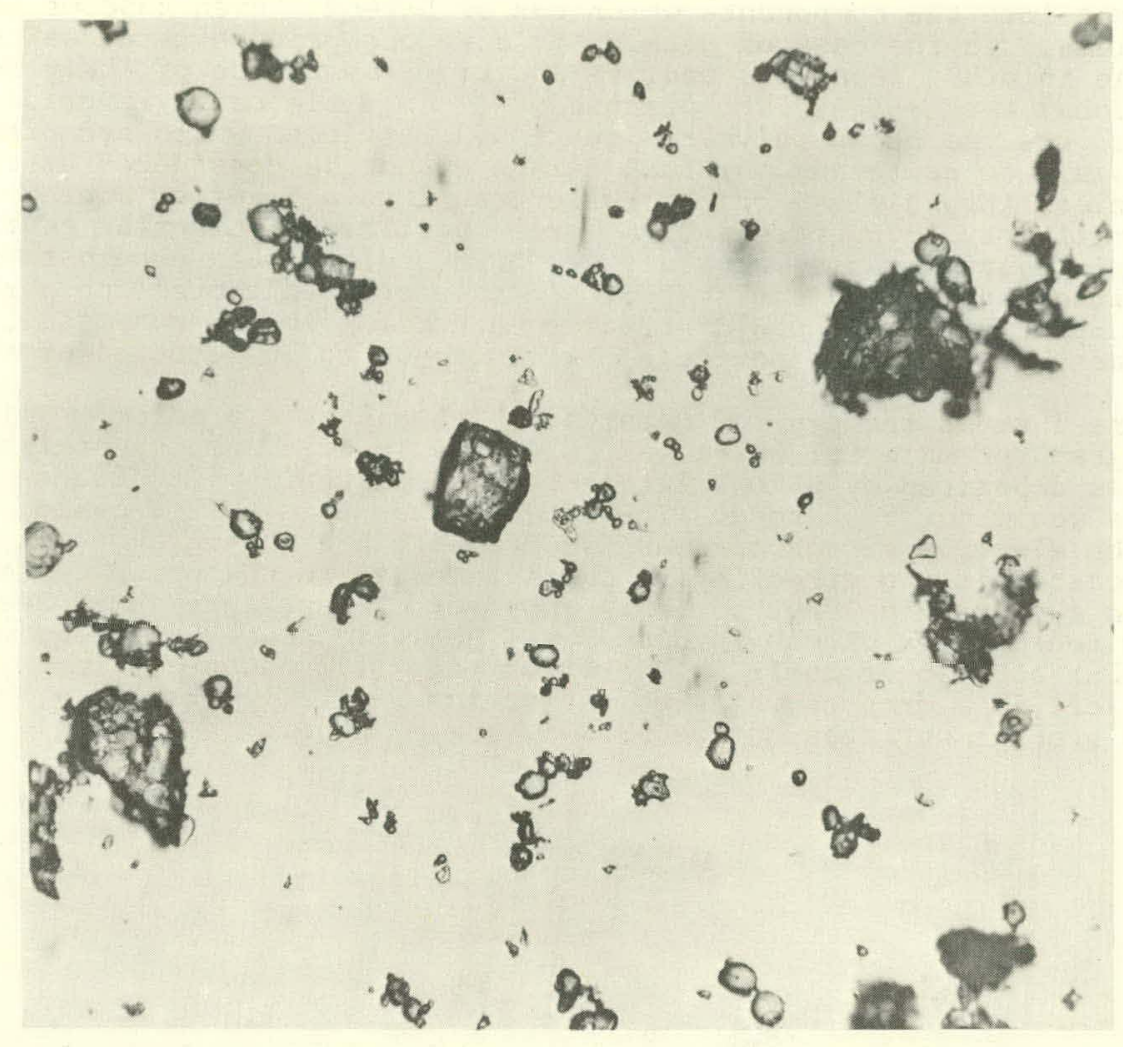

Figure 2

Only when a device is operated at an energy level which is sufficiently high to destroy any aglomeration without interference is the aglomerate not a problem. If the device operates at a lower energy level then the same aglomerate produces a cleanliness problem. In some cases it has been found necessary to increase the available energy for device actuation as a means of reducing contamination problems.

Explosive actuators have been used where single-shot, high reliability action is required. In general, contamination problems are inversely proportional to the amount of energy available for device actuation. In this same way, transmission of large amounts of energy is not sensitive to contamination to the degree that transmission of small energy levels is. At first glance it appears that almost every problem must be considered individually, each device, each application, each subcomponent, and so forth, but this is not necessarily the case. Careful observations of the requirements and problems of individual devices show that type classification within the device and across device types is possible. Classes of cleanliness vary from those required for assembly and preparation of thin film devices to those involved in the manufacture of heavy rotating electrical machinery.

The need for cleanliness must be examined on an economic basis--that is, the cost for attaining a desired degree of cleanliness must be weighed against expected benefits and requirements. Costs invariably rise with the necessity for eliminating the possibility of contamination effects. Note, I say "contamination effects" must be eliminated, not the contaminants themselves, since their complete removal is for all practical purposes impossible. Let us examine contaminants and some possible procedures for eliminating them.

Consider four major areas where contamination affects the operation of a precise device. These areas include manufacturing, assembly, storage, and operation. 
Manufacturing may consist of casting, stamping, rolling, molding, and machining operations, and it may include materials which may be metallic, plastic, or a combination. Contaminants introduced during manufacture operations include casting inclusions, carry-over from previous manufacturing operations, and so forth. Generally this kind of contamination consists of fairly large easily distinguishable inhomogeneities which will later become contaminants. These may be removed during the cleaning process, and standard cleaning processes are usually effective for removal of all materials which are not physically or chemically well bonded to the submaterial. Contaminants produced during manufacture are not too serious if they are removed. Subsequent normal cleaning operation can eliminate them. Personnel who are responsible for removal of these contaminants must be we 11 versed in these arts.

Major contamination problems are introduced during the assembly of parts where installation of fasteners with some fitting operations is required. Assembly processes involve an appreciable amount of hand labor and hence personnel problems increase. During assembly, fitting, and fastening processes abrasive particles are produced which are small enough to be suspended in air for some time. These particles may be redeposited somewhere in the assemhly areao. The 1.dryer particles, of course, fall almosl lirectly downward from where they have been produced. The normal content of particle contamination in the air may vary from a few hundred particles per cubic fout to several million particles per cubic foot. The size of particles can reach approximately 50 microns even in a controlled white room. Figure 3 shows some expectcd deposition rates on horizontal surfaces. This curve will give an idea of what type of deposition one might expect once he has a reasonable idea of the concentration of the material in the air. This particular curve was drawn for particles which cover the general 1 to 6 micron atmospheris dust size distribution. When parts are expnsed for any appreciable period of time the fallout can illıedse by a very sizeable amount. Note that the abscissa on this curve describes a logarithmic scale in number of particles per square millimeter per minute. The usefulness of the clean air supply is obvious from the data shown.

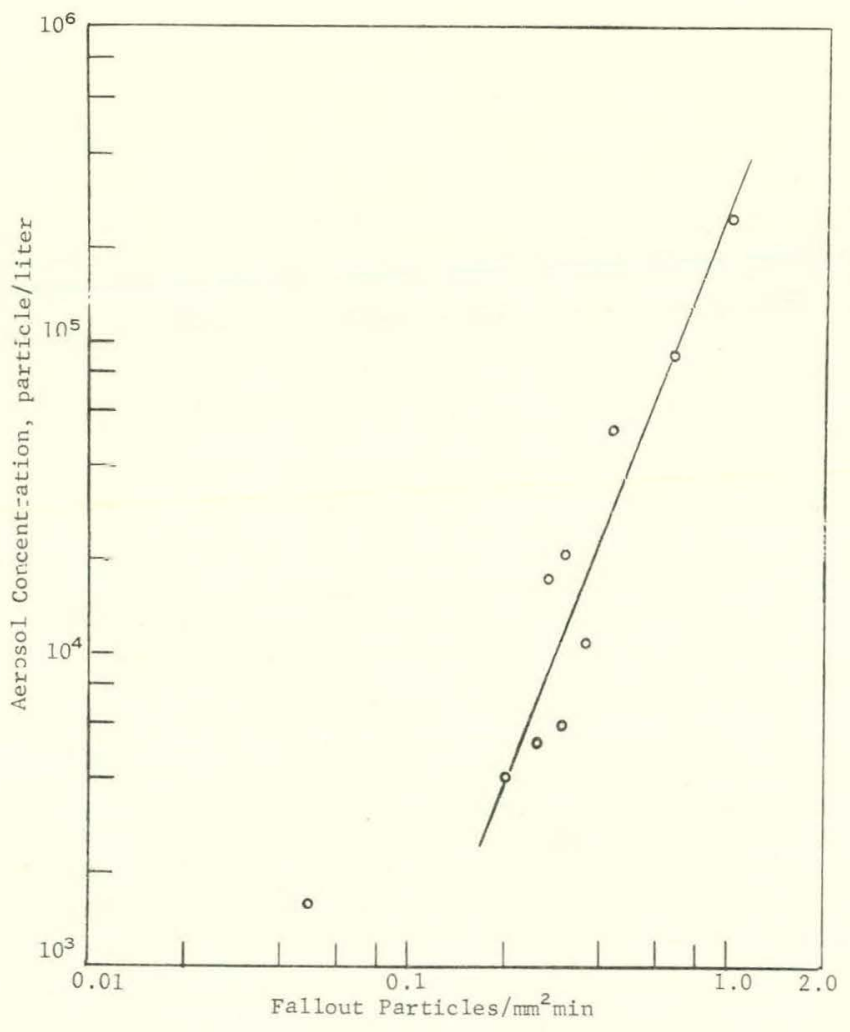

Figure 3. Relationship between aerosol concentration and rate of particle deposition 
Taken in conjunction with the rates shown in Figure 3 , the concentrations which one may expect in areas shown in Figure 4 indicate the necessity for keeping the air as clean as possible.

\begin{tabular}{|c|c|c|c|c|c|}
\hline \multirow[b]{2}{*}{$\begin{array}{c}\text { Particle Size } \\
\text { Range, microns } \\
\end{array}$} & \multicolumn{5}{|c|}{ Number of Particles per Liter } \\
\hline & $\begin{array}{c}\text { Precision } \\
\text { Assembly } \\
\text { Room } \\
\end{array}$ & $\begin{array}{c}\text { Small } \\
\text { Enclosed } \\
\text { Hood } \\
\end{array}$ & $\begin{array}{l}\text { Semi- } \\
\text { Clean } \\
\text { Room } \\
\end{array}$ & $\begin{array}{c}\text { Prefiltered } \\
\text { Air } \\
\text { Supply } \\
\end{array}$ & $\begin{array}{c}\text { Genera } \\
\text { Plant } \\
\text { Area } \\
\end{array}$ \\
\hline $0.5-0.7$ & 257 & 363 & - & - & - \\
\hline $0.7-1.0$ & 16 & 40 & 746 & 2,123 & 56,870 \\
\hline $1.0-1.4$ & 1 & 8 & 189 & 528 & 18,480 \\
\hline $1.4-2.0$ & 0 & 0 & 43 & 100 & 3,660 \\
\hline 2. $0-2.8$ & 0 & 0 & 12 & 19 & 375 \\
\hline 2. $8-4.0$ & 1 & 0 & 2 & 6 & 42 \\
\hline $4.0-5.6$ & - & - & 4 & 4 & 12 \\
\hline Total & 275 & 411 & 996 & 2,780 & 79,400 \\
\hline
\end{tabular}

Figure 4. Particle counts in various areas of a plant

It is often necessary to clean individual components during the assembly process. Again it is sometimes difficult to realize that the cleaning process itself can be a source of contamination. Any cleaning process involves transfer of dirt from a higher concentration to a lower one. Hopefully, the higher concentration is on the part and the lower one is in the cleaning fluid, and not vice versa. One can contaminate during cleaning as result of transfer in either a dry or a wet stage. Dry transfer usually occurs when very large numbers of particles are removed by wiping with an absorbent material. The absorbent material can deposit fihers on the surface, or it may be that the absorbent cannot break the bond between the contaminant and the suslace itoolf. Wiping action can cause electrical charging of the surface and any particles in the air if they are opposilely charged will be attracted to it at a very great rate. Wet cleaning exposes the contaminated surface to a clean fluid which wets the particles and the surfaces. Agitation removes particles from the surface, the contaminated fluid is removed from the surface, and the surface is then dried. The mechanism used in this cleaning process often results in partially or improperly cleañed surfaces. Differences in energy distribution in the cleaning tank where ultrasonic cleaners are used, careless handling during vapor-degreasing processes, and increased sticking probability when a wet object is exposed to a dirty air stream all result in contamination of a supposedly clean device. This phase of the problem is not connected directly with the contamination source as such, but with the removal of previously acquired contaminants .

The air in the environment in which precise devices are assembled is well cleaned and conditioned. Normally a superinterception filter is used which removes particles 0.3 micron and up with high efficiency. Even so, the assembly environment often contains an appreciable number of particles large enough to cause problems. The assembly environment then adds contaminants to the air which was previously cleaned. This does not contradict Mr. King's earlier statement. The air can be cleaned to almost any degree required, but the environments through which the air passes subsequently add contaminants to that air. Some particles penetrate even in an effective superinterception filter. Consider air with concentrations of some 10 million particles per cubic foot larger than 0.3 of a micron. Even with a filter of 99.97 -percent efficiency, several thousand particles per cubic foot can still pass through. It is advisable to refilter the air by utilizing a clean work bench or a multiple filtration system. The control of entering air implies care in the installation of the filter assemblies. The relatively high pressure drop, which is really only a few inches of water at most, across a high efficiency filter will aggravate the rate at which dirty air can bypass the filter if even a small hole or crack in the filter installation or in the bank of 
filters exists. Most contaminants in a clean environment are produced by reentrainment from a surface where they were previously trapped. Once this has been done, subsequent redeposition on a critical area can occur. In addition to the re-entrainment of particles, abrasions or impacts can cause particles from walls, ceilings, or floors to enter the atmosphere.

Lubricant droplets and cooling liquids in cleaning liquid droplets may contain particles which will contaminate critical surfaces and cause damage at a later time. But the greatest source of contaminants is generally agreed to be the activity of the personnel. Figure 5 demonstrates the correlation we obtained in a number of work spaces using the personnel load factor as the independent variable and the contaminant concentration in the air as the dependent variable. The degree of correlation is obvious, and, after we first plotted it, we replotted it because the curve looked too perfect. The contamination arises from several sources. Walking produces transient turbulent air currents that encourage re-entrainment from floor surfaces; dust is pumped from inside shoes, and material is transported through the clean uniform interstices. Body surfaces shed particles of skin and hair continuously. Skin flakes depend upon the amount of abxasion to whish the skin is exposed and the condition of ll!e skin itselt. Perspiration and other body exudations contribute to the problems. Extensive training is necessary to minimize the effects of the contaminauls which are inevitably pruduced by personnel.

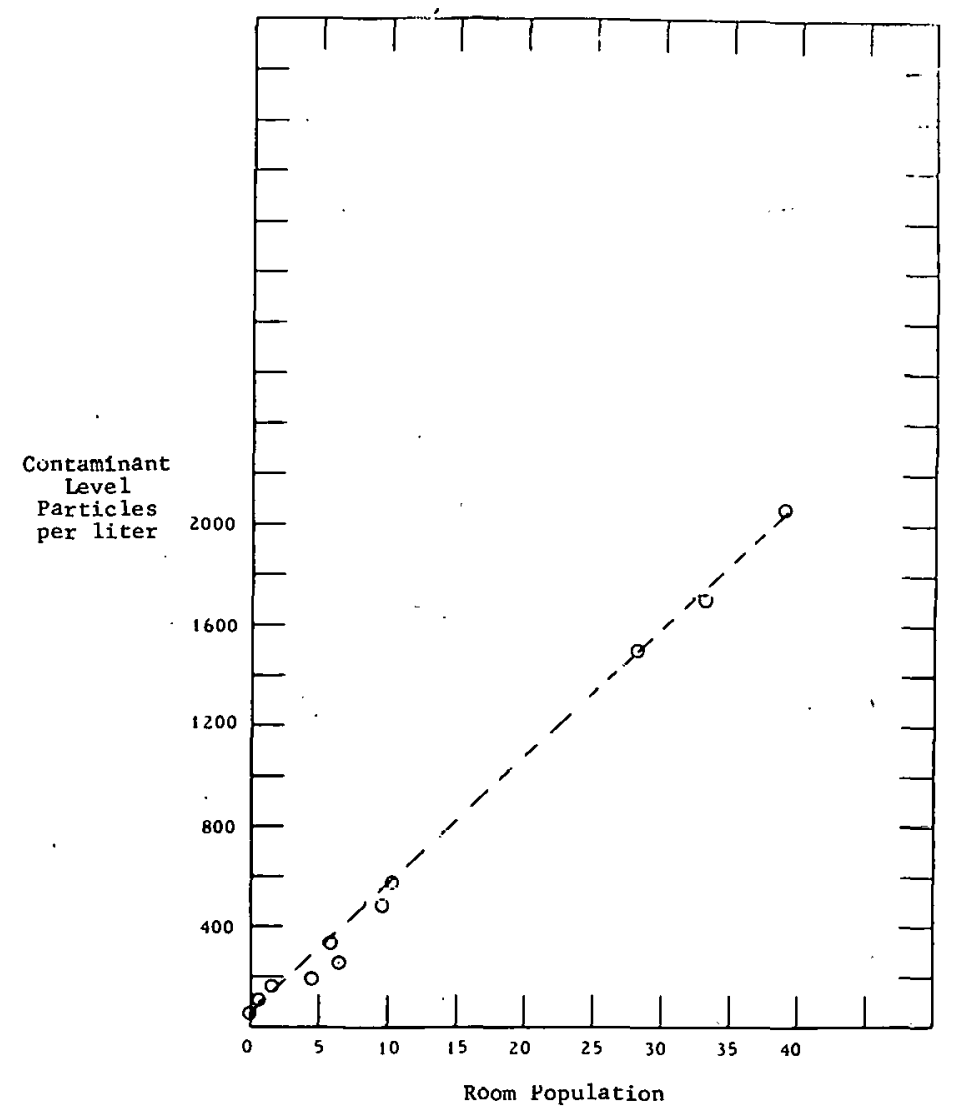

Figure 5

Sometimes during or after assembly a device is stored. The storage period may range from a few hours to 10 years. During this time, contamination of the device, even if it has a protective covering, can occur. Shipping from one location to another creates an additional problem. Particles present within a device, or on the interior of the case, can be transported from a harmless to a critical 
location by vibration. The mean concentration of particle contamination in a - sealed case may be very low, but, if breathing due to temperature differences occurs, then the contamination level can be maintained over a fairly long period of time. Thus continual diffusion to device surfaces can occur. Improperly cleaned containers will transfer particles to the device. This is especially true of padded containers and plastic containers. Contours of padded containers trap particles which are not released until the device causes deformation of the padding. Plastic containers pick up particles from the air and retain these particles as a result of electric charge. After the charge leaks off, the plastic surfaces will deposit the particles on the device. One of the possible causes of device failure is the generation of particulate contamination during normal operations. The necessary stresses involved in the normal operation cause wear and friction which produces particulate contamination. There is a series of articles appearing in the journal Wear over the last 5 or 10 years which describes the rate of contaminant production as a function of materials of construction and stresses. These articles may be of some interest to designers especially. Particles can migrate to a critical location. This type of problem is best controlled by properly designing the device, assuming that knowledge is available on particle effects. By "design" I am referring to correct selection of mating surface materials and of mating surface clearances.

At this time we have not solved all the problems in the contamination field. The manufacturing contaminant production problems that have been solved include those due to cutting oil contamination which can be removed quite easily by standard degreasing processes. With regard to problems of casting inclusion, however, although we can state that these problems exist and that we know quite definitely what they consist of, we do not have the solutions for them. We know that castings can contain inclusions which may be harmful, but by using plastic filler or metal filler we can take care of those. The problem of removing grinding operation contaminants is not at all solved. As sembly operation problems include those of mechanical assembly processes which can be controlled to some extent by improved quality control. These problems can be solved, but they will require appreciable expenditure of time and effort for satisfactory solution. Particle transport and re-entrainment problems in an airstream are probably easiest to handle. They require only sufficient expenditure in time, space for air cleaning, and velocity control measures. If necessary, the expenditures can go to such arrangements as assembly or manufacture in a complete vacuum system. Ihe problems can be solved. Personnel operation problems are not easily handled and I rather doubt that they will ever really be solved. The best we can do is to keep a thumb on them and hope they don't pop out from under too often. Training personnel to avoid dirtproducing situations is a major problem in itself. Production and transport of contaminants during storage have not been described completely nor solved satisfactorily. The requirements for cleaning, sealing, and so forth, are not thoroughly defined. Contamination produced by operation of devices is being studied to some extent, but the studies are far from comprehensive. Most of the studies on wear-particle production deal with particle production in the 50-micron-and-up range. I think we should start looking at the problems of particle production in the 1-micron-and-down range.

In conclusion $I$ would say that much of the knowledge required for practical contamination control and required for future contamination control is now available. It requires that qualified organizations and persons agree on the information needed to fill the gaps in our knowledge, to define exact requirements, and to examine and/or catalog present information. . 


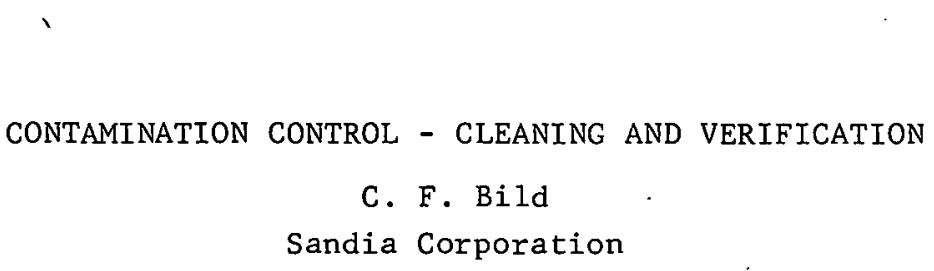

In the sophisticated componentry of today's technology, very small amounts of a contaminant can cause failure. Clean air and work areas are essential to effective contamination control, but are only a partial solution to the over-all problem. Your program chairman asked that I highlight some of the other aspert.s, with emphasis on cleaning and verification methods. I plan to do this within the framework of Sandia Corporation expertence.

Before discussing cleaning methods and verification, it is necessary to first say something about reasons for cleaning, important factors in achieving cleanliness, and types of contaminants.

Following are some of the major reasons for cleaning:

1. To achieve low and stable contact electrical resistance

2. To control insulation resistance

3. To prevent mechanical interference

*4. To achieve low or reproducible friction characteristins

5. To enhance adherence of films

*6. To eliminate corrosive residues

${ }^{{ }^{*}}$ Cleaning can aggravate as well as help.

Sandia has been concerned with all of these reasons, but achieving low contact electrical resistance and good adherence of films have probably been the two major areas of concern. Note that in two of the reasons mentioned, cleaning can aggravate as well as help; namely, in achieving low friction and in eliminating corrosive agents. For example, development prototypes with contaminant films acting as lubricants may work well. Later, production units made and assembled under strict cleanliness procedures may gall or corrode. Also, if the design contains crevices that are difficult to.rinse, a corrosive cleaning agent may be trapped and contribute to corrosion, instead of preventing it. Care must be taken during development to avoid such pitfalls.

Some of the important factors in achieving cleanliness are:

1. Design

a. Geometry (for example, the avoidance of crevices which could trap contaminants)

b. Materials selection (for example, the avoidance of materials which outgas to produce contaminants):

c. Process definition (for example, the use of welding instead of soldering where possible in order to avoid flux contamination) 
2. Manufacture
a... Environment
b. Fabrication methods
c. Cleaning methods
d. Cleanliness verification tests

3. People
a. Personal actions and habits
b. Technical know how

The major types of contaminants with which we are involved follow:

1. Discrete particles (airborne, processing debris, wear pruducts, debs 13 generated by perennnel and ciothing, etc.)

2. Organic films and resldues (cutting oils, machine lubricants, parting compounds, mold release, cleaning agcnt residues, process materials, outgassed products, contact "polymer" material, solder flux, finger prints, etc.)

3. Inorganic films and residues (tooling smears, process materials, plating residues, corrosion products, cleaning agent residues, finger prints, etc.)

I should mention at this point that there is considerable confusion in the literature as to when to call a particular type of contamination a film or particulate. matter. Because of this confusion, we hear some people say, for example, that the majority of electrical contact contamination problems are the result of particulate matter and others say the result of films. Yet both may be talking about the same thing.

With this background, let us look at the methods of cleaning that are in common use (Table I):

\section{TABLE I}

Cleaning Methods

\section{Type \\ Chemical. \\ Agitated chemical}

Mechanica1

Electrica 1

Thermal

\section{Cleaning Material}

Etchant, solvent, detergent

Solvent, detergent

Abrasive

\section{Techniques}

$$
\begin{aligned}
& \text { Immersion, spray, vapur } \\
& \text { Ultrasonics, mechanical. } \\
& \text { agitation } \\
& \text { Scrubbing, tumbling, blasting } \\
& \text { Glow discharge, electropolish } \\
& \text { Vacuum heating (electron bcam, } \\
& \text { Induction, resistance) }
\end{aligned}
$$

It is important to remember that no one cleaning method or cleanliness verification test is universal. Each is specific, and because of this, it is necessary to know the probable types of contaminants before defining an effective cleaning method. Also, the degree of cleanliness required depends on the function of the part. 
Sandia has been concerned primarily with two general approaches to cleaning. One approach is typified by cleaning of parts for high reliability, long-life vacuum tubes, and it involves a very rigorous cleaning schedule and strong cleaning agents. To illustrate how rigorous these cleaning schedules are, one typical tube assembly being manufactured for Sandia has 54 parts. A total of 153 operations are required to put these 54 parts together; 41 of the 153 assembly operations, or approximately 28 percent, are cleaning operations. This particular supplier is very knowledgeable in contamination control and worked out cleaning operations including methods such as vapor blast to remove gross particulate matter and oxide films, solvents, detergents, and oxidation-reduction reagents to remove organic matter and ultrahigh purity water for rinsing. Ultrasonic agitation of the liquids is utilized. Also, numerous other types of cleaning such as acid cleaning, alkaline cleaning, and vacuum firing are sometimes used. In vacuum tube cleaning processes, extreme cleanliness is necessary for high reliability and long life. Parts and subassemblies are relatively simple in shape without capillary crevices and no plastic parts are involved. Thus severe, rigorous methods are necessary and can be used.

A second approach to cleaning, with which Sandia is concerned, is quite different and it constitutes the majority of our problems. This approach involves the cleaning of parts, subassemblies, and complete assemblies of components made of a variety of materials including metals and plastics. These assemblies often contain large numbers of parts and usually include many crevices and capillary traps from which strong cleaning agents cannot always be thoroughly rinsed. Typical of such components are timing and switching devices with wheels, gears, rotary and stationary printed circuit boards, electrical contacts, and bearings requiring low and controlled friction. Because of the large amount of handling during assembly, it is necessary, in addition to part cleaning, to also clean subassemblies and complete assemblies before sealing of the containers. Epoxy staking operations, adhesive bonding and sealing, soldering, and other assembly operations further complicate the picture. The variety of materials, plus the crevices and capillary traps, prohibit the use of strong cleaning agents such as can be used on simpler piece parts. Therefore, compromise procedures utilizing relatively mild solvents and detergents are used, followed by extensive rinsing and low temperature vacuum bake. Ultrasonic agitation of the cleaning liquids, at a relatively high energy level, is used to penetrate the assembly. The problem is aggravated in cases where the assembly or fixturing if relntively masive in that much of the ultrasonic energy is damped and absorbed. Also, there is a limit as to how high an energy level can be used or some of the more fragile parts will be damaged. Extreme care must be taken in design of cleaning fixtures. Thus everything about the cleaning operation becomes a compromise. All this says that more attention must be paid to processing and handling operations with the purpose of preventing contamination.

A typical cleaning procedure for the type of subassembly or final assembly just described consists of five steps. The first four steps are: (1) trichloroethylene solvent, (2) a nonionic detergent, (3) distilled or deionized water, and (4) high purity isopropyl alcohol. Between each of the se first four steps, the assembly is blown dry with dry filtered nitrogen. Particular care is taken to see that the nitrogen is clean to avoid recontamination. The fifth and last step is usually a low temperature bakeout.

There is no single solvent capable of removing all types of contaminants without being so reactive as to damage parts being cleaned. Therefore, the choice of solvent is always a compromise. Trichloroethylene cannot always be used because it will attack some plastics and insulation materials. With most plastics, no problem is encountered with trichlor unless the plastics are incompletely cured. Acid and alkaline solvents, though very effective on some parts, can, of course, not be used in the type of component assembly just described. The rather mild cleaning procedure just outlined has been found to be effective and "safe" for most of these applications. The types of solvents and cleaning schedules vary with the particular manufacturing line and assembly sequence and with the particular contaminant removal problem. Two of the most commonly used solvents at Sandia are trichloroethylene and isopropyl alcohol. It is important that these solvents be pure so as not to leave deposits, and it is important that trichloroethylene be chemically stabilized to eliminate free $\mathrm{HCl}$. Also, regardless of the solvents used, parts should normally be heated in a vacuum to remove final traces of solvent because it is difficult to remove even relatively volatile solvents from capillary-like enclosures by any other method. 
The detergents most commonly used at Sandia are of the nonionic type and have, in general, done a satisfactory job. Recently, Alconox, an ionic detergent, has been compared with Igepal, which is one of the nonionic detergents, and has proved superior in removal of certain specific contaminants. This comparison was made in preparing substrates for vacuum deposition of metallic films. Further evaluation of this ionic detergent is continuing. The effectiveness of Alconox will be mentioned again during the discussion of verification tests.

One other example of a cleaning method used on Sandia products will be mentioned; namely, the preparing of metal surfaces for painting. A typical cleaning procedure consists of: (1) wipe off gross contamination with a dry cloth, (2) abrade the surface with sandpaper, (3) rinse with water while wiping with clean cloths, (4) wash with abrasive powder cleaner and wet cloth, (5) rinse, (6) clean with chemical solvent, (7) rinse with water, and (8) dry with filtered compressed air.

These abbreviated descriptions of cleaning processes are illustrative of a few methods used by Sandia suppliers, ard are quite ineomplete. For example, a detail procedure for electrical contacts may cover several pages, spelling out such items as the required environment, personmel washup and clothing, handling procedures, fixtures, cleaning equipment, purity of materials used, sequence, times, ultrasonic frequency, orientation of parts in cleaning bath, temperatures, and storage instructions. Also, the cleaning procedure may vary with the type of part being cleaned; for example, electrical contacts, o-rings, plastic parts, metal parts, assemblies involving many crevices and capillary paths, parts coated with dry film lubricants, and printed circuit boards--all require individual consideration.

After cleaning the parts or assemblies, the next problem is to verify oloanliness. Verification methods can be direct, such as visual and water-break methods, semidirect utilizing fluorescent dye or radioactive tracers, or they can be indirect, such as electrical contact resistance or film adherence tests.

Among the more common direct tests are the visual, the water-break, the atomizer, and the solvent tests. The visual test is frequently used and its sensitivity can vary from low to relatively high, depending on the knowledge and experience of the observer and the magniflcation and lighting used. It is also tedious and time-consuming. The water-break and water-atomizer tests depend on visual observation of the contact angle of water droplets and are effective for water repellant contaminants only. The water-break test is performed by immersing the surface to be tested in a container of deionized water and withdrawing it in a vertical position. If the dibunt of remaining water-repellant contaminant is a monnlayer or less, the water film on the part will be continuous and will remain unbroken for a period of 30 to $6 \mathrm{U}$ seconds. The tilue for the water film to break and draw up into droplets or partially wetted areas is an indication of the amount of water-repellant contaminant present. On grossly contaminated parts, water break occurs immediately. The atomizer test is similar but more easily interpreted and more sensitive and can detect traces of contaminant or fractions of monolayers. In this test, parts are sprayed with water from an atomizer, and where water-repellant contaminats are present, the droplets will not spread and uniformly wet the surface. Since the majority of contaminants we are concerned with are water repellant, the water-break and atomizer tests are very useful. These methods are frequently used in the laboratory to compare efficiency of cleaning methods and are also useful in manufacture to monitor cleaning operations and to test cleanliness of parts having simple shapes. A freshly cleaved mica surface is often used as a reference to check the operation of the test.

Also, a series of go/no-go photographic standards may be used. However, test techniques utilizing visual standards are time consuming and are subject to individual interpretation and require considerable personnel experience. If the contaminant is not water repellant, it will, of course, not be detected by water break or atomizer tests.

Sandia is presently conducting a study to determine if color photographic standards for water-break and atomizer tests will enable easier interpretation than black and white photographic standards. Initial work has been with printed circuit boards. 
Another direct test is the solvent drop test. Choice of the solvent depends on the suspected contaminant, but trichloroethylene serves for the majority of contaminants with which we are concerned. Following is the technique as developed at Sandia. First, to make sure that the solvent itself is not contaminated, a drop of it is placed on a clean glass slide and allowed to evaporate. If the solvent is pure and the slide clean, no stain or a barely perceptible stain will result. Next, a drop of solvent is placed on the surface of the part being tested. After a few seconds, the drop is stirred by and then picked up by a capillary tube and transferred to the glass slide. If the surface of the part contained significant soluble contaminants, these contaminants will dissolve in the solvent and concentrate in the periphery of the drop and a pronounced ring-shaped stain will show on evaporation. The technique is also often applied "in place" on the surface of the part being tested. Sensitivity of this test is similar to that of the water break. Again visual interpretation is required, which is a disadvantage in applying the method to a production line. This technique can also be used for identification of contaminants since the solvent drop containing the contaminant can be easily transferred for infrared analysis. In addition to the direct verification tests just mentioned, there are numerous other less commonly used direct techniques, all of which are specific to various types of contaminants.

Two of the semidirect methods involve purposely contaminating the parts prior to cleaning with tracer components such as fluorescent dyes or "tagged" radioactive atoms. It is hoped that if the tracer contaminants are removed, other contaminants will also be removed. The fluorescent dye technique is less sensitive than the water break and also requires visual interpretation. The radioactive tracer technique is more sensitive than the water break and is capable of quantitative go/no-go interpretation. But it has drawbacks from the expense and health hazard standpoints, as well as from the fact that it is not a direct test. In addition to being of some value as a semidirect verification test, the radioactive tracer technique is a good tool for comparing the efficiency of various cleaning methods for specific contaminants. Another example of a semidirect method is the use of a cleaning agent that is electrically conducting, thus permitting monitoring of the rinse water to a certain quantitative low value of conductivity. (General Electric has done considerable work in this area.) The use of an ionic detergent such as Alconox is an example.

A recent Sandia study by Dr. B. T. Kenna involved the use of radioactive tracers to evaluate the efficiency of various cleaning methods, including use of Alconox, for removing specific contaminants. The radioactively tagged contaminants used were hydrochloric acid solution of iron-59 stearate, an aqueous solution of diethanolamine, silicone oil, and an aqueous solution of urea plus lactic acid. (The urea plus lactic acid material is actually artificial finger print per Military Specification C-1507.) The substrates studied were glass, alumina, sapphire, and Kovar.

Table II shows comparative results for Igepal and Alconox detergents in removing diethanolamine contaminant from a sapphire substrate. Distilled water alone is shown as a control. After cleaning with Igepal or Alconox, distilled water was used for thornugh rinsing. Sodium-22-tagged Alconux was used to check the removal of the Alconox detergent during rinsing. The Igepal was not tagged. Note the comparison of final counts per minute for the control part washed with distilled water only and those cleaned with Igepal and Alconox. The counts show that Alconox was more effective for this particular contaminant. You will recall that Alconox is ionic, permitting a production line test on conductivity of the rinse water. Alconox also proved more effective than Igepal for the iron stearate and artificial finger-print-tagged contaminants previously mentioned. However, to illustrate again that no one cleaner will do all jobs well, neither Igepal nor Alconox was effective in removing the tagged silicone oil. The examples just mentioned are a small part of a fairly extensive cleaning evaluation study, but they illustrate how radioactive tracer techniques can be used to evaluate cleaning methods.

Two examples of indirect verification tests for cleanliness are the measurement of contact electrical resistance and the measurement of adherence of paints or metal films. Such tests can serve to prevent bad parts from going into stock, but finding out at this late stage that cleaning was inadequate can result in a lot of expensive rejects. 
TABLE II

Comparative Removal of DEA from Sapphire by Water and Cleaning Agents

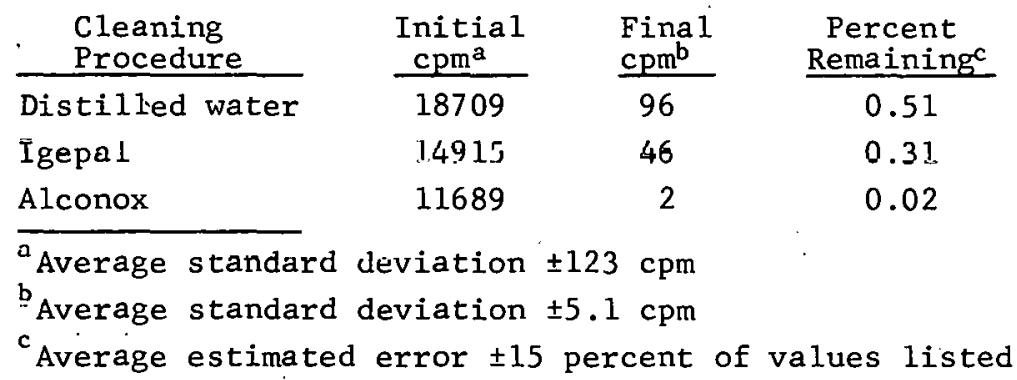

Much of the work of Sandia's contamination control personnel is Sherlock Holmes-type detective work dimed at identifying the contaminant and eliminating the source. An example may be appropriate before concluding.

A certuin component, i,nvolving a high-voltage application, went into productinn. Some of the assemblies failed the hi-pot test and others did not. Contamination was suspected. One part of the componient assembly was a hat-shaped Kovarglass seal. These were being procured from two different suppliers, and it was soon determined that trouble was occurring only in those components utilizing seals from one particular supplier. A supply of these seals was obtained, and the inner surface of the seal was found to be coated with an organic compound containing sulfur. The contamination on the inner surface was traced to an inhibitor used in a pickling operation of the seal prior to electroplating the outer surface of the Kovar. The answer, of course, was for the supplier to stop using the particular inhibitor. The study did not end there, however, as there were a lot of seals to salvage, aud a cleaning method had to be worked out to remove the film. Fortunately, it was a simple piece, so strong methods could be used. Solvents, boiling detergents, acid, and alkaline cleaners were tried without success. The film was extremely stubborn. Finally, a $500^{\circ}$ to $600^{\circ} \mathrm{F}$ bake was tried and was successful. 'The standard cleaning procedure for the part had utilized only a low temperature bake of $225^{\circ} \mathrm{F}$. Fortunately the $500^{\circ}$ lo $600^{\circ} \mathrm{F}$ bake could be used in this case without harm, and the parts were salvaged.

In conclusion, I will sum up, in general terms, my feelings as to the 3 tute of technology of contamination control and also pinpoint those areas that $I$ think need major continuing effort.

Contamination control is an extremely big field. In the area of controlling airborne contaminants, much progress is being inade. Undoubtedly, the higgest step forward has been the introduction of the laminar flow clean-air principle introduced by Mr. Whitfield. Cleaner air at lower cost and less inconvenience is a very significant contribution. A comprehensive specification for clean rooms, which a working group of this conference hopes to accomplish, will be another step forward.

But, as just stated, contamination control is an extremely big field, and at least in Sandia product, nonairborne particulate and film contamination constitutes our major problem. In looking at what remains to be done, we need to consider the areas of identification; cleaning methods; controls on processing, handling, and storage; verification tests; and knowledgeability of personnel. Although much can still be done to improve identification and cleaning methods, $\dot{I}$ feel that there are, at least, adequate means presently available. As for verification tests, although several are suitable for laboratory studies, much work needs to be done to develop improved quantitative, go/no-go methods for production line verification.

To me, the most urgent present needs are:

1. Improved controls for processing, handling, and storage

2. Improved quantitative, go/no-go methods for production line verification of cleanliness 
3. More knowledgeable personnel in both development and manufacture.

First, how can we achieve improved controls on processing, handling, and storage? The answer is that the designer must prepare definitive specifications and the manufacturer must prepare detailed processing, handing, and storage sheets and see that these are followed. This, of course, assumes that both the design and manufacturing groups are sufficiently knowledgeable to do an adequate job. At Sandia, we frequently ask industry to exert contamination control well beyond what they have been used to in their commercial product. Therefore, the preparation of the detailed processing, handling, and storage instructions and the early control of them often become a joint effort of the development agency and the manufacturer. But the manufacturer plays the key role in the preparation and implementation of production line instructions, because many facets of cleaning and handing depend on the actual production line and the assembly sequence.

Second, how can we achieve improved quantitative, go/no-go methods for production line verification of cleanliness? The answer lies in some good, ingenious, laboratory work and clever adaptation to production line use. Increased attention by a working group or ASTM Committee would also be helpful.

Third, how do we increase personnel awareness and knowledge of how to cope wi.th contamination problems among both development and manufacturing people? It is even hard to convince some people that contamination is a serious problem area. Some of our specifications include the following statements: "There shall be a formalized training program established by the supplier which will explain the reason and need for adherence to established cleanliness rules. This training program shall be conducted for new personnel and at least every three months: for al1 personnel. The success of the controlled facility will depend to a large measure on the conformance of the personnel to these procedures. The training program shall include the following: lectures, visual aids, and on-the-job training..."

However, specifications and process sheets can define what should be done and some of the things that should not be done, but one can never anticipate on paper all the things that should not be done. Only knowledgeable people on the manufacturing line can control this. Actualiy, most of Sandia's contamination problems can be traced to inadequate processing sheets, unanticipated sources of contamination, and insufficient awareness of the problems. The solution quite frequently is for a contamination control specialist from Sandia to do the detective work of tracking down the source of the trouble. Then it can be corrected.

Certainly much more attention needs to be paid to training of personnel in contamination control before production starts. But the key to the "people" problem, I believe, is for each development agency and each manufacturer of critical parts to have one or more specialists whose full-time job is contamination control. This is not a part-time job! 
FIRST DAY

Afternoon Session

$33-34$ 


\title{
INTRODUCTORY REMARKS
}

\author{
Colone L I. R. Perkin
}

Mobile, Alabana Air Materiel Area

Gentlemen, as I read the agenda here I see that we are trying to accomplish three things at this conference: (1) the first is to establish clearly the requirement for a federal standard, (2) the next is to examine the technical aspects of the current state of the art, and (3) the last is to establish a working group. I think the discussions this morning should have clearly established the require-ment. Some of you I know, and I think it is quite unnecessary to dwell on a subject of establishing a requirement for clean rooms in a form of standardization. We know that we have incurred heavy. costs, both in dollars and in operating efficiencies because we haven't had a standard for clean rooms. For this reason, I am particularly grateful to Lou Hopkins and to the Sandia Corporation for taking the initiative to act as a catalytic agent in deriving a federal standard. I am happy to see this assemblage here and I know that some of you came here at great personal inconvenience, but I do think if we continue on a course of arriving at a federal standard your presence here will be well worth whi1p.

This afternoon we are going to get down to some of the meat and potatoes of what we were talking about this morning, and I would like to present Lt. Austin. I know what he is going to tell you and I think you are going to find it very interesting. 


\title{
AIR FORCE REVISED TECHNICAL ORDER 00-25-203
}

\author{
Lt. P. R. Austin \\ Mobile, Alabama Air Materiel Area
}

The history of Technical Order 00-25-203 has some very fine roots which can be traced as far back as pre-World War II days. Necessarily, we have come a long way since that time. It wasn't until 1958 that work on a formal Air Force publication regarding the subject of clean rooms was begun. The initial work was a mammoth job with many unknown areas to bo considered alld organized. The Air Force considered the first publication of the T.0. a very workable document for its time; but with the advance of technology and the rapid development of the state-of-theart in both clean rooms and contamination control, it was realized that a revision of the current in-force Technical Order was needed.

Last year about this time our higher headquarters at AFLC directed Hq Middletown Air Materiel Area, Olmsted AFB, and, more particularly, the Directorate of Maintenance, to up-date T.0.00-25-203. Currently our recommendations for the proposed revision of T.O. 00-25-203 have completed the major part of the coordination cycle at Hq AFLC. It is hoped that in the next month or so Hq USAF approval will be given for this Technical Order and publication permission received.

It is the intent of this presentation today to give you an insight into the proposed revision of the Technical Order, with the substantiating reasons behind each of the mentioned changes. This presentation will encompass the major revisions of the Technical nrder. Nirborne palticulate s1ze-distribution relationships will be discussed in detail with both theoretical relationships and empirical data samplings presented during the first phase of the presentation. These empirical data samplings were taken at various locations throughout the United States. One intent of this presentation is to show that the slope of the curve for the Air Force Standard Clean Room is parallel to the time settling curve as stated by Stoke's law. Superimposed upon these relationships will be the requirements for missiles, instruments, optics, thin films, and monomolecular deposition operations. Contamination level for the Air Force Standard Clean Room will be treated quite heavily.

The second phase of this presentation will consider temperature, humidity, pressure, illumination values, as related to the proposed Air Force standard clean Room. Thirdly, the role of clean work stations, both as used in the Air Force Standard Clean Room and uncontrolled areas, wili be discussed. The fourth and final phase of this talk will consider the newest developments in regard to both clean room construction and related monitoring techniques.

So far, I have used the term "Air Force Standard Clean Room" without further explanation. Currently the Air Force Technical Order actually dictates four classes of clean rooms. As a result of our investigations, we have found that a standard clean room, in conjunction with clean work stations, could adequately handle the majority of products overhauled within the Air Force today. I would like now to explain the processes we went through to arrive at these conclusions. Therefore, let us first attack an area which has presented us with the most problems.

What one statement can be made concerning airborne particulate matter which will enable us to understand its nature most? The fact is there are many statements which can be made, but one of the first statements which we should consider is that there is a definite settling relationship for airborne particulate matter. This relationship has been defined by stoke's law and is essentially a 
linear logarithmic function in the particle size ranges associated with clean rooms. Consequently, particles of the larger sizes fall out more rapidly than the smaller particles. A settling velocity relationship for airborne particulate matter has been presented in the chart "Characteristics of Particles and Particle Dispersoids" by Stanford Research Institute, Menlo Park, California

Figure 1 shows the curve titled "Particulate Time Settling" (PTS). This data is represented in the Stanford chart as the terminal gravitational settling for spheres of specific gravity equal to 2.0. This data has been plotted in Figure 1 as the inverse function of settling velocity; that is, time required for a sphere to settle 1 centimeter, as shown by the scale on the right-hand vertical axis. Also plotted in Figure 1 is the curve "Air Force Standard Clean Room-Operational Limit" (AFSCR). The slope of this curve is essentially parallel to the slope of the particulate time settling curve for particles between 2 and 25 microns in size.

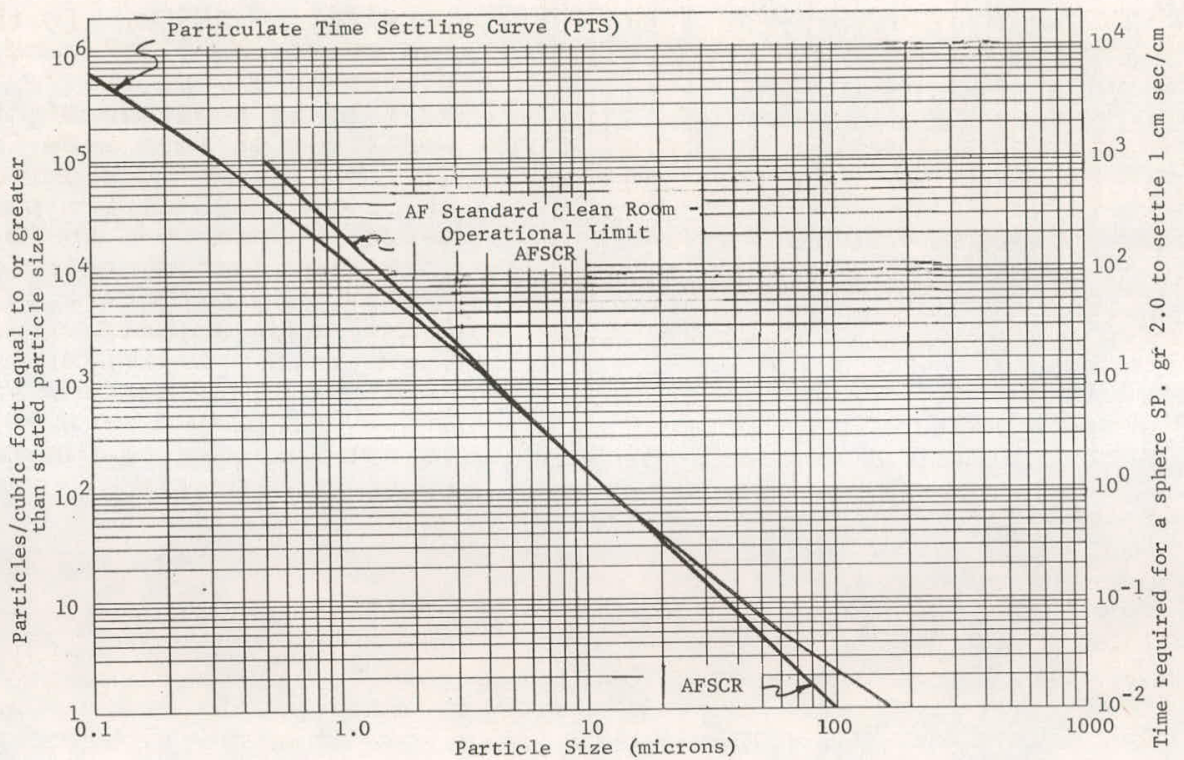

Figure 1. Particle size distribution curves

The logic to be used in the following discussions will be:

1. The empirical data samplings obtained at various locations throughout the country are essentially parallel to the slope of the PTS curve in the ranges 2 microns and larger.

2. The slope selected for AFSCR is essentially parallel in the same ranges to the particulate time settling curve.

3. Therefore, the empirical data samplings in these ranges are paralle 1 to the Air Force Standard Clean Room curve.

It is acknowledged that the particle time settling curve is but one of many curves that can be drawn representing the settling time of particulate matter, but Stoke's equation shows that this slope is representative of settling time for particulate matter within air. If particulate matter is of such a shape and configuration that it has a greater projected drag area than the spheres used for the PTS curve, a shifting of the curve will take place but the particle relationship of one size to another will remain essentially the same. Until further computed settling times for various particle shapes are developed, this curve represents to a high degree of accuracy the settling relationship for particulate matter. 
Figures 2 through 22 represent empirical data samplings obtained by both manul and automatic counting techniques. These figures are part of the report Size Distribution Relationships for Airborne Particulate Matter (Philip R. Austin, lst Lt. USAF, MAMES, Olmsted AFB, Pa.).

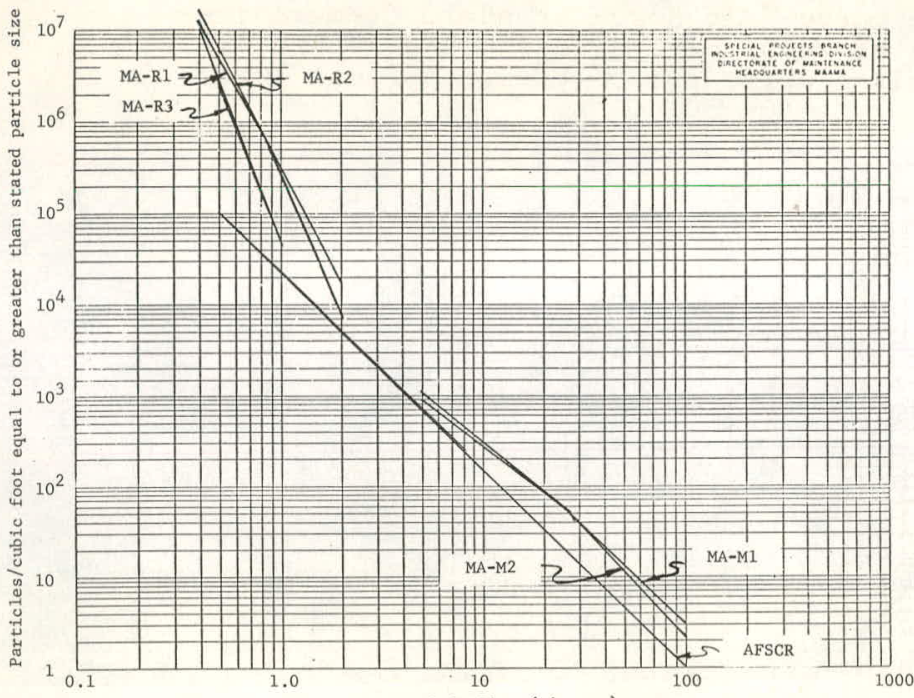

Figure 2 .

Curves MA-M1 and MA-M2 were actua11y obtained by use of manual counting techniques. Notice that the slope is falling parallel to AFSCR. In the size ranges for curves MA-R1, 2, and 3, we have a different slope. We feel that the cause of this is that the significant force on particles of this size is no longer gravity, but rather the aerodynamic forces in the room. A 1-micron particle will take about 5000 seconds to fall 1 foot. In this time, aerodynamic forces can very easily buoy particles so that they do not travel down or settle out, but begin to accumulate. Empirical data continue to reinforce this conclusion. Curves MA-R1, and 2 were taken by a Royco instrument in our building at 01msted. Curve MA-R3 is of outside air.
Figure 3 .

This figure shows curves for distribution of particles from 1 to 8 microns. We wanted to find whether there was a change in slope of these curves, and we found that there is. These slopes bend around, and, when they get past the 2-micron range, the curve starts to follow the AFSCR slope.

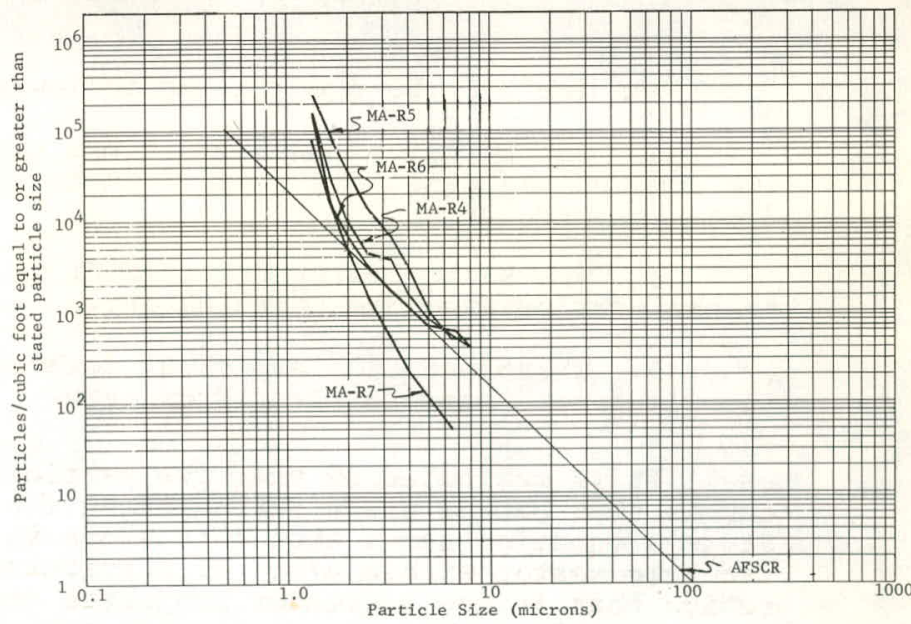




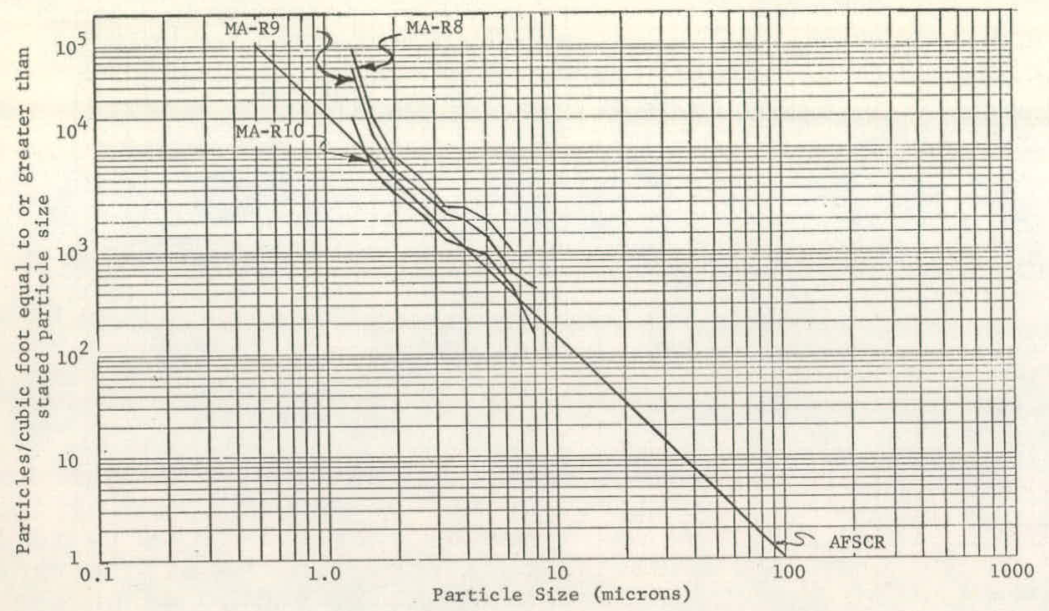

Figure 4 .

These are curves from areas within our own system showing that various clean rooms are forming along this line.

Figure 5.

Here we have data taken within a bootie area, essentially what we considered to be a Class 1 clean room.
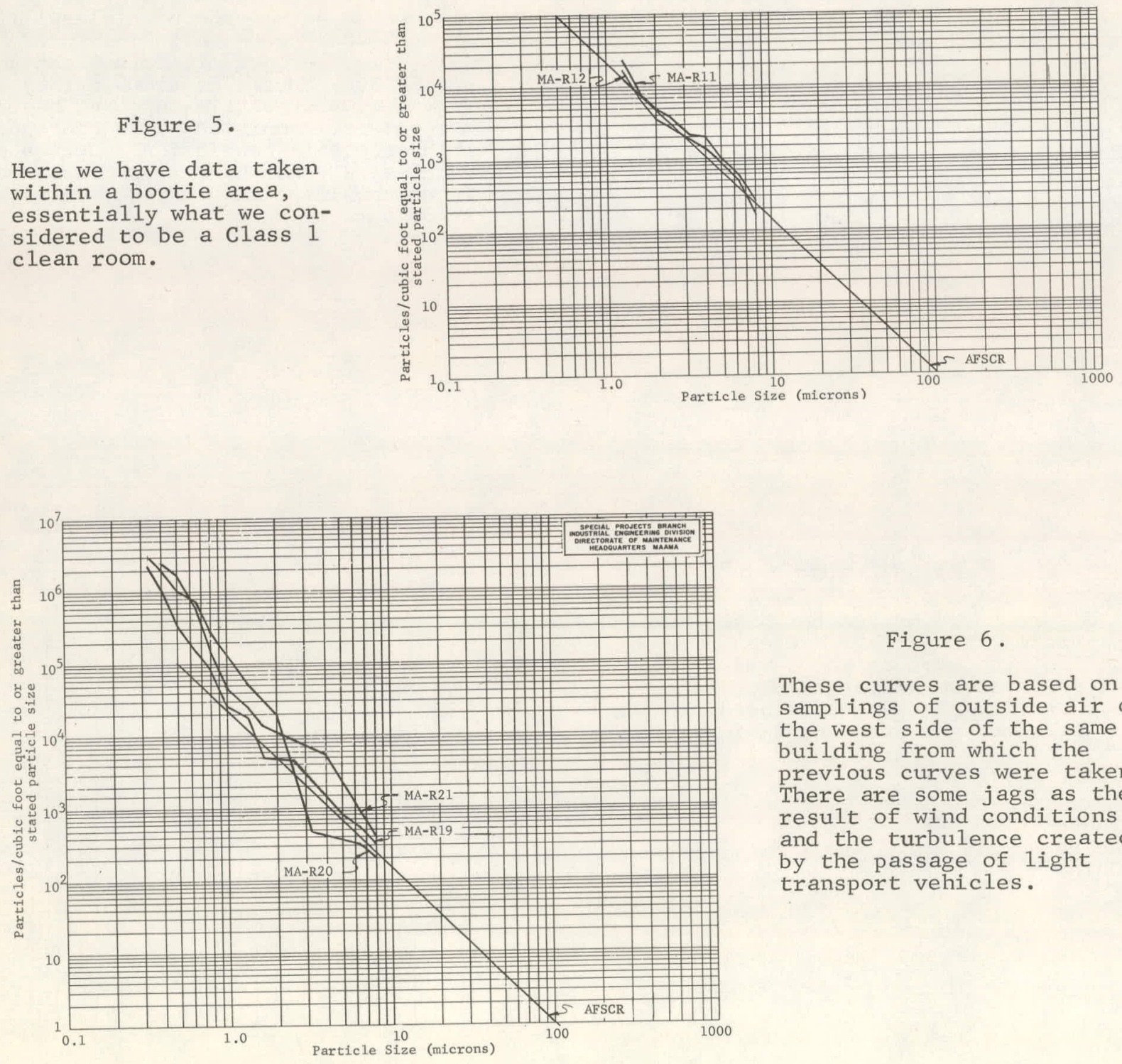

Figure 6 .

These curves are based on samplings of outside air on the west side of the same building from which the previous curves were taken. There are some jags as the result of wind conditions and the turbulence created by the passage of light transport vehicles. 
Figure 7 .

These curves are based on samples of outdoor air at Warner Robins Air Force

Base, Georgia, using manual counting techniques.

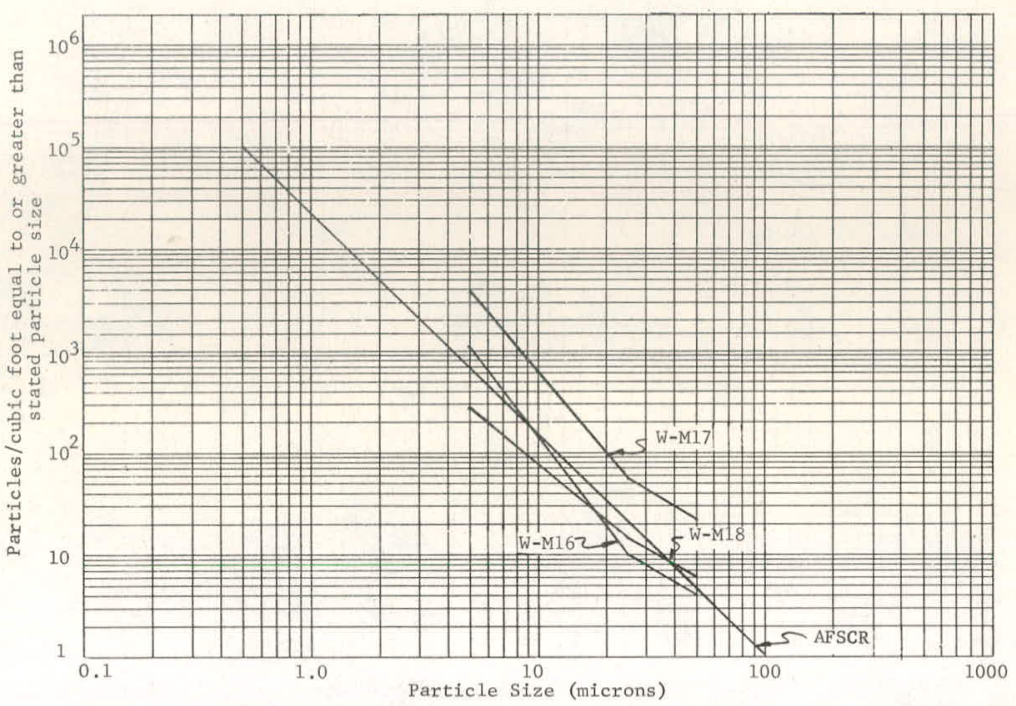

Figure 8 .

This sample was taken inside Building 160 at Warner Robins with the Royco counter. Notice that when particles get above 2 microns, the slope starts to change and run parallel with the AFSCR .
Figure 9.

These curves were taken at Heath Air Force Station, Ohio.

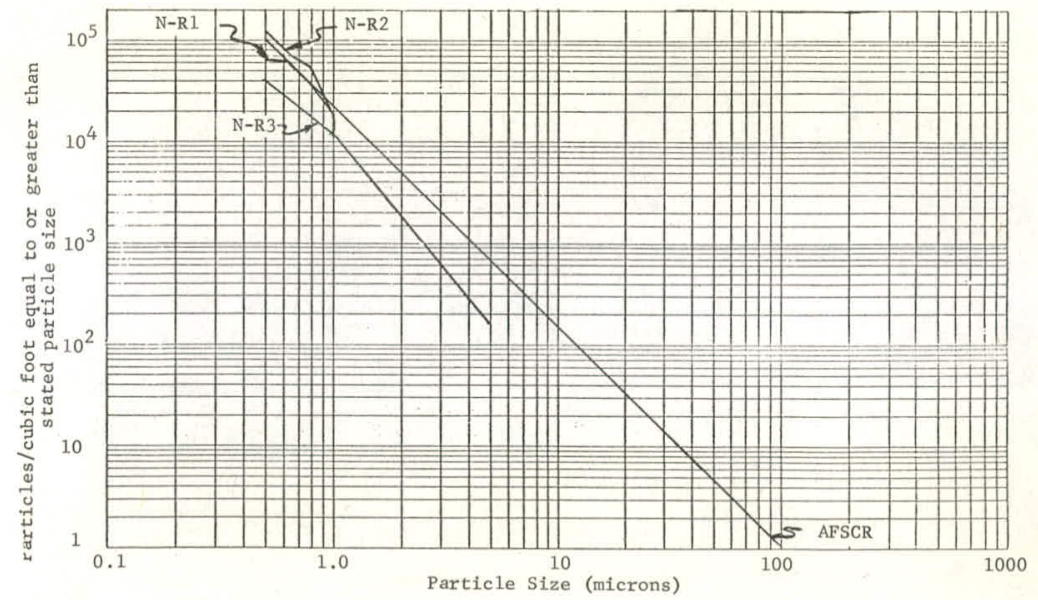




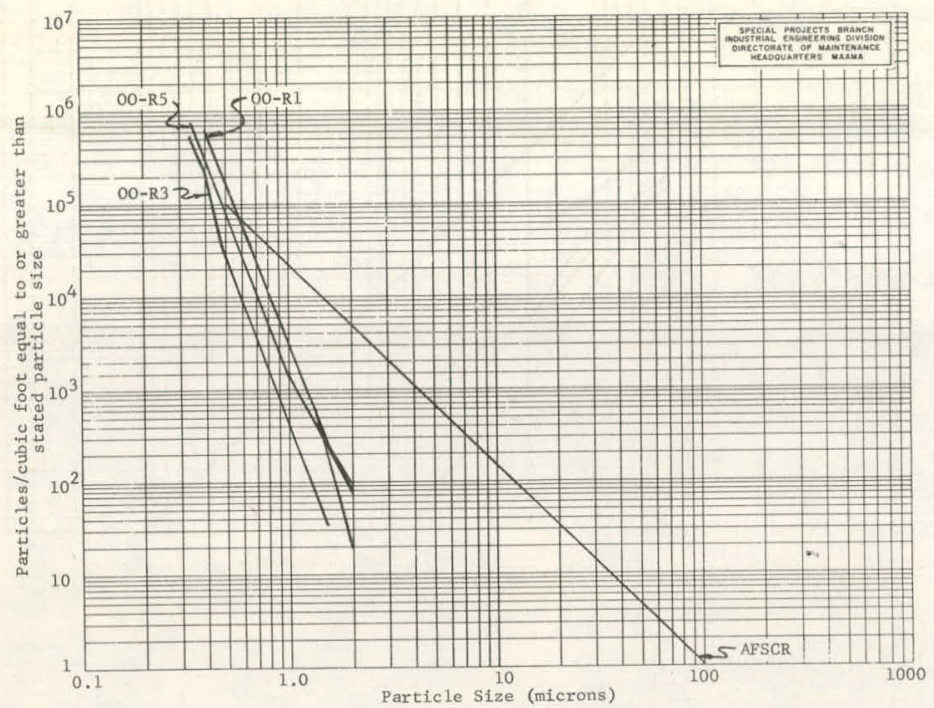

Figure 10.

These curves were taken at Hill Air Force Base, Utah. Particle sizes investigated there were 2 microns or less. You' 11 notice that we have the same slope for particles less than 2 microns. This slope is not to be interpreted as a characteristic of the Royco instrument for particles less than 2 microns because later I will show you curves taken by a different light scattering defice in the same region which show the same shape.

Figure 11 .

These curves were taken by Royco instrument people. Curve $\mathrm{R}-1$ was taken in January 1962 and $\mathrm{R}-2$ in March 1962. $\mathrm{R}-2$ is for the Eagle Rock area northeast of Los Angeles, maybe an hour or two after a rain storm.

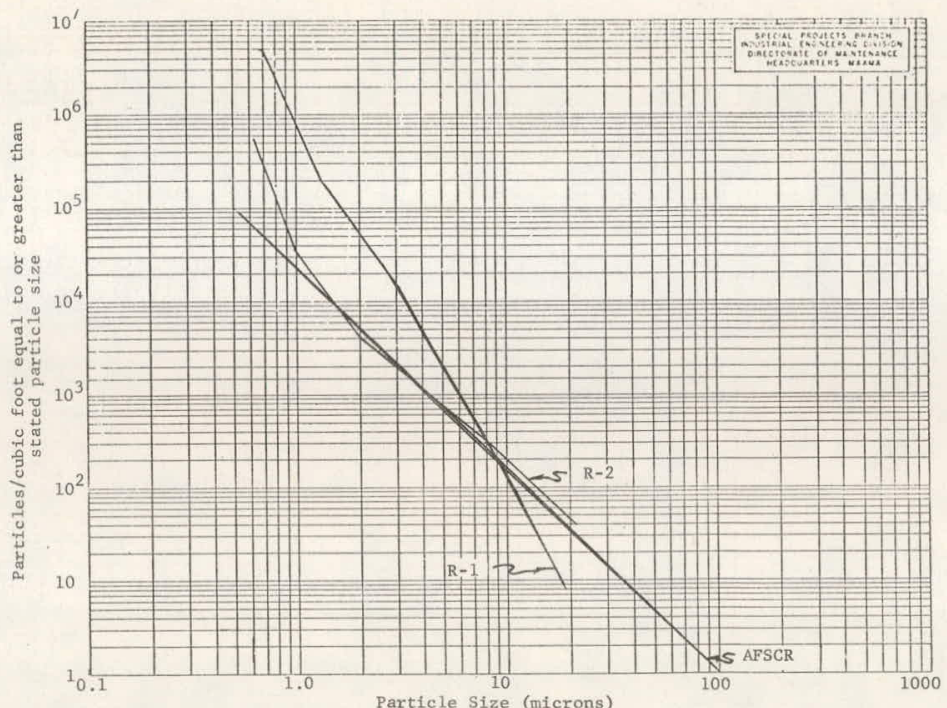

Figure 12.

This is a grouping of curves. A-1 represents city air in Chicago and $\mathrm{A}-2$ country air in the Illinois area outside Chicago. $\mathrm{M}-1$ and $\mathrm{M}-2$ represent samples of millipore filter of country air and city air. The $G$ curves were taken at Warner Robins AFB. Notice the definite break. We get two different slopes. 
Figure 13 .

These curves were taken at Grumman Aircraft. These were longer sampling periods of 10 minutes. These bumps in the curve are probably the result of the air being cleaned up by the time of the next cycle.

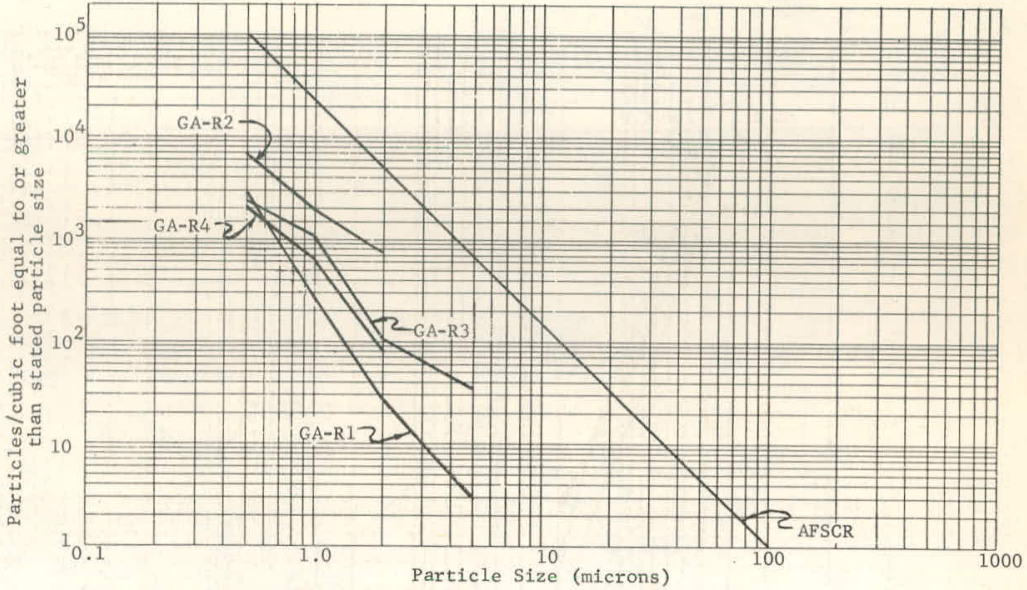

Figure 14 .

GD-R1 and R2 were taken at the General Dynamics, Pomona cross-flow room in October. GD-R3 is the curve for the anteroom to their laminar flow room. GD-R4 is for the computer room at General Dynamics. It appears that up in the $10^{6}+$ range there were a lot of coincidence losses from using the Royco counter; al1 the particles were not being counted. That might be the explanation for the move, or it might be that there were aglomerations.

Figure 15 .

These curves were also taken in the General Dynamics room, in February. GD-R5 represents an ambient condition across the work bench. We then put three men working on opening a gyro assembly directly upstream from the monitoring device. GD-R6 represents the change in contamination level with three men doing a particularly dirty operation. GD-M1 is the contamination level at the exit of the room. GD-M2 represents the effect of my doing calisthenics in the room. We got a very significant increase in the larger size particles, but not in particles of smaller sizes. This shows that these garments are actually dumping the larger size particles.

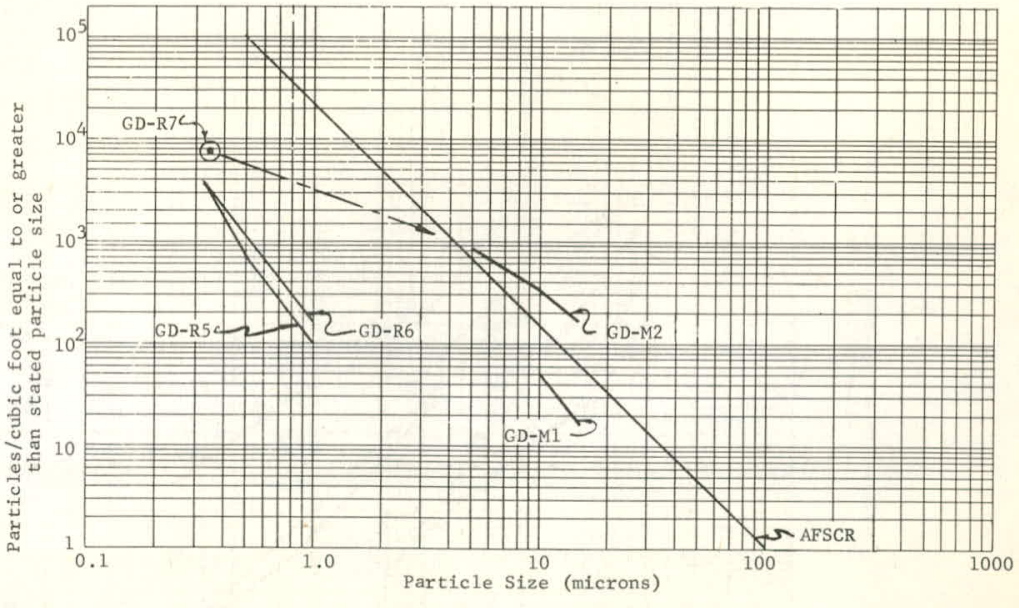




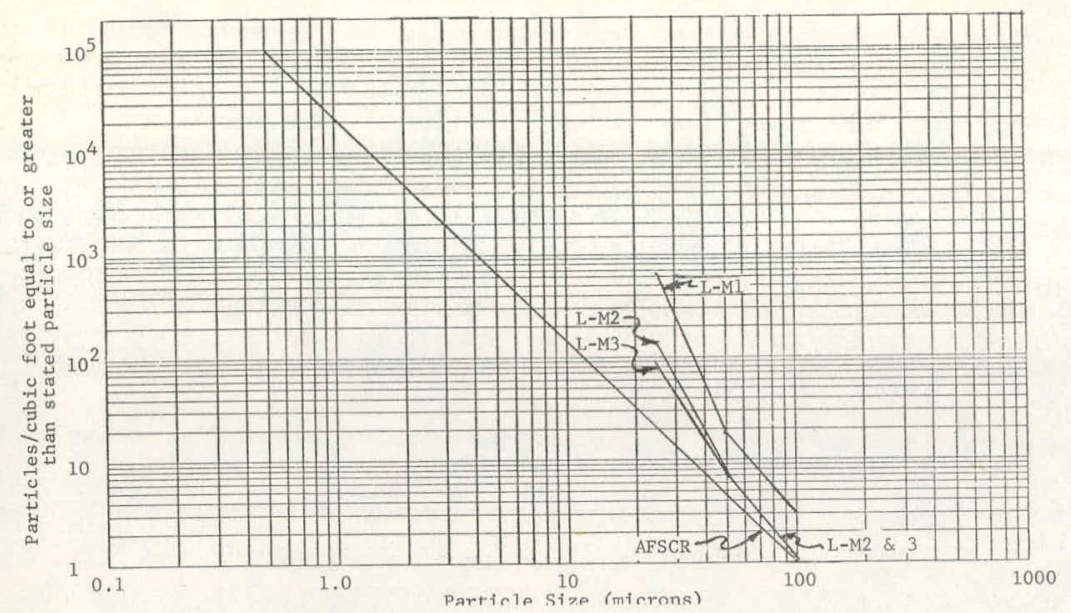

Figure 16.

These curves were taken by Lockheed, Van Nuys. They represent January 1963 data in their Rooms 1, 2, and 3. Notice they were monitoring essentially larger size particles, 25 microns and larger.

Figure 17.

These slopes were taken back in June 1962 by Lockheed.

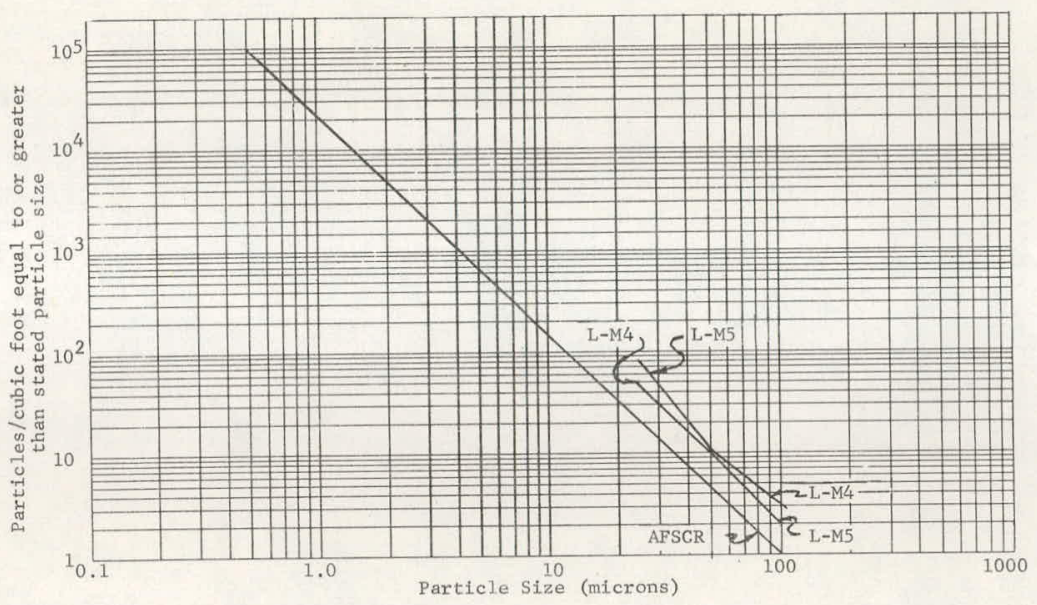

Figure 18.

These are curves from various Sandia facilities. The curves reinforce our conclusion that the size distribution relationship is essentially paralle 1 to the AFSCR which is para1lel to the function of Stokes law. 
So far we have shown the reasons for the selection of the slope of the Air Force Standard Clean Room. I would like to now present the reasons for the selection of the contamination level for the quantity relationship of the Air Force Standard clean Room. This can be done by pictorially representing the requirements for missiles, instruments, optics, and thin films. Referring to Figure 19, you will notice the area titled "Missiles and LOX Systems about the 100 and 200 Micron Range," displayed on the right-hand side of the picture. The larger area above this contains the requirements for products having clearances in the range of 0.0001 inch and greater, such as instruments, gyros, electronic components, precision measurement equipment, oxygen systems, engine pumps and actuators, hydraulic systems and pneumatic systems. You wili notice that the Air Force Standard Clean Room will be able to handle the majority of these products.

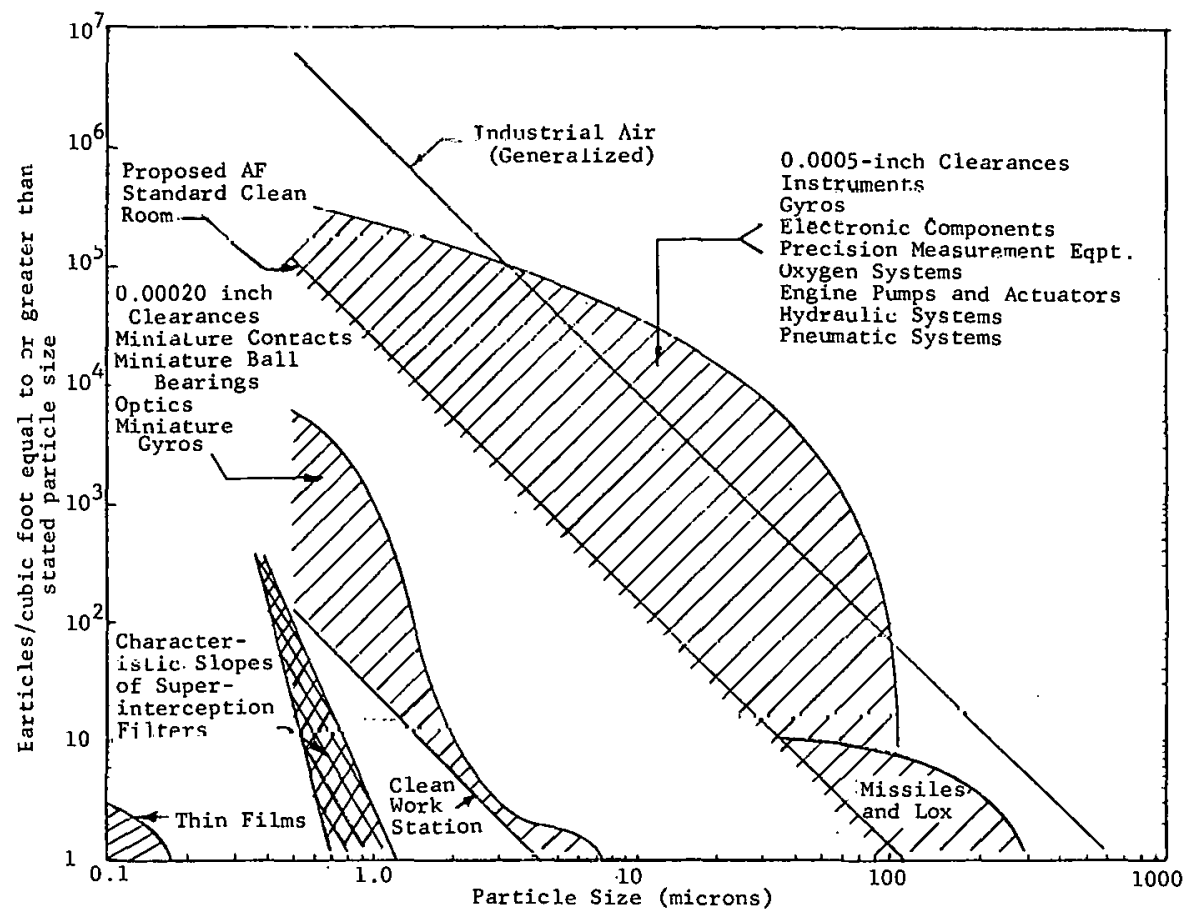

Figure 19.

I would also like to take the opportunity at this time to explain the rest of this curve. Notice that the area below the large center area is titled "Twenty Millionths Inch Clearances, Miniature Contacts, Miniature Ball Bearings, Optics, and Miniature Gyros." The products spelled out here have clearances in the range 20 to 100 millionths of an inch. To handle this condition, we would like to make use of clean work stations. This I will go into in a little more detail a little later on. Notice also here in the cross-hatched area the characteristic slopes of superinterception filters. These slopes are in no way fixed since it is difficult to measure particles of this size. This area only represents generally the area in which the slopes of absolute filters most likely fall. The last area to be covered is that directly at the intersection of the vertical and horizontal axes, which is tilted "Thin Films." This area contains requirements of several millionths of an inch thickness or clearance.

Let us now discuss the next environmental condition, temperature. What facts must be considered to arrive at a logical operating temperature?

1. We must have a temperature range which is comfortable to the personnel who are wearing clean room clothing.

2. The temperature range should be compatible with both persome1, product and test equipment. 
3. The temperature range can be easily maintained by normal air conditioning (of $\dot{f}-$ the-shelf).

4. The rate of temperature change is relative to the product. We propose to meet these conditions by requiring that the air-conditioning system be able to provide a temperature range of $67^{\circ}$, to $77^{\circ} \mathrm{F}$ and be able to control the room rate of change to 4 degrees per hour. Let me explain this a little bit further. In fact, we are saying that the room can operate at any temperature between $67^{\circ}$ and $77^{\circ} \mathrm{F}$. This temperature is compatible to clean room personnel, product and test equipment. By requiring a room rate of temperature change no greater than 4 degrees per hour, we will be able to perform calibration of equipment requiring control of $\pm 1 / 2$ degree. The reason for this is that normally a calibration of an item, whether it be precision measurement equipment or standard pieces of equipment, can be calibrated within a period of 15 minutes. When calibration of the se items is performed which requires exact temperature control, the temperature about the item is recorded; thus, in a 15-minute period of time, the maximum rate of change of the area will be only one degree. Further, an item which is in this environment acts as a heat reservoir or sink such that if the exterior environment were to change one degree, the item would not experience this fast a temperature change. Looking a little bit more generally at the over-all room conditions, requiring that a room have no greater change than 4 degrees per hour is not a very tight requirement. When an air-conditioned room is in opcration, temperature feedback controls can normally control a rnom to these requirements. It is most unlikely that if a room were initially at 69 degrees temperature, that at 2 hours later it would have incrcased to $77^{\circ} \mathrm{F}$. Under the specifications stated here, it is felt that almost any item which is worked upon within a clean room can be handled by these temperature requirements.

Let us now turn our attention to humidity requirements. This area can be handled fairly easily. Products are not sensitive to humidity tolerance except in a few instances. A product cannot tell you, nor does it know itself, whether it is at 35-percent humidity, or 40-percent humidity, or 45-percent humidity; nor can it tell you when it experiences a change in humidity in this range. If an item is subject to corrosion, it will know the difference when the humidity passes 50 percent. Thus it is important that the relative humidity be controlled below this value. Our experience has shown that a maximum of 45 -pcrcent relative humidity should be required. On the opposite end of the humidity scale, it has been shown that static electricity tends to build up on Insulated materials when the relative humidity is less than 25 percent. In many cases, plants have had to dump water vapor into the air-conditioning system to bring the relative humidity back up above this value. If improperly done, this could become a large source of particulace ulitter. In many cases the static electricity problem can be corrected by selecting suitable clean room garments. We lave not seen that a low humidity is detrimental to the worker. In fact, people are present in this low humidity every day when they are flying aboard high-altitude aixcraft. In such environments, relative humidity factors are way below the 15-percent leve1. Complaints by pilots and passengers on low humidity and its effects are for all practical purposes nonexistent.

Let us now turn our attention to the problem of illumination. We must have illumination within a clean room, sufficient to illuminate and define intric.ate areas of a product. The tendency today has been to greater and greater illumination, with some facilities having more than 200 candle power at the working surface. The effect of this high illumination has been not an increase in visibility but an actual decrease in visual acuity. The reason for this is that the high intensity light tends to contract the pupil of the eye which focuses the majority of the light rays on the cone receptors of the eye. These are color receptors and are less sensitive than the rod receptors in the eye. Experience has shown that illumination levels in the range of 100 to 125 foot-candles will enable the personnel to adequately see the product without high background glare. This enab les the eye to operate at a point of high efficiency, using both rods and cones of the eye. Should a small area need intense illumination, a pinpoint light should be employed to define these areas; thus, in the proposed Air Force Standard Clean Room, proposed illumination levels of 100 to 125 foot-candles at working level will.be required.

So $f a r$, we have centered all our attention on the Air Force Standard Clean Room environmental cuntrol conditions. Now let us consider contamination control environment of 4 orders of magnitude better than the standard clean rnom. This control can be achieved by the implementation of clean work stations (Figure 20). 


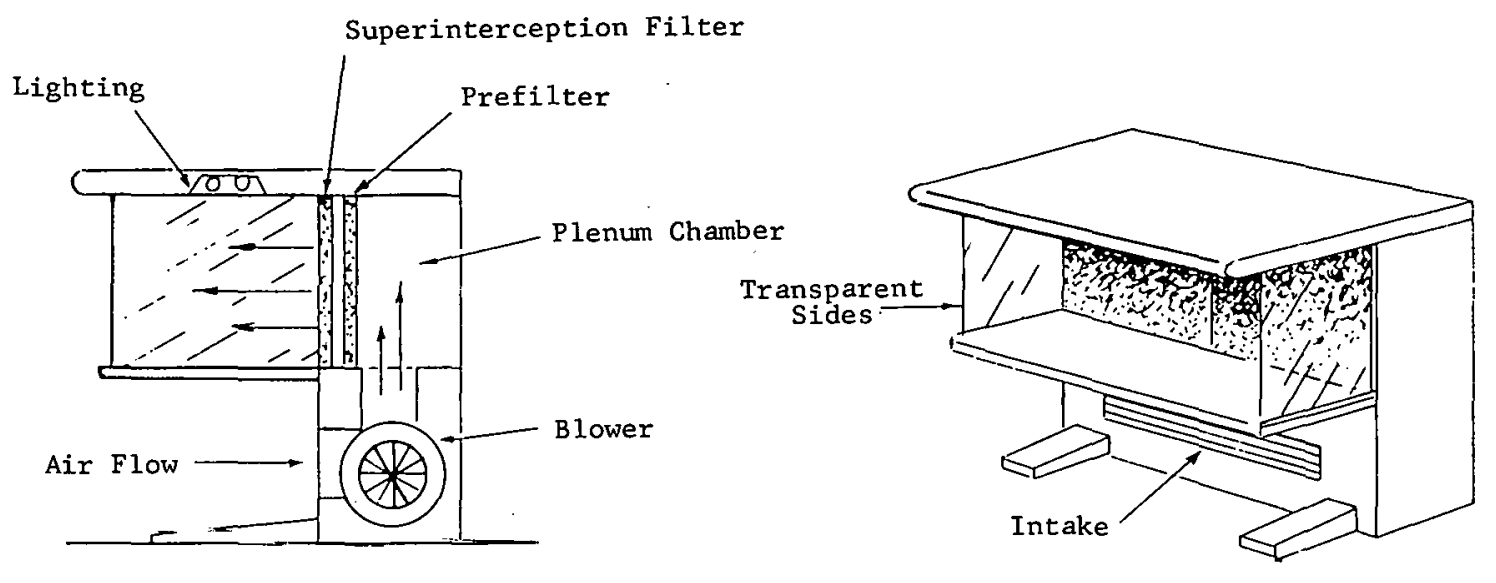

Figure 20. Horisontal clean work station

I might add here that Sandia has contributed greatly to the development of effective clean work stations. I will not go into any detail on clean work stations as to their construction techniques within the station, etc., since these will be covered in following sessions, but I would like to point out that these stations do enable us to control contamination to levels not previously achievable. The clean work station allows us to control a small volume of air exactly, rather than try to control the entire room which is oftentimes poorly controlled. The economics of controlling a small volume of air directly about the product is obvious. There is much less air, much less power, and a higher degree of control achieved. Saying it another way, the clean work station insures the most positive contaluination control for our sophisticated items.

Clean work stations can materially upgrade an average room with ease. A : 6-foot clean work station placed willıln an axioting clean ronm will decrease the contamination level of the room since approximately $72,000 \mathrm{cu} \mathrm{ft}$ of air are recirculated within the room through the absolute filters of the bench. Pursuing this relationship a little bit further, if we were to place 20 percent of the floor area in clean work stations, over 100 to 125 room air changes would ensue.

We foresee that clean work stations will greatly increase our capabilities in field installations. Remote sites such as radar installations and electronic installations oftentimes require repairs on their components. Many of these components must be overhauled within clean rooms. It has been an economic burden to transport each item back to a repair facility and then retransport the overhauled item back to the sitc. Flexibility and mobility are essential for field operations. By providing clean work stations at the site, much minor repair can be accomplished by attending personnel.

Let us now take time to discuss several new types of clean room construction. Due to the increased demand for environmentally controlled areas, a number of reliable companies now manufacture prefabricated clean room components. The advantages of this type of construction for clean room use are many. They include savings on engineering costs, lead time, modification time, etc. In a separate study the T.0. monitoring group recommended that the Air Force develop and stock standard components designed for use in future clean room construction.

Ideally, for supercleanliness a room should have a complete ceiling of absolute filters as an entry air diffuser. The floor should be a grating through which the room air is exhausted. This would produce near vertical flow. The construction problems involved, however, make this an expensive clean room. The cross-flow room represents an economical departure from the ideal design. The smallest walls in the rectangular room are made the entry and exit areas. The air flow in this room is across the room, hence the name "Cross-Flow Room." Although not potentially as clean as the vertical flow room, research has shown that the downstream areas are still many times cleaner than conventional rooms. The crossflow room has the added advantage of not requiring sophisticated wall coverings and, therefore, construction costs have been running slightly cheaper than for conventional-type rooms. 


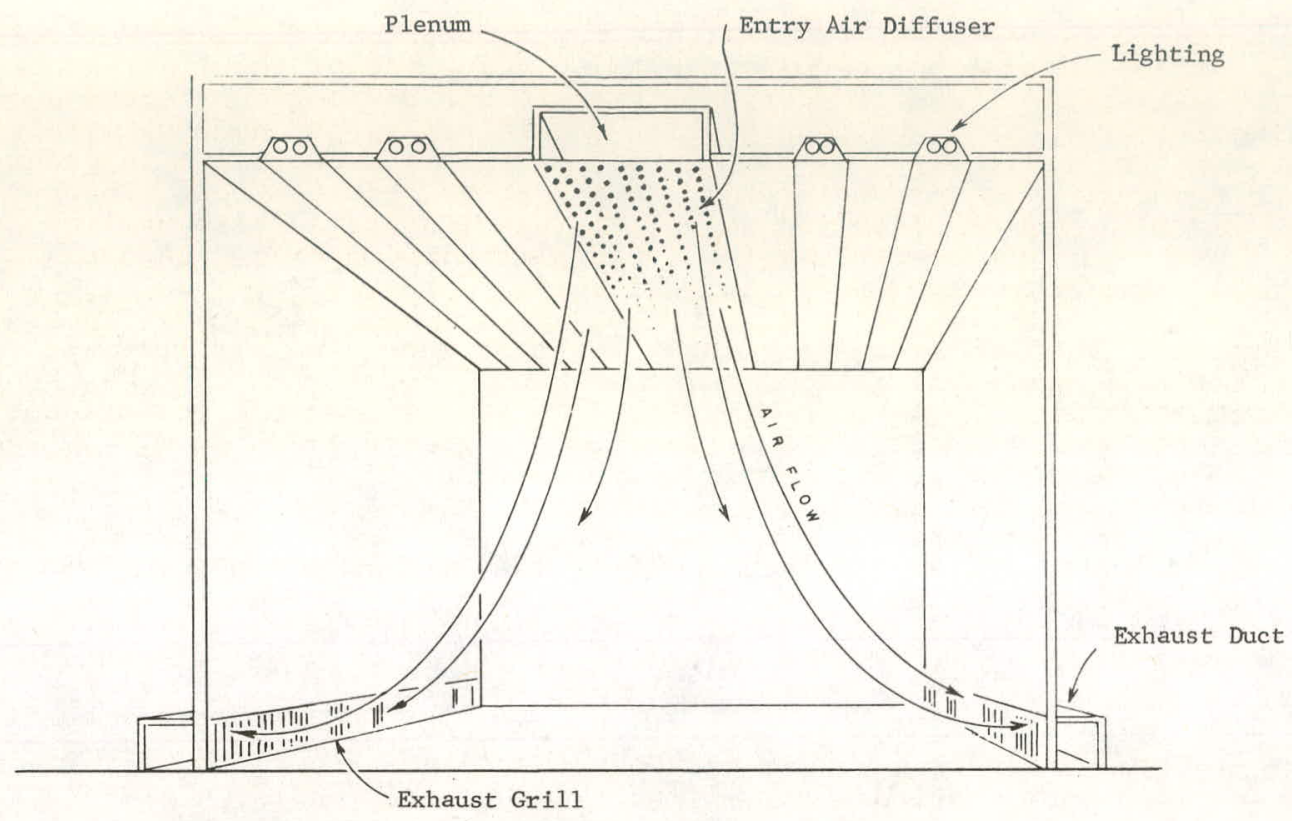

Figure 21. Conventional clean room

It is important that conventional and prefabricated clean rooms have a proper air-flow pattern as it is shown in the above.

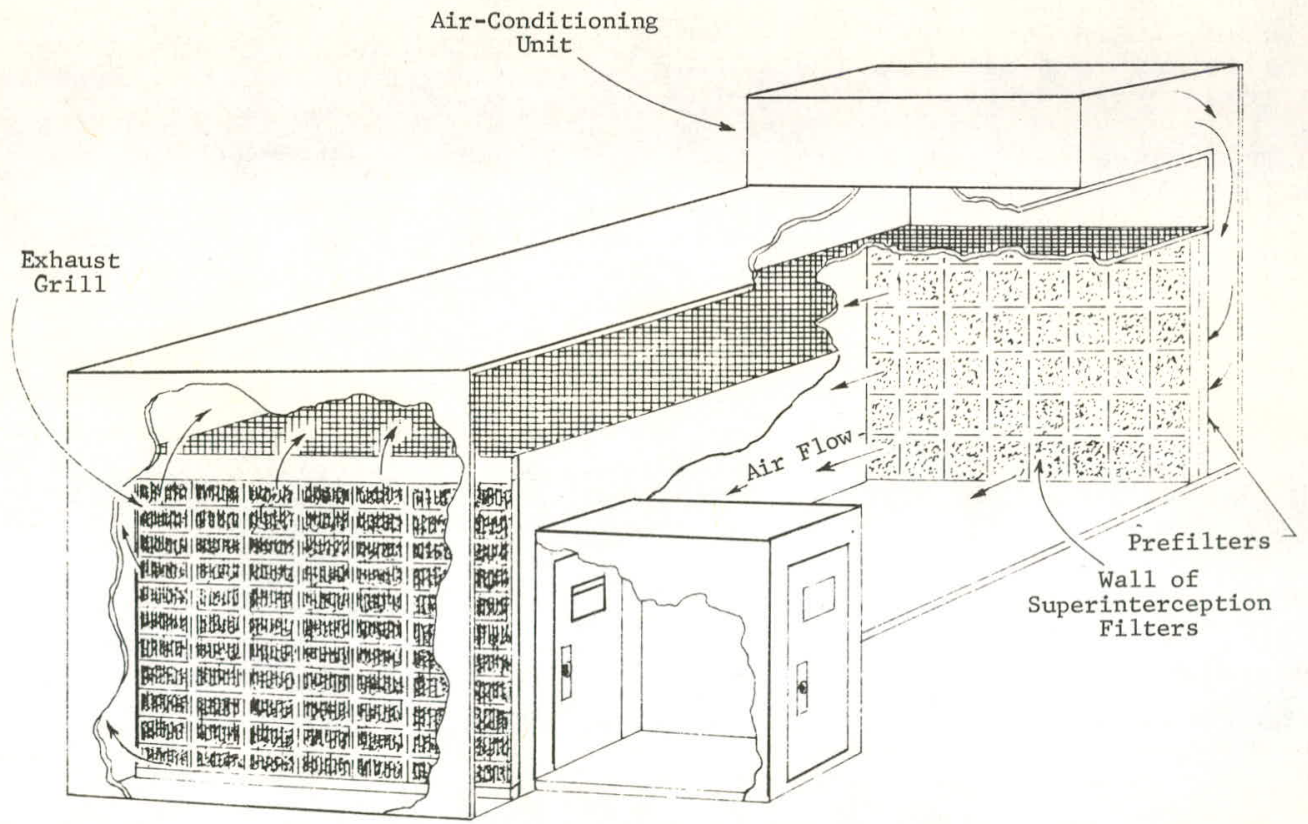

Figure 22. Laminar flow room

The cross-flow room as shown in the above is another adaptation of the Sandia laminar flow room. 
I think it is important that we take but a moment to discuss monitoring techniques to be considered in the revised T.O. The use of the light-scattering phenomenon as a means to count dust particles in air has been perfected somewhat beyond the research stage. Although still requiring a great deal of maintenance and know-how, the reliability of automatic counters is improving. In general, automatic counters will read accurately in the range from 0.5 to 5 microns. As the cleanliness level of clean rooms improves, it is necessary to utilize automatic equipment since there are so few large particles ( 5 microns and up) that a statistically accurate sampling is impossible.

Automatic counters are particularly adept at measuring particles in the lower micron size range, but it is felt that manual counting techniques such as the ASTM F25-63T Method or the S.A.E. ARP743 Method wil1 enable us to adequately monitor the contamination level of an Air Force Standard Clean Room. We feel that the manual counting techniques should be used as the basic method for checking an Air Force Standard Clean Room since these methods tell us both quantitative and qualitative results. As I have shown at the beginning of this presentation, manual counting techniques will monitor the contamination level for an Air Force Standard Clean Room.

Before I close, I would like to leave with you the principal conclusions which may be drawn from this discussion, which are:

1. The contamination level for an Air Force Standard Clean Room is compatible with the majority of items now processed in clean rooms.

2. The contamination level for the Air Force Standard Clean Room is compatible with both instrument and missile area requirements.

3. Clean work stations can be employed as a tool to obtain contamination levels of 2 orders of magnitude better than the Standard Clean Room.

\section{QUESTIONS}

F. C. SHADEWALD, U.S. NAVAL AIR STATION: I was interested in your statement that you recommend 100 to 125 foot-candles for illumination. You apparently don't agree with the illumination engineers who recommend up to 2000 foot-candles for a high precision room?

LT. AUSTIN: General Electric uses about a 50 candle power light in one of their operations. We have seen in Air Force night blindness studies that the rod receptors of the eye are the most sensitive to defining outlines and objects, and they are the most sensitive to seeing shadowed areas. If we put too much contrast between light intensity and the product itself, which necessarily has shadow areas, the person working on this item cannot see the product itself. Pinpoint lighting, such as under a microscope, does a very adequate job, but to have the room illuminated by 2000 fout-candles at bench, level would cause severe strain on the eyes.

MR. SHADEWALD: At North Island we specify in our rooms a minimum of 200 foot-candles sustained, and we have found that actual measurement after the rooms were complete was about 380 foot-candles, which we find good.

LT. AUSTIN: I think it was General Dynamics who had about 400 foot-candles at bench level, and they found that they had to cut out half their bulbs because people couldn't stand it. spec?

R. L. STADLER, THE MARTIN COMPANY: Is the air flow a part of the standard

LT. AUSTIN: No. The standards which will be required will be the contamination level, temperature, humidity, illumination, and noxious vapor control. How to achieve this contamination level will be up to the individual. We don't want to stifle inventiveness, new designs, and so forth. This is a guide line. If you don't know how to do it better, we suggest using this because this will give you the type of cleanliness required. 
MR. STADLER: You mentioned 25 percent as the lower level of RH. Is that going to be minimum?

LT. AUSTIN: We are in debate about this right now. We know of one base even in our own system that is running at 18 percent $\mathrm{RH}$, and they have no trouble whatsoever. We would not like to require a lower humidity level. We would like to simply specify a maximum humidity level. We do not need humidity tolerance. Some operations in industry, such as in thin film deposition-type operations, where humidity is a very important part of evaporation processes, have to control humidity to 2 percent. But an item such as a gyro is not sensitive to a change in humidity.

C. P. SHELLY, NORTRONICS: I am concerned with the absence of dew point specifications. Did we eliminate these for a reason? These are now becoming necessary in clean room operations because cooling of electronics is frequently necessary.

LT. AUSTIN: What range are we talking about? Lower than 50 percent RH? What type of operations exactly are you talking about?

MR. SHELLY: Where you have an electronic package and as part of the prectsion assembly you must cool the package. Unless you control dew point you would have condensation.

LT. AUSTIN: I don't quite see why you would get condensation. You are running your temperatures in the range of 66 to 77 degrees. You are not putting 40 degree intake air in.

MR. SHELLY: I am talking about your using a separate cooling device to cool your package.

LT. AUSTIN: I think you have a particular operation here which would warrant an exception if you were using this type of thing for a clean room. We don't normally have this individual coolant to worry about as a source for condensation. Actually you have a very sharp temperature gradient in this package. If you are running it at 45 percent $\mathrm{RH}$ and you are getting condensation, you must have a very appreciable delta $\mathrm{T}$ drop across your product. This is an individual case.

SCOTT SIMPSON, NASA: Why do you need such a close control with temperature? You mentioned a half degree.

LT. AUSTIN: It is really not a close control as stated. I am saying you are able to get a half degree control by specifying a 4-degree ioom rate of ohange. You can start the room initially at 67 degrees in the morning, and, if you can control your rate of change to increase temperalure in the room 4 degrees per hour, you are able to achieve a half-a-degree temperature rate of change. There are few products that $I$ know of that need this type of temperature control during calibration. Let us take an item which has a certain amount of heat. You know what your heat change is, and you are calibrating this item. What I am trying to get at here is that we don't have this requirement of close temperaturc control that has been previously stated in clean room specifications. rooms?

MR. SIMPSON: Would you say a little more about the Class 1, 2, 3, and 4

LT. AUSTIN: We are having really one class of standard room. The reason for this is that the way the Class 1 and Class 2 rooms are currently spelled out, the contamination levels would be much grealer than industrialized air. Ac.tually you have a dirty environment In which you are overhauling your prodict.

MR. SIMPSON: Here you are speaking of one problem, contamination in the air. There are many other facets to the clean room, such as the discipline of the employees.

LT. AUSTIN: I didn't hope to cover the whole revision of the T.O. here. I am just picking out some major areas. We realize the dirtiest things in the rooms are the people. We have two major principles: (1) as soon as the contamination is generated by these people get it out of the ronm; (2) as much as possible, keep the contamination from being generated. 
MR. SIMPSON: In your class, then, you are speaking mainly of the air itself. There will be just one class of air.

LT. AUSTIN: Right, if the requirement for contaminants within the air is greater than the requirement we have for the standard clean room, then we are actually talking of tolerances of an order of magnitude better, and so we should put them in a station or environment which will control the contamination level to that required for the product.

M. W. MCKENZIE, MARTIN COMPANY: Will a standard method for manual counting be part of the Tech Order?

LT. AUSTIN: We feel, from the data presented here today, that there is a definite size-distribution relationship for airborne particulate matter. We feel that manual counting techniques will adequately define the slope of these rooms for the standard clean room. If you are going into contamination levels such as the clean work bench, then you are going to have to use one of two processes, either an automatic counting technique--this would be the light scattering devices which right now are expensive and really research tools--or a deductive method by which you know the medium is guaranteed to be 99.97 percent effective by DOP tests.

LT. FRITH: I will say, since this is my portion of the T.0., that we are going to use the ASTM collection technique using the membrane filter. In the old T.O. it calls for the Greenberg Smith. We will change all that on the new T.O.

MR. HAMILTON: Do you have anything in the new T.O. with regard to gaseous contaminants in the room? $\mathrm{SO}_{2}$ gases react with fluorescent lights and produce sulphuric acid droplets.

LT. AUSTIN: We11, we have not seen this happening too much in our areas. We have not seen or been able to trace contamination problems to gaseous items coming through the filters and redepositing.

MR. HAMILTON: If you measure a clean room and count the microscopic partic.lps, you will find that ng your room gelv cleuner the conceulration of submicroscopic particles rises. The number can get up to $100,000 / \mathrm{cc}$ of particles of the order of about $1 / 1000$ of a micron.

A. L. LIEBERMAN; ARMOUR: I gather the question was, what is the effect of gaseous contaminants which later turn into solids or particulate contaminants? This is a very real effect. In addition to this, the continuous presence of particles in the neighborhood of $1 / 10$ micron and down in concentrations of 10 to several hundred thousand particles per cubic centimeter is also a very real effect. But in view of the present state of the art, this is a secondary or possibly a tertiary problem. The existence of particles which are bypassed through leaky filters or which are produced within the rooms by personnel is so much the greater problem that the problem of the very small particles is not of great importance at this time. Possibly 5 to 10 years in the future a rewrite of the Tech Order may be in order to take care of these, but right now this is strictly a research problem.

MR. MCKENSIE: If I understood the original Tech Order right, I believe it dealt mostly with particulate control. In revising it, you have the liquid oxygen systems included. Will it be any effort to put into the spec hydrocarbon control or chemical control?

LT. AUSTIN: We are lrying to provide an environment in which these type products could be overhauled or worked upon, so that we would be controlling all the particles up to this range or even above this range with this type of slope. We would hope to find no more than one particle in the 100 micron size range, whether it be a hydrocarbon or whether it be some solid material. We are only providing control on the atmospheric conditions.

H. I. PAUL, BOEING: Where did you obtain these engineering requirements for particles on components and so forth? 
LT. AUSTIN: This is from Air Force experience. We have over 5000 instruments and items within our system. We took a cross-sectional look at the tolerances, clearances, and so forth, which these items have, and then we took a look at the contamination level in which these items were being overhauled and we four. out what our reject rates were and how the products were doing while being overhauled in this contamination level. We found out we were getting a satisfactory product out with a contamination level similar to what we portrayed in that halfmoon area in Figure 19.

MR. PAUL: This standard clean room will not be clean enough for some work, and some of that work will be on things which are too large for work bench handing.

COL. I. R. PERKIN, MAAMA: We are talking about the largest common denominator we can get. There are certainly exceptions to the rule, and that is where the problem which you bring up will have to be handled. In your case you would have special requirements.

D. W. BALT.ARD, SANDIA: I would like to comment on this also. You con1त use the cross-flow room Lo get intermediato clganliness at:ages; you could also use resycling clean work stations in standard clean rooms to upgrade them from the 100 micron size to something better.

MR. PAUL: We are thinking in terms of a component 33 feet by 200 feet. The laminar flow room may not actually work on this size.

MR. BALLARD: If the laminar flow room won't work in this particular instance $\frac{\text { I don't know what would. }}{\text { d }}$

LT: AUSTIN: When you put a pressure drop across two walls, unless you block up the exits, you will get a cross-flow room. Even if the distance is 200 feet, you will still get air moving through the room. It is just like a low velocity wind tunnel, and we have had plenty of experience with these. In essence you set up a 200-foot wind tunnel, and you do your work in there.

MR. LIEBERMAN: I have one question with regard to the use of monitoring devices. At this point it appears that you are favoring either a light scattering particle counter or an ASTM membrane filter. What allowances have you made lor subsequent use of such devices as the condensation nuclei counter, the ion counter, and sonic electrostatic radiation counters? The companies using settlement devices which do not necessarily "coumt" the small particles, are able to control small particles quite well. Is there any allowance going to be made for them?

L'l. AUSTIN: Our monitoring techniques have been established for the standard clean room, which has a much higher contamination level than the area which you are discussing for this condensation nuclei-type device. We have put in our technical order, as guide lines, these different monitoring techniques. The guide lines say that if you don't know a better way of doing it these methods will get you some place. These will give you acceptable data, but the advancement as we go along will bring out new devices. The ASTM method does a good job for us. What we are after is the most economical method for monitoring our rooms. We are not looking for a research tool because we are dealing with production right now.

C. E. BODEY, AUTONETICS: Should we be required to repair instruments in an environment and under controls either far more critical than that of the original approved manufacture, or, in the other case, less critical? Should we require a substantially finer and more expensive environment for repair than we do for the original manufacture, or, equally important, should we require a less critical environment for maintenance and repair than the original manufacturing spec?

LT, AUSTIN: What wc are trying to do is to get a room which will do for the majority of products. In a particular case where one might get involved with onc product which was originally built at a certain level and then a new level is desired, I guess we would have a hassle between the people requiring this new condition and the people that want to do it at a different level. 


\title{
NAVY SPECIFICATIONS AND FACILITIES
}

\author{
F. C. Shadewald \\ U.S. Naval Air Station
}

\begin{abstract}
In 1955, North Island was having difficulty with instrument bearing failures. Investigation revealed that the primary problem was dirt. This investigation led to the design and construction of the first clean room at North Island. This was a small room, 33 by 23 feet, and the specifications ( $I$ am quoting from the specs) called for a temperature of $68^{\circ} \pm 5^{\circ} \mathrm{F}$, humidity $40 \pm 5$ percent, and lighting of 50 to $/ U$ foot-candles. A iote in the cpesifiratinns said that the room must be dust free. We actually ended up with roughly what the Air Force considers a Class 1 room. Shortly thereafter, the Naval Air Station was required to set up a West Coast standards laboratory. This room was approximately 70 by 52 feet, and was essentially a temperature controlled room. Temperature was held at $68^{\circ} \pm 1 / 2^{\circ} \mathrm{F}$. Humidity and dust were secondary considerations, so they were not even mentioned in the specifications. At the same time a requirement developed for a helicopter blade bonding booth. It was determined that this work had to be done in a temperature-humidity controlled, dust-free atmosphere. Consequently, we built two booths at practically the same time for altogether different purposes.
\end{abstract}

A real need for an ultraclean room came in 1956.

The WF-2 aircraft carries the ASN-28 inertial guidance system, and in 1956 North Island was designated as the overhaul base for this system. The ASN-28 inprtial guidance system contains two gyros, each capable of detecting motion 3000 times slower than the movement ul Llite livui hund of a slock and aronirate ton less than 1 second of 1 degree. The gyro as such was used extensively during World War II in bomb sights, compasses, and gun controls. Later gyros were made much more accurate. The real breakthrough came with the floating gyro in which the gyro wheel, approximately the size of four evenly stacked 50-cent pieces, was placed in a helium-filled container. This egg-shaped package was then floated in another container filled with a highly viscous fluid. This system provides the gyro with a virtually friction-free environment. The extreme precision of the floating gyro created unprecedented production and maintenance problems. Its reliability and efficiency can be destroyed by contaminants one-third the size of particles in cigarette smoke. The specification requirements for the ultraclean room for overhauling the ASN-28 called for temperature of $72^{\circ} \pm 2^{\circ} \mathrm{F}$; maximum humidity of 40 percent; and a filtration system capable of removing 99.95 percent of all particles measuring 0.3 micron or larger. The facility itself was divided into men's and women's dressing rooms, a cleaning room for the ultrasonic cleaning of gyro parts, a balancing room for the calibration of the gyro instruments, and a main assembly room. A positive pressure of 2 pounds per square foot is maintained in the main assembly area, and this reduces to $1-1 / 2$ pounds per square foot toward the less critical areas.

Before completion of the first clean room, we began building another clean room of approximately 4000 square feet. In this room we attempted to rectify some of the errors made in constructing the first room. A sheet vinyl wall covering was used rather than a sprayable vinyl. Al1 storage cabinets for instruments and such were recessed into the wall. Al.1. corners were made in a 4-inch radius rather than the previous $1-1 / 2-i n c h$ radius.

While the second room was being built, we were already in process to build a third room which was to be used as a calibration and test area for the inertial platforms that were being overhauled in the two existing booths. The requirements for this booth were less stringent than for the two previous booths, except in one 
respect--temperature. The test and calibration equipment to be placed in this room operated on a continuous basis. The temperature had to be maintained at less than 78 degrees. If at any time the temperature for this equipment exceeded 78 degrees, it would require recalibration, a long, drawn out process. To insure 100 -percent reliability of our air-conditioning system, two complete air-conditioning systems were specified for this room. Each system worked independently, and each system was capable of carrying the normal air-conditioning load working independently.

Some construction features of this calibration room might be of interest. We had to build into this room 10 highly stable inertial platforms. The idea was to keep our vibrations from the surrounding area. The entire pedestal area was first surrounded by a barrier wall of steel and concrete. This wall extends under the floor approximately 10 feet. Within this barrier wall we have these 10 stable pedestals. Each is made up of reinforced concrete approximately 8 feet high with a base 8 feet square and tapering upward to 4 feet square at the floor level. The pedestal is completely isolated from the surrounding floor so as not to get any vibration into the pedestal area from the other areas. Each of these platforms has to be level within a half a second of 1 degree of arc, be vihratinn free, and be orlenced toward a true north within 1 second of 1 degree.

That is roughly the history of the rooms that now exist at North Island, but apparently we are not anywhere near complete as far as clean rooms are concerned. We have approximately 25,000 square feet in clean rooms at the present time, and there are four projects now under design fur additional clean rooms which will total about an additional 15,000 square feet. 


\title{
U.S. ARMY MIL-STD-1246(MI)
}

\author{
J. W. Hodges
}

Redstone Arsenal

In deciding on what to talk about today, I decided to take it from the viewpoint that the primary objective of this meeting is to come up with a broad Federal standard. From that viewpoint, I felt that I could review the standard which has been fully coordinated throughout the Army. We now have a project assigned by DSA to coordinate this standard with the three services to come up with a triservice position. In this way the Department of Detense will be able to come to industry with known stated requirements. My review will emphasize the questions that developed and the problems which we discussed in arriving at our decision as to what type of document we wanted.

We had various arguments among ourselves as to what we should do in arriving at the standard. Should we adopt the Technical Order system, or should we come up with a type of document generally referred to as a "procurement type document"?

The first question that arose of major consequence was, "Do we buy clean rooms or clean products?" We discussed this extensively. One side said that we require only items of supply. Others said that we require clean rooms to maintain those items of supply. A third group said that we know our requirements, but we have no way of telling whether those requirements are being met. Could we assure clean products without requiring clean rooms? Should we specify product cleanliness or merely the environmental cleanliness? When we started this study in 1958, we felt that we basically had to do both. We determined that we did need a document on clean rooms and on levels of cleanliness. We ran into another problem in determining the contents of the document covering clean room requixements. How were we to specify these requirements if we could adequately define them? We came to the conclusion (and I think this is compatible with the Air Force position) that we would offer this standard as a guide and specify that which we knew.

Then we had to determine the format of the document that we were to put out. The particular selection may have been in error. We came up with a combination standard which contained handbook data--levels of environment or specified levels of cleanliness applicable to the environment in the form of classifying clean rơous.

We have four classes of clean rooms. Basically they are the same, with the exception of the fourth, as the Air Force classes, with perhaps minor changes in stating the requirement. The humidity control is the same, the temperature control is the same, and indication of the type of work in each class is about the same. The requirements for the Class 1 room specify that a dust count shall be taken at representative locations in the controlled area before and during operation at 3-hour intervals, and the dust count shall not exceed 25,000 particles per cubic foot of air between 5 and 50 micron size. For our Class 2 room, a dust count is to be taken at representative locations in the controlled area before and during operations at 2-hour intervals, and the dust count shall not exceed 2000 particles per cubic foot of air on any reading. There shall be a maximum of 1500 particles between 5 and 10 micron size and a maximum of 500 particles between 10 and 50 micron size. In essence our four classes are the same as the Air Force classes with the exception of Class 4, and I' 11 go directly to it. All requirements for Class 4 are the same as for class 3 with the following exceptions: we increase the air replacement rate; intake air shall be cleaned with a filter system capable of entrapping particles of 0.3 micron size and larger; there will be a maximum of 50 particles per cubic foot of air between 5 and 10 microns and a 
maximum of 10 particles per cubic foot of air between 10 and 50 micron size. We use the same dust monitoring system all the way through for the four classes. The only difference between us and the Air Force is that they are using clean stations and we are tightening the requirements on the over-all environment.

I would like to indicate here the future plan for the standard. I already have indicated that we are going to coordinate this with the other two services for refinement, and we feel that we will come up with levels of environmental cleanliness suitable for all of the services. Perhaps we may add one or two levels of cleanliness in doing this, but these we feel are planned changes in military management requirements for product cleanliness and clean environment. We feel that, once we have standardized, not the clean room, but levels of environmental cleanliness, within the middle of the document we can have a very concise standard. We feel also that this general data is suitable and could be useful for industrial architects, industrialists, and people having certain environmental requirements. These people would thus have a reference document or handbook to familiarize themselves with the general state of the art in this area. We feel that this particular format--standard and handbook--would keep separate dissimilar requirements and yet did to the over-al1 understanding of the requirements.

\section{QUESTIONS}

JOHN A. HAUPTMAN, LOCKHEED, SUNNYVALE: Are we stil1 going to have the problem of tying the room to the product in the product requirement?

MR. HODGES: We feel that, if this format is adopted and understood, the product specification will specify the level. It would be the responsibility of the person designing the product to select from established levels or else to feed in requirements that would change levels.

MR. HAUPTMAN: I don't believe it is possible for a designer to specify ahsolutely the requirement, because he can't take into consideration the factor of time. Time enters the picture and the designer has no control over that.

MR. HODGES: This is a question that I haven't understood. I wonder if there is anybody in the audience who could answer this question.

LT. AUSTIN: We have been looking at the question of how long an item should be exposed to a known environment, and what exposure over a period of time does to the product. I have done some calculations on the probabllity of a cercalin slue particle falling out on a critical area, and I think this is one approach that we should take in determining what our requirements should be in relation to the cleań room.

MR. HAUP'lMAN: Isn't it going to be neccssary ultimalely lo measure the part to determine whether we have contamination control?

LT. AUSTIN: I think this is the case. I think we must know what clearances are involved, and I think the designer himself can predict how long it is going to take to manufacture the product or to overhaul it. Any design engineer knows the complexity involved in assembling a product. This is an industrial engineering function, so I don't think we can say that we don't know the time. The factor that we don't know is how many times he has to do it over until he gets it out.

\section{LT. CLIFFORD F. FRITH, USAF: Have you actually tried these standards?}

MR. HODGES: No, we haven't. We have just printed the standard, and we have no experience in relation to the standard itself.

LT. FRTTH: Are you going to require the contractor to design to this as the ultimate level, so that when the room is "in operation" it will meet these standards? We are finding that people build clean rooms to certain criteria, but when we put the operation into the room we go above the specifications. 
MR. HODGES: I feel that the manufacturer or the producer must have the latitude to develop or establish a clean room, not in accordance with the standard, but according to the requirements of the item.

CHARLES P. SHELLY, NORTHROP: You gave some figures on your four classes of clean rooms. Your figures seem of the order of 10 times tighter than the Air Force classes. I am wondering whether it is your intent to resolve these differences in the services before industry is faced with this problem?

MR. HODGES: In other words, whether we will resolve these matters among the services before we come to industry? Ordinarily this is done simultaneously. It may be, however, that once we get a letter to the Air Force and Navy we will decide to call a working group together to work this out.

M. T. KOERNER, AFLC: I'd like to make it known that the Air Force has under preparation a manual for use in the design of clean rooms in addition to the T.0. which is being prepared under the direction of Colonel Perkin. This manual is now in rough-draft form and it will be sent into Headquarters, USAF. It will have to be coordinated with the Army and Navy, as will the manual that you have under preparation.

MR. HODGES: Actually, I don't know the manual itself, but it could be the basis of a handbook that we feel is necessary to support a standard.

MR. KOERNER: The document is a handbook which will cover all the design ramifications for the real property part of the clean room. It will be used as a counterpart of the T.O. which sets up the actual environmental requirements neces.sary by the using agencies. It will present guide lines for use in the design of military facilities as designed and constructed by the Air Force.

S. GAVURIN, RCA: In bidding, if it is left up to the design engineer to specify criteria for the standard, how can we compete with our competitors?

MR. HODGES: If these are known levels of cleanliness, presented in the standard, they should be followed. However, if you design an item that requires a higher level of cleanliness, then the justification to change that standard rihnild immediately be preturuled. Th1s being the case, that fustification would be the evidence of the actual requirement. How would this interfere with your position?

MR. GAVURIN: Under the present concept of fixed price contracts, naturally price has to meet the workmanship and performance and you have to tighten every screw in every area in your entire machine to become competitive. You can outclass yourself if you leave it up to your design engineers, because naturally they are going to look for perfection in the product they are designing. I would think that the services would have to put in the requirement, during their requests for bids.

LT. AUSTIN: When we go out to industry and we ask for a Mk 3 fighter, we don't say, "Give us a Mk 3 fighter built in a clean room." Wé want a Mk 3 fighter that has certain performance standards. The bidders say they can give us a Mk 3 fighter but that they will have to manufacture certain items in a controlled environment. The Air Force can then say, "If you can't do any better we'1l take it into the system as such." Then we maintain it in our system for a period of 5 years. Clean room classes should not be specified in any way or when we go out for a contract bid. This would come back as a requirement from the designer, stating that he can't make the item unless he puts it in a clean room facility.

C. $W$. COBLENTZ, NATIONAL BUREAU OF STANDARDS: Lt. Austin, how can you predict the contamination if you don't know what the rate of contamination continuously brought into the room is?

LT. AUSTIN: We do know some of these factors. We know what the ambient contamination level is outdoors, and so we know how much contamination we are dumping into the room. We also know that if we increase the rate of flow of the air into the room, we can extract the contamination that is generated. We also have some data now--I did calesthenics in one room--on how much contamination is generated by physical activity in the room. Measurements down stream from my calesthenics gave an Indication of how much contamination is generated by a person performing severe activity within the room. These are the tools which we must use to predict how much contamination would be in the room. 
MR. COBLENTZ: Are there any gauges which indicate what number of particles one person would emit or produce?

LT. AUSTIN: It all depends on the activity of the person, how clean his garments are, and how clean his tools are. We have under design a jig to determine how effective garments are as personnel filters. The idea is to foolproof the room the best way possible. This you do by getting rid of the contamination as soon as it is generated, and also by providing controls over the personnel and over the tools which you use to work on the product. 


\section{SUMMARY}

Colonel I. R. Perkin

From what yuu liave heard, I think it shnuld be obvious that the Air Force agrees wholcheartedly with Mr. King that the empirical approach is the one we should pursue. As a practical matter'we have no choice; there is no alternative. We feel that it is a mistake to try to clean a universe. Why clean up the whole room when it is really only a little piece that you want to keep clean? Furthermore, six months from now or a year from now, you may be faced with a product line that is so entirely different that you don't need the clean room any more. We feel we should be realistic in the clean room area. We feel that if we can overhaul, produce, repair, or fabricate 95 percent of our items within one spectrum, and that spectrum can be covered by a standard clean room, we should take advantage of it. This is what we propose to do with the Air Force Standard Clean Room. If upgrading is required, let us do our upgrading with a clean station. If further upgrading is required, then let us consider this as a particular problem. This of course is what we are doing. I think it should also be quite obvious from the discussion, that there are many, many gray areas. That there are inconsistencies is true, and I. think this points up the need for standardization more than ever. 
EVENING ADDRESS

The Medical Use of Clean Rooms

W. R. Lovelace II 


\title{
THE MEDICAL USE OF CLEAN ROOMS
}

\author{
W. R. Lovelace II
}

\begin{abstract}
Albuquerque is one of the few places in the world where the life scientists, physical scientists, and engineers have worked closely together. My first cxperience working with engineers and scientists was at Wright Field in World War II when I gave up surgery for 4 years to do research in the Air Medical Laboratory there. We worked with physical scientists and engineers nn such things as Lhe development of g-sirits and prcsgurized dircratt cabins. I learned among other things that there should be a continuing change in specifications which you gentlemen finally end up with .
\end{abstract}

During World War II we had what we called a walk-around oxygen bottle that lasted for 6 minutes. Sitting back comfortably in Dayton, we felt that 6 minutes was a long time. We kept getting reports saying, "You fellows at Wright Field don't realize what it is like to be in combat." Six minutes go by in a hurry. We wrote up a very fine specification for a new piece of walk-around oxygen equipment that would last for 36 minutes. It took us 14 months to develop it and get it into production. Meanwhile, the men in the field took some of our high-pressure oxygen equipment which we had declared obsolete, put a reducing valve on it and put a continuous flow regulatior on $i t$, and within about 45 days they had developed an oxygen supply that would last 45 minutes. When we finally came up with our equipment that lasted 36 minutes, they said, "Thanks a lot, but we have had something a little bit better for quite awhile."

When we went into World War II we had what we call continuous flow oxygen equipment in which a steady flow of oxygen enters, the rate depending on the altitude. We shot down a German airplane near Cairo, and we found out that the Germans had what was called a demand oxygen regulator. Every time the user took a breath it tripped. a valve, releasing pure oxygen above 30,000 feet or a mixture of oxygen and air below 30,000 feet. We went into production with it. The Germans had a stiff tube about an eighth or quarter inch in diameter from the demand regulator to the command oxygen mask. We thought that we could make it lighter and more flexible. Within two weeks we were producing up to 1000 masks a day. After three days the Boeing Company in Seattle said, "Dr. Lovelace, we hate to tell you but something has gone wrong. With a crew of three men instead of our ordinary crew of thirteen in the B-17, at the end of two and a half hours we were losing all our oxygen supply instead of it lasting twelve hours." It turned out that the big flexible tube had a natural frequency, and as the B-17 flew along the tube moved about automatically sucking all the oxygen out. We went back to the German system with a stiffer tube. This story illustrates why it is very important to make continuing changes in specifications. You must freeze on a specification, of course, but you must begin to consider every so often to make changes.

From now on what I am going to say should be considered a joint presentation of Doctor Whitcomb, Head of our Surgical Department, and myself.

I believe it would be wise for representatives of the working committee which you eventually form to actually watch us do an operation. Things have changed a lot since I used to be a brunette. To get into our surgery area, we have to take off all our regular clothes, put on a green suit, put on special socks, special shoes which are conductive, and then put on a green hat and a special mask. Then over our conductive shoes we put still other clean shoes. We are not allowed to leave the operating room without going through the whole process again when we reenter. That is the way surgery has advanced. The minute you go into the doctor's room, you are in an entirely different environment, and it is very important. In 
the old days when I first started surgery we didn't even have sulfanilamide. That came along and began to change our mortality and our mobidity rates. Mortality refers to the death rate. Morbidity refers to the complications arising as a result of an operation. Many years ago, in certain types of cases, we used to have a mortality rate of 15 percent. In those same cases today we are down to 0.7 or 0.8 percent. That is a real nice low percentage. That sounds pretty good, but on the other hand the engineering or the physical sciences can make these figures 100 percent. The best experimental subject for a doctor is still a human being. We can't run you on a 24 hour a day fatigue test because you must have your rest and you must have your food and so forth; and we can't expose you 24 hours a day to a temperature of 160 degrees or minus 60 degrees, but we have no counterpart for the human as an experimental subject. The longer lhuse of ue that are in medical research do research, the more we realize that we must carry over from our animal experiments to the human being and be able to end up with something that is practical from the human standpoint.

From a surgeon's standpoint, we would like to start out surgery in a completely clean room. Ordinarily, unless there is an emergency, the operating room is shut down at night so in the morning they turn on the air conditioner perhaps at $6: 45$ to ready the room when we start surgery at 8:00. Then, the second major point, we would like to remove all contamination from that room as we carry out our various surgical procedures. Say there is an abscess from a ruptured appendix, ordinari.ly what we call peritonitis, a very bad infection. We have to clean it out as best we can, but we inmediately go from a clean operating room to a contaminated operating room. With this new clean room specification, with the air coming in from the ceiling and going out through the bottom, with the water flowing underneath, perhaps, any germs that come from the abscess will go on out and we can go ahead, finish the operation, and go ahead to the next case Immediately in a clean room. If we don't have the clean room such as proposed here tonight, we have a delay of one hour between the time we take out a ruptured appendix and the time we go ahead with the next operation. I'd like to emphasize again that we can't always predict ahead of time whether a case will be clean or.dirty, but once we run into a dirty case, as of now, the whole operating room has to be scrubbed with Lysol.

You may wonder at what other times we want a very clean room. Ordinarily if you come in with a rupture or hernia, your chances of infection are very low. If you do become infected, it is generally not terribly imporlant. Conslder, howcver, that surgeons now have transplanted kidneys on identical twins. Technically, that is a very difficult procedure because you are working with very small blond vessels, but the technique has been worked out. Dr. Sweeney in Newcastle, England, two weeks ago today, showed $\mathrm{Dr}$. White a 9 -year-uld boy whose father had glven him his kidney. Ordinarily that kidney would have beell dead very quickly. We can't tolerate, unlcss we are identıcal twilis, other penple's tissues. This 9-year-old boy had been given total body radiation first which destroyed the antibudies that cause trouble, and he had been living 10 days when Dr. White saw him. The reason I bring up this particular case is that, if any one of us in this room were to take total body radiation, we would be immediately susceptible to infection, as has been proven in

Hiroshima and Nagasaki experiments. So if we have a clcan room where we transplant that kidney we are at least surc that we are not putting some infection in where we litake the long incision.

To show you how well this new clean room technique for operations can work, $\mathrm{Dr}$. Whitcomb has come out here with his staff, including a bactcriologist, and worked with Messrs. King and Whitfield and the rest of them, and operated on experimental animals. They opened up the large intestine, which is ordinarily very heavily contaminated with many kinds of different bacteria, but instead of having bacteria all over the room, some of the culture dishes had no contamination and others had either just one culture of organisms or perhaps two. I'd like to emphasize that, in an emergency, if you rupture your intestine or something else that is equally critical, we cannot wait; we must go ahead and operate. With a clean room your chances of having infection where we make the 1ncision, would be way down. We want to monitor the patient--we want to know what his oxygen consumption is, his carbon dioxide output, his pulse, blood pressure, respiration, temperature. Ail of you who have children know that they can really frighten you because they can'become ill and suddenly have a temperature up to 104 degrees. If we have to operate on a child whose temperature is high, we must monitor that temperature or else we are liable to lose the child; not through surgery, but because the child developed too high a temperature. All this monitoring equipment is very critical to us. If I am operating, I don't mind looking over and seeing the heart beat from the 
electrocardiogram and the pulse, but if it suddenly begins to be hazy because of an instrumental failure, that is very critical. We feel that all the monitoring equipment which is necessary in a modern operating room should be made under clean room conditions. Everything that is to be used in the treatment of patients should be manufactured under ideal clean room conditions. We hope eventually to have what we would call an ideal operating room where we can have conditions just as nearly perfect as possible.

Let me discuss some of the things we would have in a perfect operating room. When we operate we are quite worried about static electricity. Ordinarily the humidity must be kept at 40 to 60 percent, a little high for Albuquerque although it is no problem in Boston, New York, or places like that. We have to have every electrical outlet expose-proof. Our operating room lights have to be focused on a very small point. Ordinarily we are operating in an area of 3 to 5 inches length. We must have what we call conductive flooring. We have conductive shoes and conductive flooring because a spark of static electricity could cause an explosion with the anesthetic mixture in the lungs and the patient is through. We must have a clean room that can have high humidity. We would like the air flow from the top down because ordinarily in operating a surgeon leans over the patient. If the air flow is coming down from the ceiling, any contamination will go on down and be picked up in the water flow underneath the room. Ideally we would like a continuous monitoring of the particles in the room because if there is something that suddenly increases that particle count we would like to know so that we can be making some changes and being extra careful.

Perhaps some of you have read about surgery under positive pressure. If I had an intestinal obstruction for several hours, my abdomen would stick way out. If the atmospheric pressure is increased three times, the abdomen would shrink back down. My blood supply could begin to work efficiently again and carry off toxic products. If 100 percent oxygen or 80 percent oxygen and 20 percent helium, or 80 percent helium and 20 percent oxygen atmosphere is used then the body begins to get rid of the nitrogen in the intestine. Technically, better surgery is possible when organs are near normal size. So perhaps we want to monitor the pressure in the future.

We may possibly want to use ultraviolet light to improve operating conditions. Dr. Clapper, head of our microbiology department, couldn't believe his eyes at the Sandia clean room. They took out all particles above 0.37 micron in size. That meant that we didn't have to worry about seaph infection. A staph infection after surgery is a serious thing.

It seems to me that, as time goes on, perhaps by the addition of heat we will be able to knock out viruses. I am not worried about virus infection such as $f l u$, but I am worried about virus infection in the lungs.

Dr. Naples at the Utah Medical School has recently worked on a disposable fiberglass mask to wear in surgery. We are using more and more disposable equipment in surgery and medicine.

When our space capsules first went into flight, they had millions and millinns of particles in them. In fact, some of them had so many particles that the astronauts could see them. We worked very closely with these astronauts, especially with the initial group, and I well remember when John Glenn finished up his examination here at the clinic he said, "In the first place I wish every doctor in the clinic could go through the same procedure next week just to see what it is like; and in the second place, I didn't know there were so many openings in the body and so many different sizes and so many different depths." As we go farther and farther into space, we are going to need cleaner and cleaner space craft.

I am sure you realize that, on the moon project Apollo, we ought to have a crew of three. As I recall, it takes 66-1/2 hours to go to the moon and then they will orbit the moon perhaps one or two times. Two of the three will get out into what we call a bug, go down and land on the moon and run their experiments and then come up and rendezvous with the Apol1o. They will leave the bug in orbit and come on back to the earth. The heat of re-entry will take care of the external bacteria.

Clean rooms will eventually be used for growing tissue cultures. If you put a piece of tissue in the right medium, you can grow it. Many of those tissue cultures now die because they become contaminated. With a clean room we hope to be able to grow cultures week after week, and perhaps even year after year. This approach would be extremely valuable for cancer research. We know many things 
empirically, but we want to qualitate this research, and we want to study it in detail, especially in the areas where we don't do as well as we might. We want to study virology also. There are all kinds of viruses, and I am sure many of you realize that viruses cause cancer. Viruses are very small, and it takes a phillips or some other microscope to study them and making the identification is very hard.

One of the big medical problems today is the survival of premature babies. They have practically no resistance to infection. A premature nursery in a clean room will increase the chances of survival of premature infants. In addition, once in a great while, some kind of infection starts going through a nursery and it has to be clused down. With a clean room perhaps that will never happen.

In the atomic energy field, of course, there is the possibility uf being $a x-$ posed to a very large dose of radiation. One of the biggest problems is that a person then develops anemia or shortage of blood cells. In addition, he is very susceptible to infection. If they could be put into a clean room, their chances of secondary infection would be very low.

We would like to have isolation clean rooms.

We also would like to have clean rooms for burn cases. The hardest case of all that we have to take care of is a severe buril. IL destrnys the skin and can go down to the decper tissues. Infection is a serious problem. If it goes around the back of your body you just can't stretch out and rest because you are always putting pressure on the burned area. With a good clean room, those patients--many of those patients who die today or have serious complications--would live.

One of the things you dur' $L$ liear doctnrs talk much about, but which is very important, is autopsies. In most instances, if we can do what we call a postmortem examination or an autopsy examination, we can tell exactly what happened. It may be one year or twenty before we can apply all these data, but as we develop better and better use of computing, we can store our information and utilize it. Doctors doing these autopsies are exposing themselves to all the infection that that patient had when he died. With a clean room, this infection would be pulled out through the bottom of the room. I think that as a side effect, or benefit rather, that would be very helpful.

We hope to have portable rooms in future years. These rooms could be taken any place in the world where there is a disaster, such as the Texas City disaster. If you had portable clean rooms that you could use that would be air conditioned, you could do surgery and medical care for burns and the like.

\section{QUESTIONS}

\section{QUESTION: What percentage of bacteria would a U.3 micrun filtor oliminate?}

DR. LOVELACE: I believe it would eliminate a11. As you know, if I cut into an abscess, as I have to do if I am going to complcte an operation, there would be a certain outpouring of bacteria, but with this air coming in from the ceiling they would immediately be taken down below.

QUESTION: There has been a lot of talk about laminar flow as an isolation technique. Would you, as a doctor, prefer this to a positive barrier, such as a plastic barrier, working through gloves?

DR. LOVELACE: Yes. I have worked some with plastic barriers, and when we operate we don't stay in one particular place. When you use plastics movenent becomes difficult. I know from experience that it still holds. that the sooner we can get you in and out of that operating room the better your chances are of survival because you are under several stresses: the stress of the anesthetic, the stress of surgery, the stress of the environment of the operating room. There is a big difference between taking 30 minutes for an operation and taking 70 minutes. That can be accomplished in a clean room where we can work fast.

QUESTION: What is this under floor water you are speaking about? 
DR. LOVELACE: I guess what we want is a little slant with water flowing out. QUESTION: How thick is the water?

DR. LOVELACE: It wouldn't be over 2 to 4 millimeters in thickness, just so it is a continuous flow. And if you could make a little noise with that it would make the surgeon happier. We could imagine we were up in the mountains or something.

QUESTION: What is the most successful way to arrange to watch an operation?

DR. LOVELACE: Each one of you in your own communities has surgical friends. I think the best way would be to talk to them and get them to get you admitted to watch an operation. Ordinarily we don't let laymen watch operations because in the back of our minds we worry about what they are going to do when they see what we do. I would first recommend that you all contact your own surgeons and tell him what the problem is, and I assure you they will be 100 percent cooperative because this is a serious problem. Secondly, your comittee, plus a subcommittee, could come and watch us operate under what we might call standard conditions. I think you would be surprised at the different types of instruments we use and how we use them. Each of us hates to see' a surgeon that does something exactly like the other surgenn does. 
SECOND DAY

Morning Session 


\title{
INTRODUCTORY REMARKS
}

\author{
J. F. Cully
}

Space Nuclear Propulsion Office

Albuquerque Extension

At this time, I would like to say as a representative of a fairly new government program office that I am delighted to be invited to participate in this conference. I also wish to speak in behalf of Mr. Bill Mason from our Cleveland office who will be a member of your Working Group. We do appreciate the opportunity to come and join with you in this conference.

The objective of the conference, if I may be trite and repeat it again, is to develop a Federal Performance Standard for the construction, operation, and monitoring of clean room facilities. Now we have come, at this time, a little more than half way toward meeting this ultimate objective. We have learned, so far, something of the need for such a standard. We have learned, so far, something of the various approaches that have been made toward maintaining clean room standards. This morning, our session will be devoted entirely to the state of the art in contamination control. The state of the art will be discussed by representatives nf the Military, from industry, and frnm tho govcrnmeil laburacory here at Sandia. I like to think of these gentlemen who will be speaking to you here this morning as catalysts, men who understand the need for the problem, men who know of the various approaches to the problem, men who are able to bring the scientific disciplines to bear upon the solution of the problem of contamination control. 
STATE OF THE ART (CONTAMINATION CONTROL) AND LAMINAR AIR-FLOW CONCEPT

\section{W. J. Whitfield \\ Sandia Corporation}

The increased need for very clean environments has caused Sandia Corporation, along with other cumpanies, to take a close look at clean room facility costs and the results obtained by use of clean room facilities. A close examination of the cleanliness levels found in oxicting clean rooms revealed that the existing clean roulls were not really clean. Another factor was also apparent; the cost was excessive for value received in these facilities, particularly when attempts were made to achieve cleaner conditions in these clean rooms.

Existing, or conventional, clean rooms satisfactorily limited excessive dirt found in general laboratory and factory areas until much cleaner clean rooms were needed. It was at this time that an investigation was made to determine the reason for the excessive cost of improving conventional clean rooms. One characteristic was found to be common in all conventional clean rooms--the cleanliness level in the clean room was dependent on the operation. In other words, the conventional clean room had little or no self-clean-down capability. The conventional clean room is essentially a sealed area and contamination brought into or generated in the room must be carried out manually by janitorial means (Figure 1). Many conventional clean room operators have janitors who continuously remove this contamination.

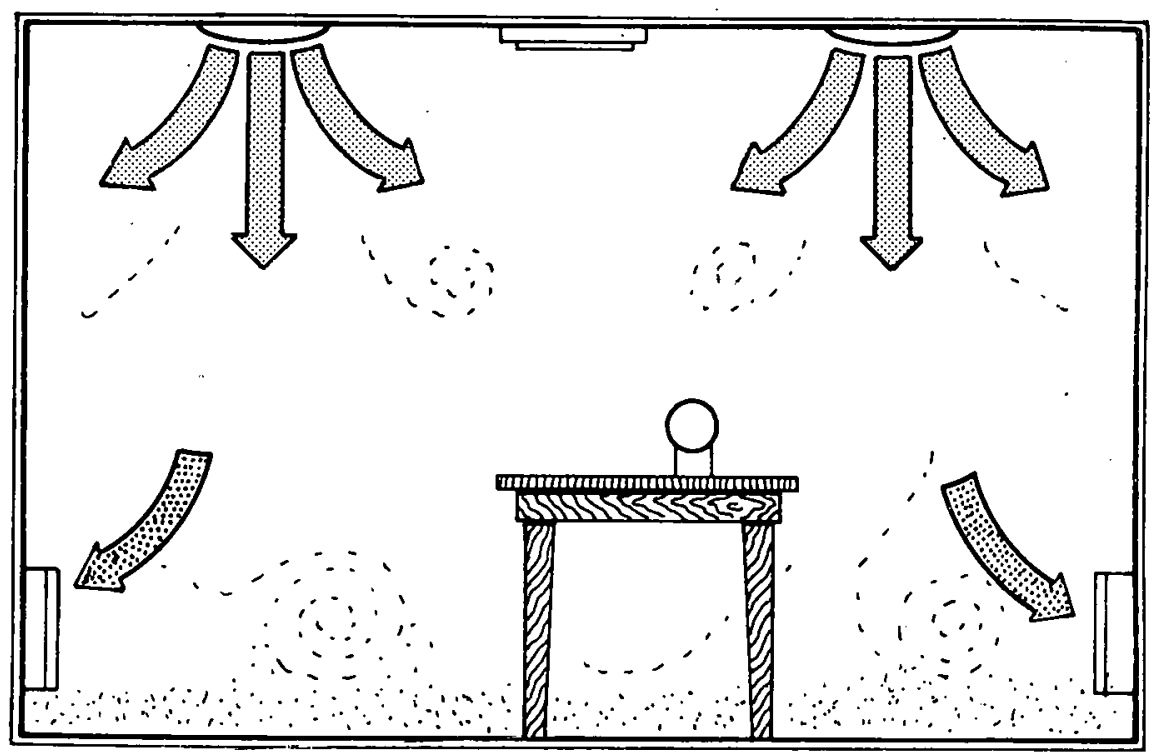

Figure 1. Conventional clean room 
In several instances, conventional clean rooms have been found to be dust traps--these clean rooms were dirtier than areas just outside the clean rooms. clean room personnel create the greatest problem by carrying in large quantities of dirt in their clothing and by shedding skin particles. Attempts have been made to clean up personnel before they enter clean rooms by using high velocity air blow-off devices known as air showers, de-dusters, etc. Special clothing has also been provided to restrict unwanted material from being carried into the clean room; however, the best of this clothing is not adequate for very good conventional clean room operation. The cost of high quality clean room clothing and of entry time (air shower, suiting up, etc.) is estimated to be approximately $\$ 2500$ per clean room worker per yeur.

Another attempt to upgrade conventional rooms was providing a larger clean room area per clean room worker. This method did help somewhat by distributing contamination brought into the room by clean room personnel. Although this reduced the concentration of contamination, it did not reduce the total amount of contamination brought in by individual workers nor did it solve the janitorial pistem, and the cost of facilities was increased proportionally. gories:

Conventional clean room problems may be grouped 1rılu threc ginerd1 Late

1. Conventional clean rooms do not have self-clean-down capabilities to offset contamination brought into the room by personnel and equipment. Most contamination has a tendency to settle to the floor or other horizontal surfaces and may be reintruduced into the air by changes in air currents, or by activity in the room. Such contamination must be removed froil the room by manual cleaning.

2. Air-flow patterns in conventional clean rooms are generally not uniform, nor are they directed in a manner which carries particulate matter away from critical work areas. In addition, they will not remove airborne contamination from the room as quickly as it is brought in.

3. Since all personnel in a conventional clean room contribute heavily to room contamination, rigid personnel controls are required.

Based on these three limitations, the Sandia Advanced Manufacturing Development Division reached the conclusion that the only possible way to satisfy current demands was to develop an entirely new type of clean room. The need was critical, fur it was obvious that unless a real advancement could be made, critical work would soon have to be done in vacuum hoods.

\section{Sandia Design Objectives}

Three objectives were sec by the Advançed Manufacturing Development Division for an ultraclean room:

1. Thit it have a self-clean-down capability which would offset both contamination brought into the room and contamination generated within the room. work area.

2. That its air-flow patterns carry airborne contamination away from the

3. That it reduce personnel restrictions.

Approach to the Problem

It was apparent that a radical design--by comparison with conventional clean room--was required. The most important initial design consideration was to provide for a much greater self-clean-down capability. It appeared that greater air flow would be a partial solution. However, it was known that when air flow is increased in a conventional clean room, the dust level rises. This is partly due 
to agitation of settled dust, and partly to the fact that dust is blown off personnel and equipment into the air. With this in mind, work was begun on development of a method to direct large quantities of air in such a way that this problem was avoided.

An obvious solution to the airblast problem was to bring air into the room through a very large area of diffusers. It appeared that this would not be too difficult to achieve, since the whole ceiling of the room could be made into a diffuser. The problem, then, however, was to provide outlets for the very large quantities of air so that particles could be carried from the room: Originally, it was thought that wall outlets of sufficient size and number could be placed near the floor to prevent very high velocities. Even with this arrangement, however, the problem of larger particles settling on the floor still existed. And since these particles would have to be removed by manual cleaning methods, it was evident that this design would not provide the required levels of cleanliness.

A perforated floor was than considered as a means of moving particles from the room. It was felt that with a perforated floor, the downward air flow would assist the natural gravitational fall of the particles. Investigations, however, revealed that it was not feasible to construct a perforated floor in a clean room. The most practical flooring appeared to be a closc-spaced grating. But there were problems associated with this, too. It was discovered that even though grating floors had been used successfully in air showers, a practical design had never bcen developed for grating floors in clean rooms. Another problem associated with the use of grated floors was that particles which had passed through the grating floor could be swept back into the room if some provision were not inade to trap them. This problem was solved by placing a rough filter material just below the grating floor. This filter served two purposes. First, it trapped particles as they were being removed from the room, and secondly, it served as a prefilter for the final, absolute filters.

To provide a uniform air flow over a large area, and at the same time to move the contamination generated by the worker away from the work area, the final, absolute filters were located in the wall behind the work bench. The basic principles of this design are shown in Figure 2.

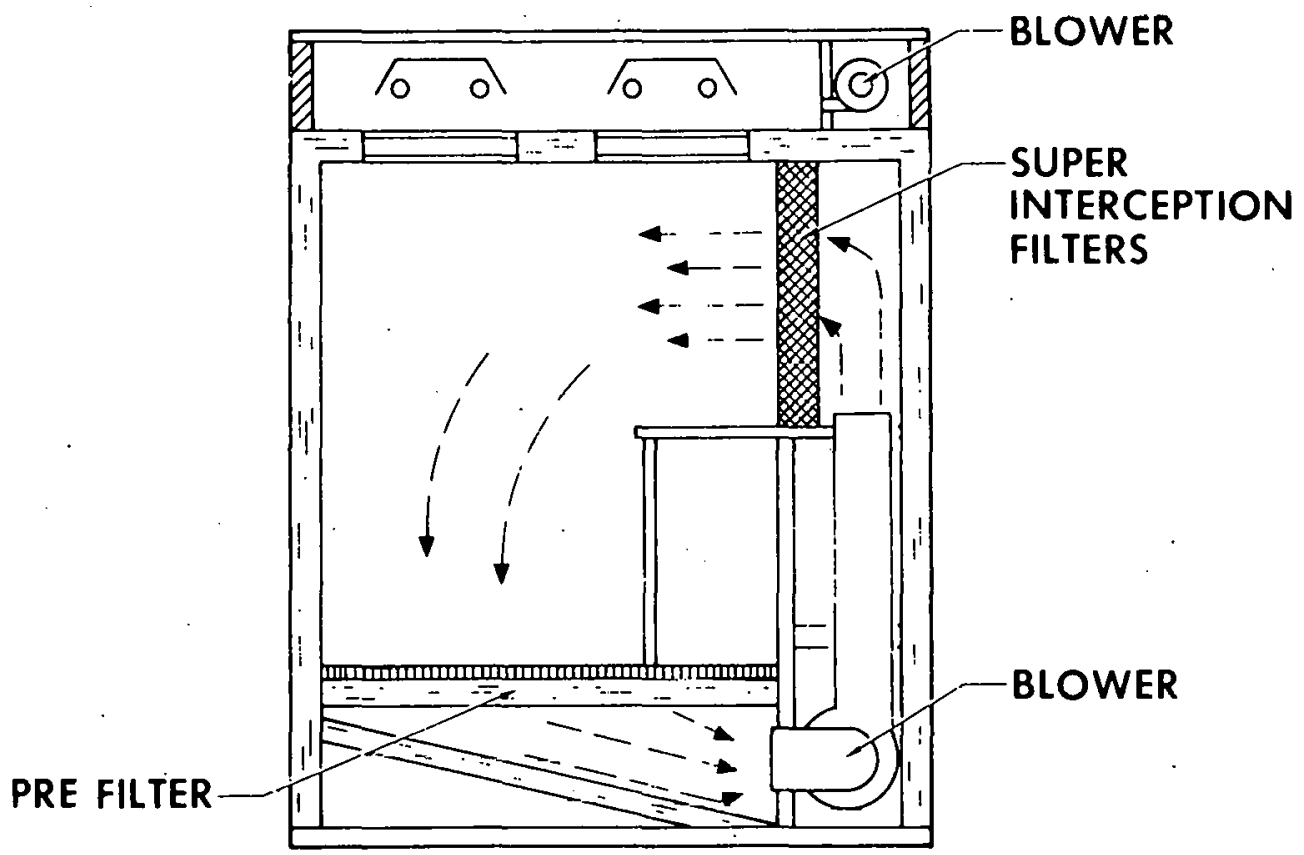

Figure 2. Wal1-to-floor laminar flow room 


\section{Construction of Evaluation Models}

Since the design shown in Figure 2 appeared to offer possibilities for providing a better clean work area than conventional designs, the decision was made to construct an evaluation model 6 feet wide and 10 feet long, with a ceiling height of 7 feet. Because it appeared that it might be possible to operate the room without an air shower, a detachable air-shower/air-lock combination was specified.

Early in the design phase it was obvious that this same principle could also be used in a portable clean room. The original design was then changed to limit the over-all width to 8 feet and to provide structural strength for handling and shipping by truck or rail.

The first portable model was designed for use inside other structures. No requirement was made for disassembly, and the unit was to be moved intact. Invitations for bids on this general design were sent out by Sandia's Purchasing Department. One company made a proposal to construct a knork-tnw, lightweight model that cuuld be moved in sections through any standard 3-foot door. l'hey proposed stainless-steel interior and exterior walls because of their low maintenance and minimum particle-shedding characteristics. These features are, of course, very important if the room is to be used as an ultraclean area inside a conventional clean room. They will. also be important when the rooul is used in uncontrolled dust areas as a temporary or permanent clean room and even more when the room is knocked down and moved.

Since it also appeared feasible to use this same dcsign in a portable, allweather unit which could be operated in areas without additional outside weather protection, a second model was ordered. This model is a rigid, unitized enclosure with a detachable combination air shower/air lock. The interior and exterior walls are painted galvanized steel. This room has a rigid base to allow the room to be handled with a forklift or crane, so that it can be transported as a unit by rail or truck. This room has a width of 8 feet, which allows truck transportation without special highway permits.

By constructing both portable models, it was possible to evaluate this design against extreme clean room requirements. The rigid, all-weather room provides a dust-controlled area for field or interior work and is portable as a single unit. This unit was built with galvanized steel interior walls so that a lowerpriced material than stainless steel could be evaluated. Interior walls of this model are not subjected to the same abrasion and damage as the walls in the knockdown model. For this reason, it appears that painted galvanizcd steel walls will be adequate. The construction of both models provided information concerning the best type of portable room needed for a given requirement.

The Knnele. = Dewn Modc1

The knock-down model of the clean room was installed in a general laboratory as shown in Figure 3 .

\section{Genera1 Description}

The exterior size of the knock-down model is 8 feet wide by 10 feet 9 inches long without the air shower. With the air shower, the room is 17 feet 2 inches long and 8 feet 8 inches high. The room is constructed in sections, and these sections are held in place by heavy-duty fasteners. These sections were designed to pass through a standard, 3-foot door.

The base of the room is divided into two sections. One section is the main plenum chamber, and the other section contains the main blowers and the air-conditioning unit. The roof is àlso divided into two sections. 


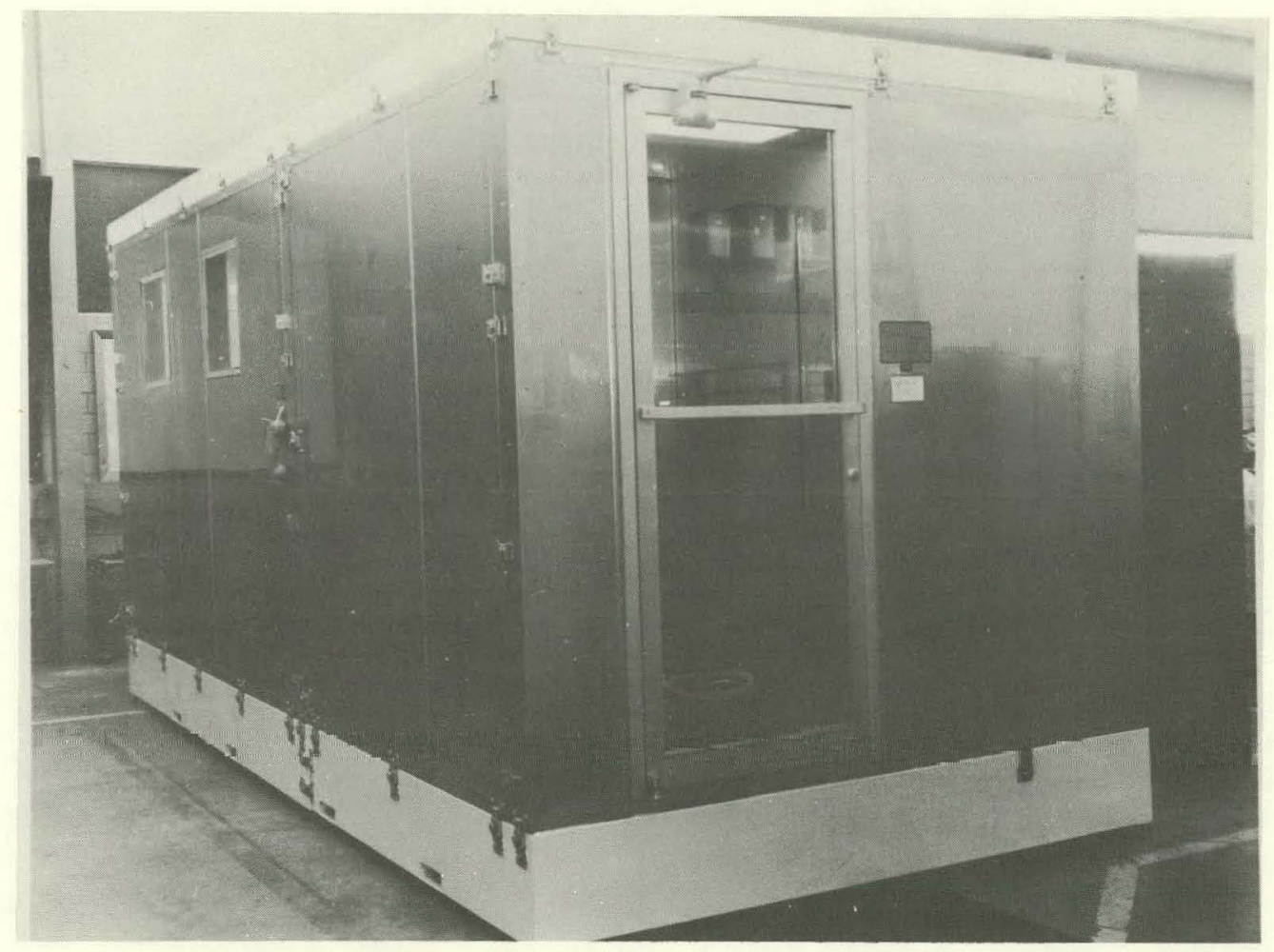

Figure 3. Knock-down model - external

The knock-down room is designed to operate either with or without the air shower. The air shower can be separated from the main room by loosening the fasteners and by removing one electrical plug. Leveling "feet" are mounted on both sections of this room.

The Rigid All-Weather Unit

This model was set up outside on a concrete base for evaluation (Figure 4). The size of this unit is approximately the same as the knock-down model, 8 feet wide by 17 feet 2 inches long and 9 feet high. It is in thrce basic units: the entry way, the main clean room, and the roof cover.

The interior of this model is the same as the knock-down model except the walls, which are galvanized steel primed and painted with a flat latex paint.

The entry way is equipped with an air shower which has been converted to a makeup air unit since evaluation of the knock-down unit indicated that an air shower was not needed. 


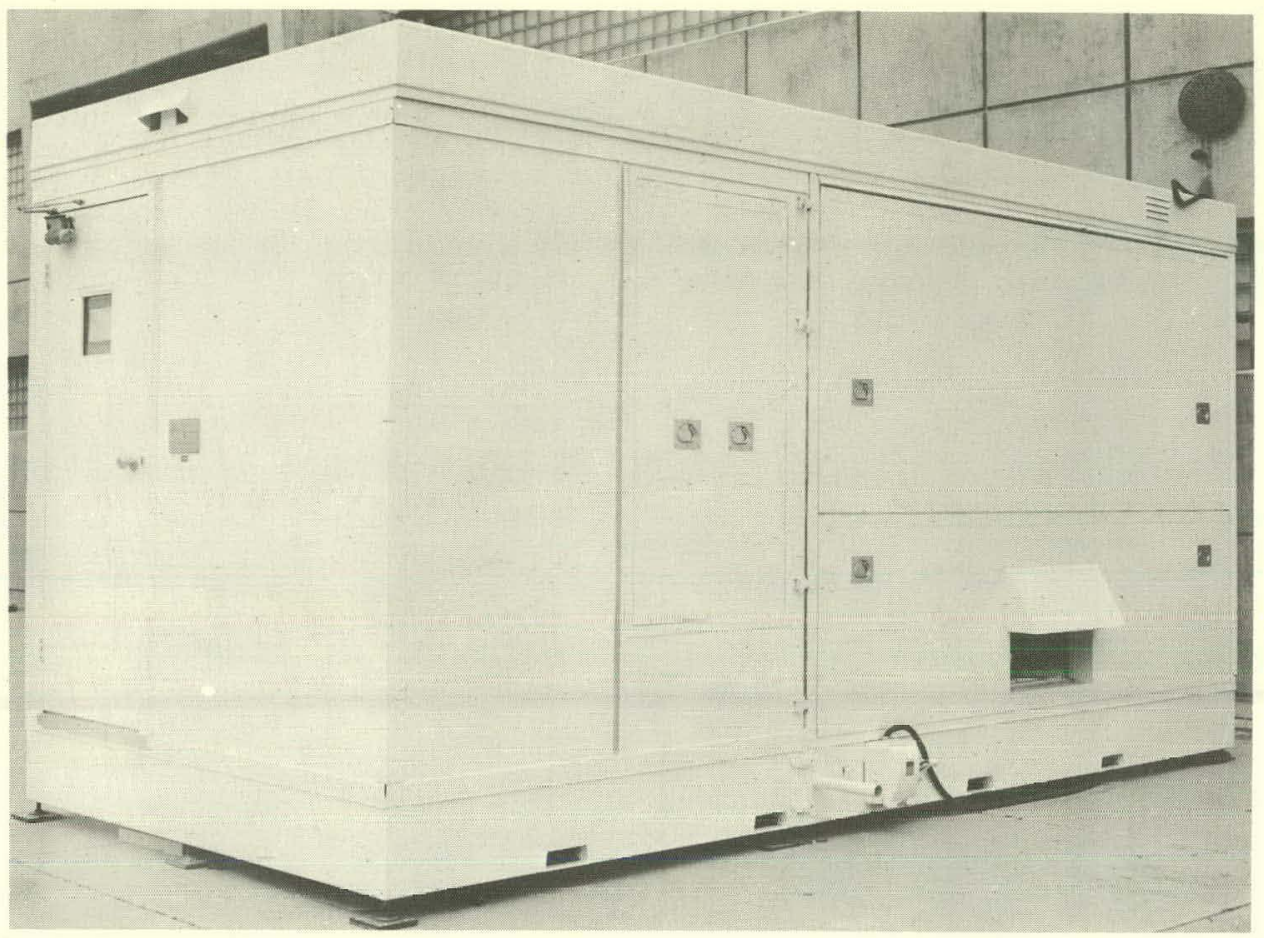

Figure 4. Clean room, rigid all-weather mode1 - external view

Evaluation Tests of the Clcan Rooms

\section{Equipment Used}

Airborne particle concentrations were monitored with a Sinclair-Phoenix photometer and a Royco particle counter, PC-200-A. Air-flow measurements were made with an Alnor "Velometer" air-flow meter.

\section{Conditions of Tests}

The particle samples were taken at the workbench edge nearest the center of the room, except for the tests made to determine that this location was representative of the entire workbench area. The Sinclair-Phoenix photometer and the Royco counter were run simultaneously for comparison data.

Airborne particle monitoring tests were run for 24 hours, except for the time required for room clean-down tests and tests involving induced particulate contamination. Careful calibration checks were made on both of the particle monitors before starting the tests, and periodic calibration checks were made during the tests.

No effort was made during these tests to exclude personnel from the room, once it was discovered that the personnel in the room did not cause the particle counts to change. No attempt was made to record or closely control the room temperature and humidity. Spot checks of temperature and humidity indicated that the temperature varied approximately $\pm 2^{\circ} \mathrm{F}$ from an average of $75^{\circ} \mathrm{F}$. Humidity averaged about 20 percent, with a low of about 5 percent and a high of about 30 percent. 


\section{Test Results}

Airborne Particle Concentration Test -- The Royco particle counter was used exclusively for this test since the other equipment and methods were found to be inadequate for monitoring the low levels of airborne particles found in the room (Figure 5). Further, data taken on five different days showed no significant change in contamination level even though personnel entered an average of 15 times per day without special clothing and without entry cleanup procedures.

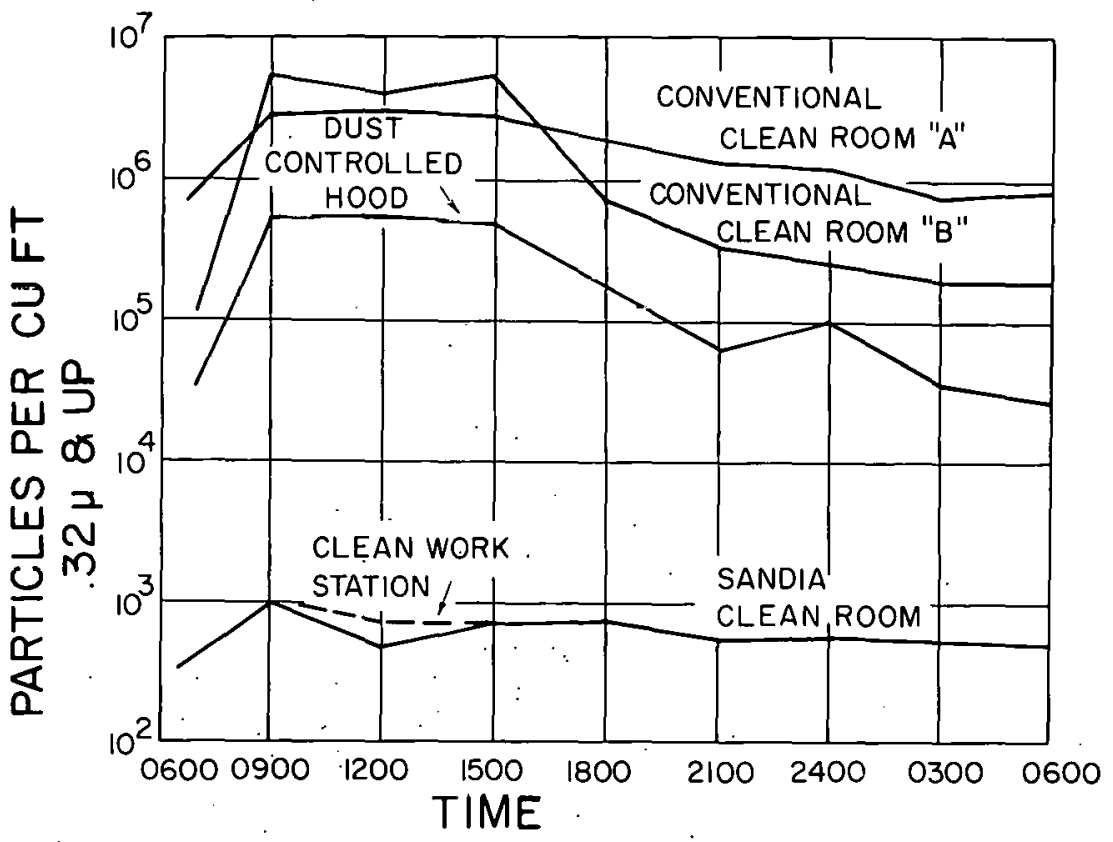

Figure 5. Dist level chart

This test was repeated in the Rigid Al1-Weather units for approximately 3 hours during a moderately high wind period. The wind was blowing 30 to 35 miles per hour and stirred up considerable dust in the air. However, no special room entry precautions were taken during this period. Although approximately 15 entries into the clean room by several personnel were made during the 3-hour period, no increase in dust count occurred as a result of the dust condition outside the clean room.

Room Clean-Down Tests -- The clean-down tests were used: (1) to test the ability of the room to remove contamination brought in or generated in the room, and (2) to test the ability of the room to clean itself after a shutdown.

The contamination removal test was conducted both visually and through the use of the Sinclair-Phoenix photometer. In the visual method, smoke was released in the vicinity of the work area. This smoke moved from the work area through the grating floor in less than 5 seconds. The Sinclair-Phoenix photometer was used for the instrumented portion of the contamination removal test. The Royco was not used for this test since its response was much too slow to sense the rapid change of contamination. Smoke was used as the contaminant in this test also, and the results are shown in Figure 6 .

Air-Flow Tests -- The Alnor flow meter was used to test air-flow uniformity. Room static air pressure was adjusted for 0.05-inch water pressure above ambient pressure (this setting was used for all tests). The air-velocity data were taken in various locations in the room; the average was 95 feet per minute. 


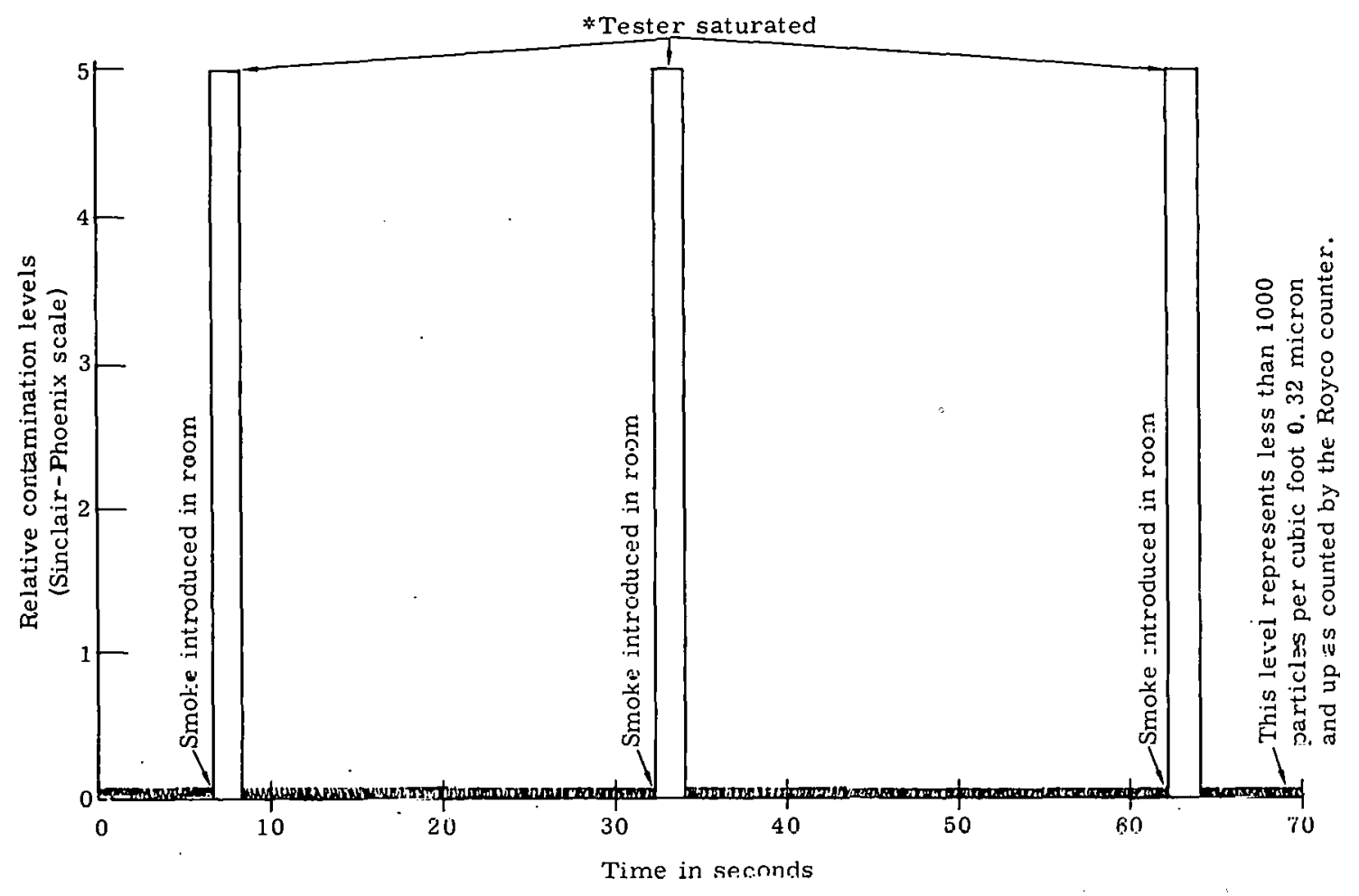

Approximately $10^{10}$ particles per cubic foot.

Figure 6. Room self-clean-down characteristics

Advantages Over Conventional Clean Rooms

Clean rooms which use laminar flow principles will provide the following advantages in ultraclean areas:

1. Very high degree of cleanliness

a: These rooms will maintain a cleanliness level below 1000 particles per cubic foot, 0.32 -micron size and larger.

b. The work area is continually washed with clean air circulated at $4000 \mathrm{cfm}$. This represents approximately ten complete changes of a1r in the room per minute.

2. Immediate clean-down characteristics

a. Contamination is removed from the work area at the rate of 100 feet per minute, or slightly more than 1 mile per hour velocity.

b. In less than 20 seconds after initial start of room air, the work area is free of 0.5 -micron particles and contains less than 1000 particles per cubic foot of 0.32 -micron size and above.

3. Personnel in the room have little or no effect on room cleanliness

Contamination carried into the room by personnel and equipment, or particulate matter generated in the room, is trapped in the rough filter in the floor.

4. Portability is achieved without sacrificing cleanliness

The high clean-down characteristics enablc the room to be operated as a portable clean room at a high degree of cleanliness. The unit can also be moved as an assemlly, or be disassembled if needed. 
5. This design can be expanded to a larger size

A double room width is possible as well as multiple lengths.

6. Operational economy

a. The room may be shut down during nonworking hours. This results in power cost savings. (With a standard 40-hour workweek, the room can be shut down a total of 128 hours per week or 76 percent of the time.)

b. Because the equipment can be shut down, the life of the equipment is extended, and less maintenance is required.

c. Much less special clothing is required. This saves both special clothing costs and laundry and cleaning costs.

d. Access to the room is not restricted. Work personnel have immediate entry into the clean room area (saving approximately 1 man-hour per ray s.lean room worker).

e: A minimum of room maintenance is needed. Room cleanup is not needed more than once a week for normal operation. The workbench may be cleaned once a day, or as needed.

7. Ease of operation

Starting involves "throwing" electrical switches to start. Shutdown is as simple.

\section{Owner cost}

This room is expected to be more economical to own than the conventional clean room.

\section{Conclusion}

It was apparent that this type air flow offered a practical means of creating and maintaining a very clean atmosphere almost independent of the operation conducted in a room. Since this type of air flow very closely approximates true laminar or fluid flow, we will now define laminar air flow for our discussion. It is that air flow in which the entire body of air within a confined area moves with uniform velocity along parallel flow lines. The real value of filtered laminar aix flow is the high degree of cleanliness that it maintains at very low velocities well below personnel discomfort levels. The 100 feet (lineal) per minute air velocity utilized in these rooms is well below the rate of 150 to 200 feet per minute, which is generally considered to be the threshold of personnel discomfort. It should be explained at this point that significant departures from laminar air flow will degrade the air-cleaning properties normally provided by laminar flow. It has been found that most obstructions created by average clean room equipment will not seriously affect the cleanliness of laminar flow rooms if the rooms initially provide laminar air flow. To obtain maximum benefit from laminar flow devices, correct adaption and utilization of laminar air flow is necessary. Tests under actual operating conditions show that the air-cleaning capacity of laminar air-flow devices is capable of recovering almost immediately from contamination released in the room, and it will provide isolation from other operations in the room.

Many applications of laminar air flow are visualized to provide a practical means of controlling airborne contamination. An expansion of the two model clean rooms is shown in Figure 7. Here two benches are provided with filters located above and back of each workbench. This design is mainly for clean room work requiring bench work for small or medium size devices.

The design shown in Figure 8 is intended for large equipment that requires very clean work environments. This design will allow free access to all sides of the equipment and provide very good isolation from the working personnel. 


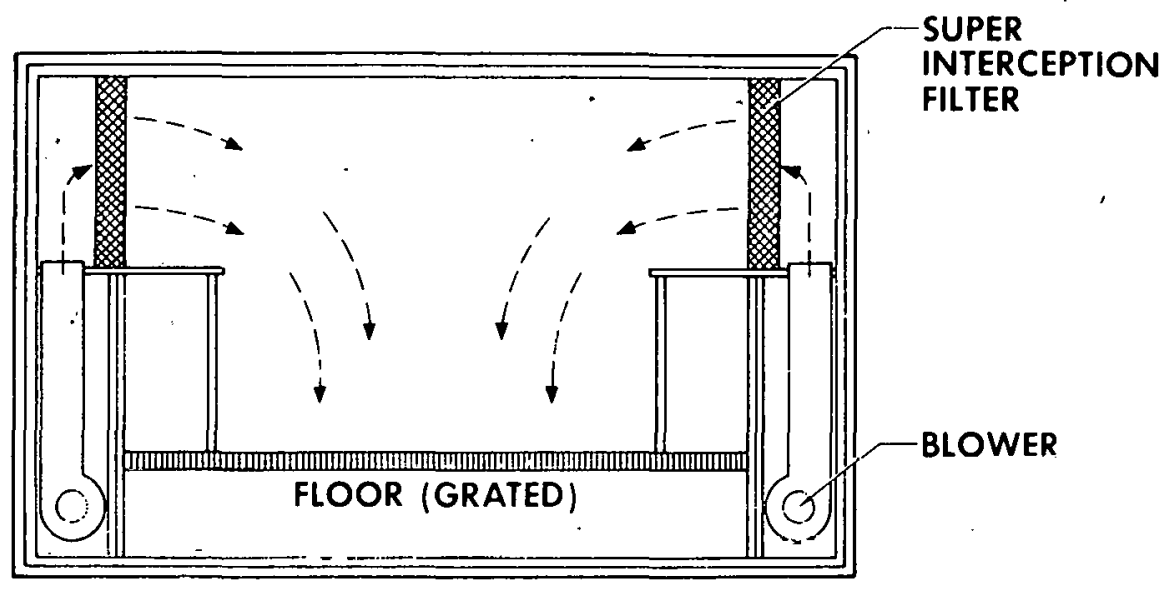

WALL TO FLOOR LAMINAR FLOW ROOM

Figure 7. Wall-to-floor laminar flow room

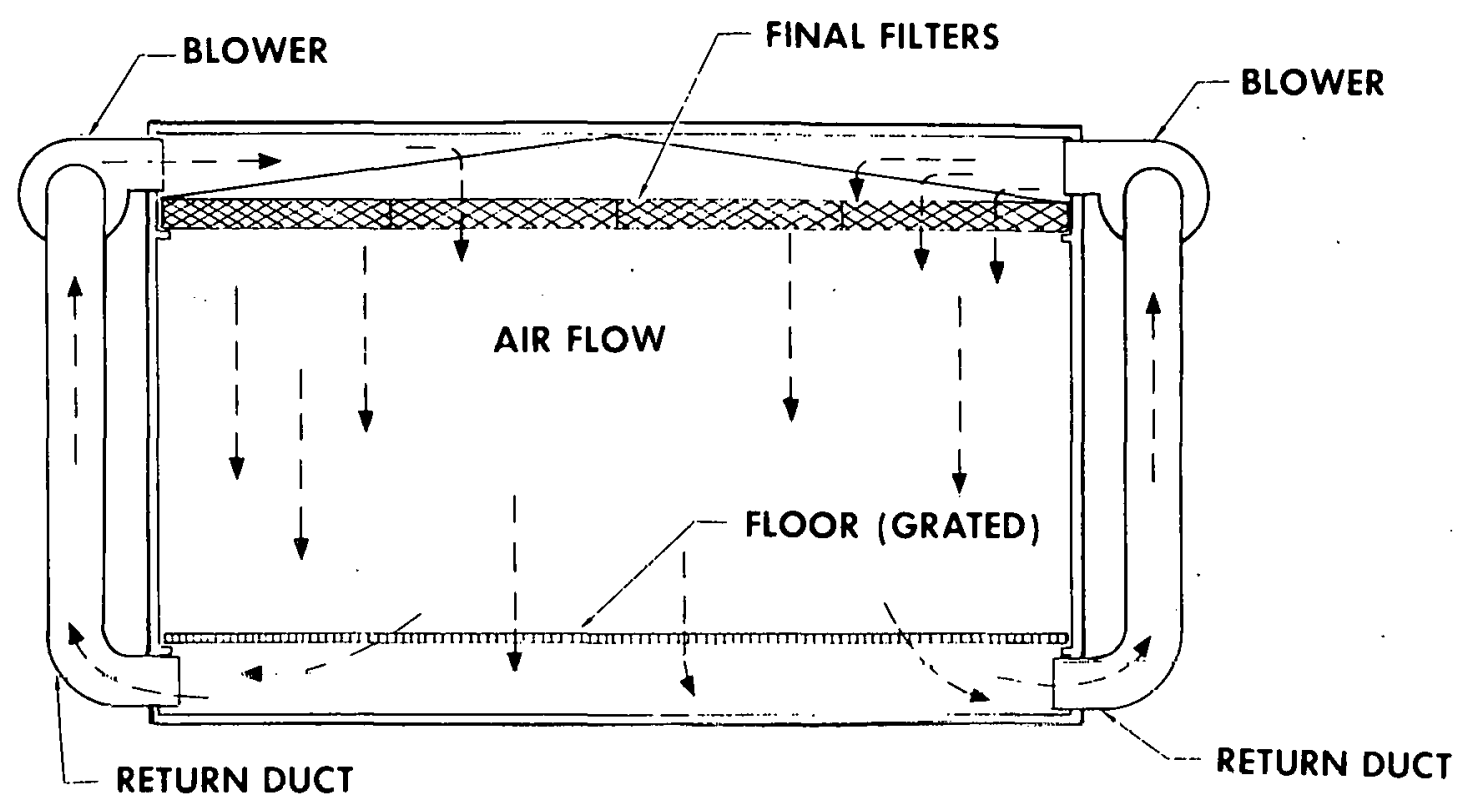

Figure 8. Ceiling-to-floor laminar flow room

A design, shown in Figure 9, known as a "cross-flow design," is being used to provide laminar air-flow characteristics at low costs. Figure 10 illustrates a practical application. A full report about this type of room will follow.

Figure 11 shows another laminar flow design that is widely used. This design has been scaled down to a bench or work station size. A full report about this design will follow.

Sufficient tests data are now available to conclude that, if highly filtered air flowing in a laminar fashion is provided and properly utilized, environmental cleanliness levels can be easily achieved which herctofore were impossible to produce. 


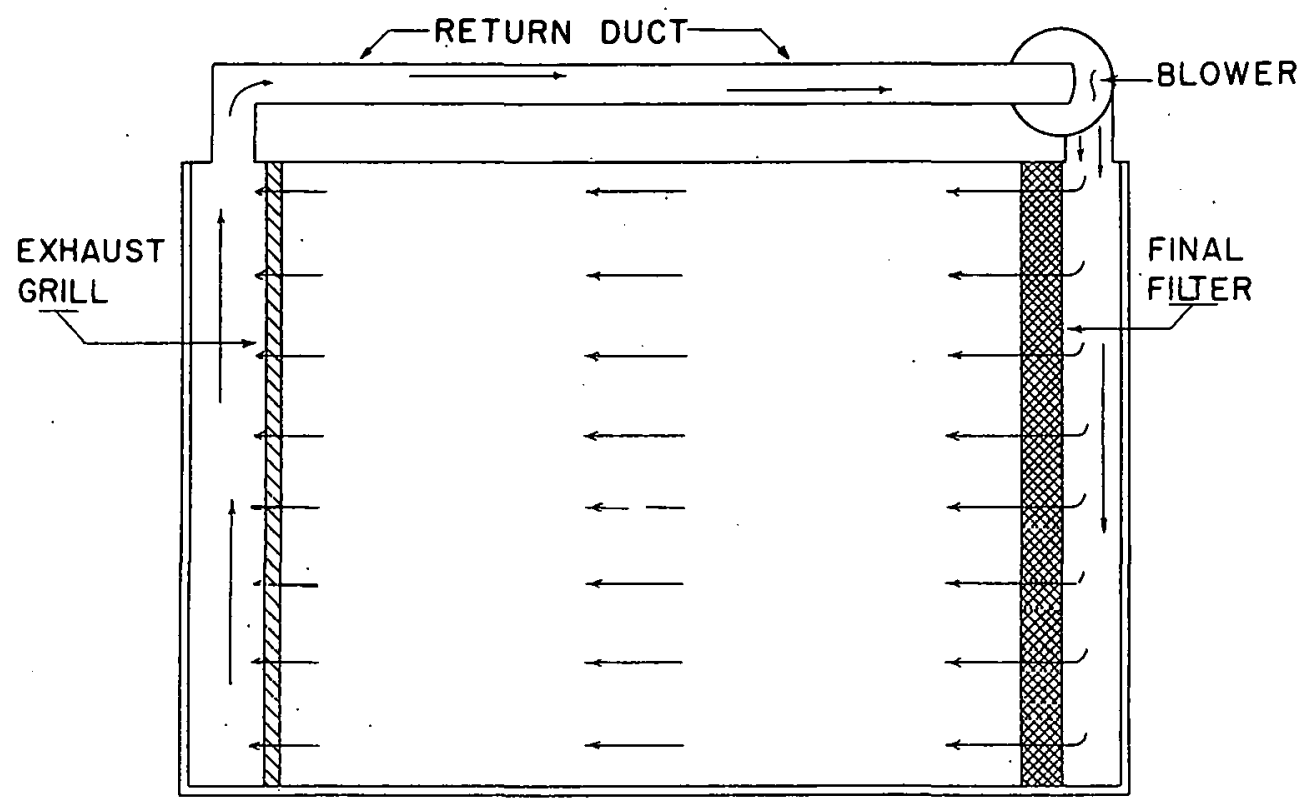

Figure 9. Cross-flow room

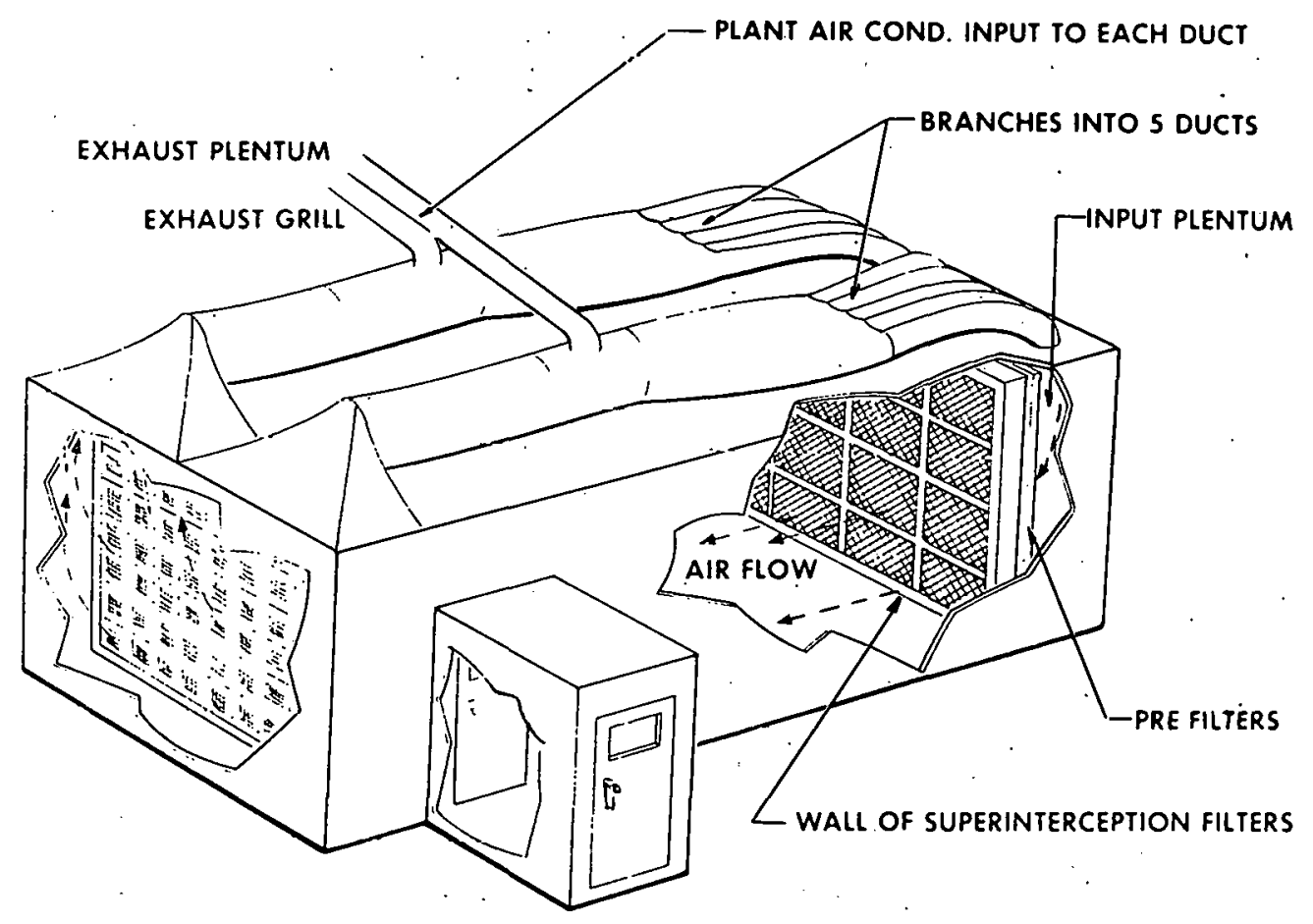

Figure 10. Cross-flow laminar flow room 


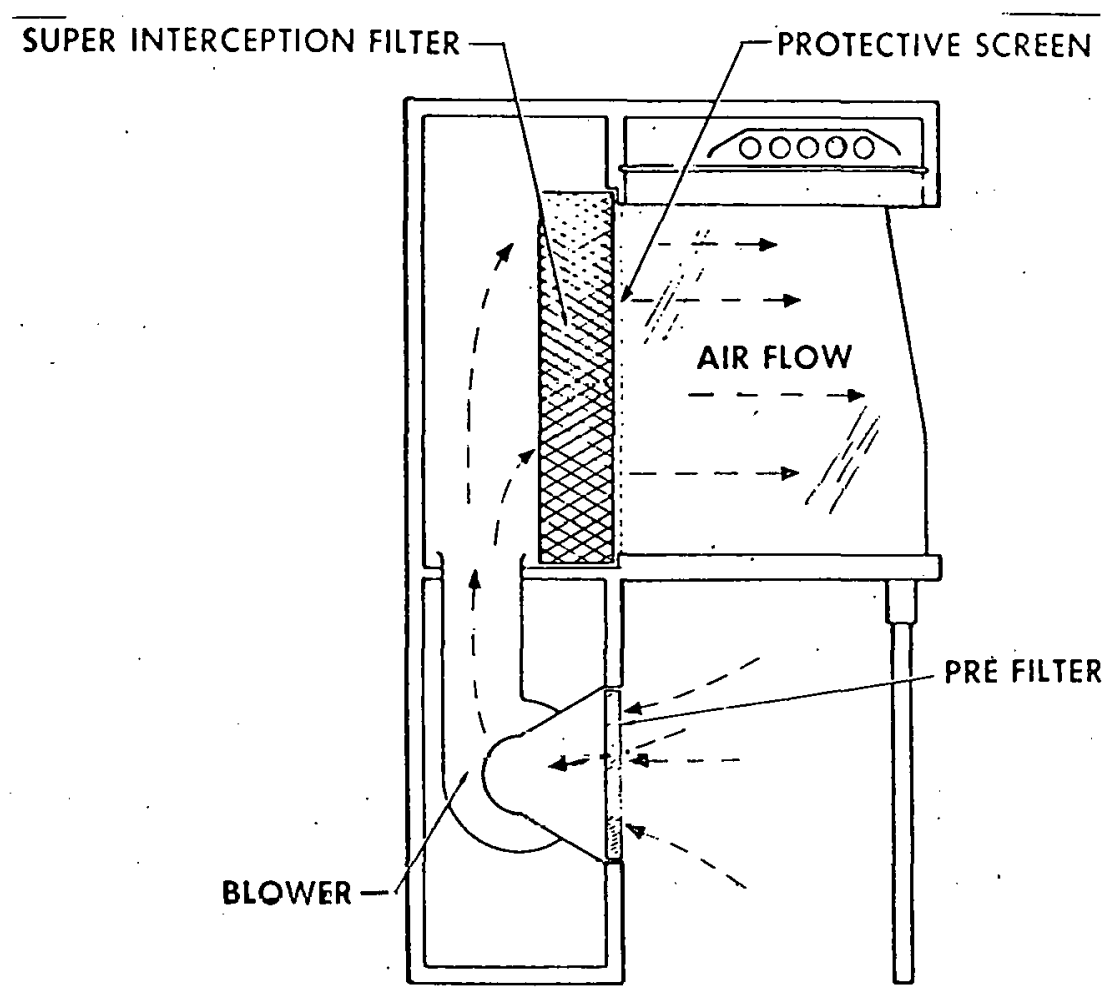

Figure 11. Laminar flow clean bench

\section{QUESTIONS}

F. C. SHADEWALD, U.S. NAVAL AIR STATION: You say that you have grating nver the entire flonr. Have you cver considesed the problem of people walking on this for 8 hours and the fact that considerable heavy equipment has to be rolled over this floor continuous 1.y?

MR. WHITFIELD: We realize this is a problem; however, some of the closespace grating floors that we know of seem to be not much more uncomfortable than ordinary concrete covered with viny 1 tile. If wc were to design a room for heavy equipment, certainly we would have to spccify gratings sufficiently strung to carry the heavy loads. This is a problem, but we don't feel it's one that would be impossible to solve. It might be a little bit more cxpensive, but if you need the cleanliness that this device can give, we feel that it is worth it. It certainly is more economical than trying to upgrade conventional clean room facilities.

MR. SHADEWALD: I notice that all of the illustrations you have of laminar flow rooms show absolutely vacant rooms--no personnel, no work benches, no equipment of any kind in it. Our experience has been that, whenever you have large equipment, it interrupts the air flow considerably and causes eddy currents, and essentialiy you no longer have a laminar flow room.

MR. WHITFIELD: This is true, and we feel that a person desiring to use laminar air flow would necessarily make. some adaptation to suit his equipment. However, an interesting fact that Mr. Marsh wili present to us is that these eddies behind such equipment as oscilloscopes, normal work benches, and other instruments are essentially clean unless some kind of particulate matter is put into these eddies. Some common sense must be used in locating equipment in such a room. We don't say that this is a foolproof device; it is a tool to upgrade clean room atmospheres and working environments. 
J. G. GROSCH, LOCKHEED MISSILES, VAN NUYS: We built one of these rooms, and during the course of the discussion with the vendor, the policies with respect to patent protection came up. I wonder, Mr. Whitfield, if you could give us a brief statement of the policy with respect to anyone else using the idea.

MR. WHITFIELD: Since these are AEC-owned patents--and it is not quite clear to me just what patents do apply here--to utilize these patents, you simply apply to Sandia Corporation or the Atomic Energy Commission for permission. We don't know of anyone yet that has been denied use of these patents, and on a free basis.

S. ORBAN, THIAKOL REACTION MOTORS: Have you tried to evaluate the cleanliness level by manual methods, such as capturing small samples with a membrane filter, such as millipore?

MR. WHITFIELD: Yes, we have. We have tried some sedimentation methods and we've tried the standard ASPM millipore methods, and we essentially come up with no change in count. In other words, the sensitivity of the method is not good enough to indicate any change in these rooms. We made careful background counts, and we came close to the same thing that we started with. We have found only the Royco particle counter sufficiently sensitive to sense any low level found in these rooms, and we find that even setting it on its most sensitive range, which we consider the 0.3 micron range, we will come up with occasional zero counts even with this device. 


\title{
LAMINAR AIR CROSS-FLOW ROOM
}

\author{
F. L. Flinn and J. Gosma \\ General Dynamics, Pomona
}

Why a Clean Room?

The most direct questinn asked of General Dynamics, Pomona personnel since the cumpletion of the clean room has been, "What made you believe you had to have a clean room rather than merely an area that would maintain a certain temperature and humidity?" Basically, the tolerances specified for components to be assembled and tested within the room are down in the miliionths of an inch--much less than the sizes of dust particles found in any open plant area. Since the size of particulate contaminants must be less than the clearances of mating parts to avoid damage during assembly, we needed a dust-controlled room with counts not to exceed those given as Class 4 in the familiar Air Force Technical Order 00-25-203. This was our reason for requesting a clean room and a very good one. But, as is often the case, what you need and what you can get with available funds are not necessarily the same. Facing this fact, it was resolved to compromise and specify a room having dust counts not to exceed those given in Class 2 with fondest hopes that we could do better.

Why a Laminar Flow Clean Room?

The principle of "total control" of air in the room includes not only temperature, humidity, and cleanliness at the source of entrance to the room, but also the nature of flow within the room itself. This latter is of extreme importance since we consider it is basic knowledge that absolute filtration is common practice in terms of the trade, but the control of contamination introduced by people, parts, and equipment has heretofore not been "common practice." This is where laminar flow comes into the picture (Figure 1). Laminar flow has air coming into the room through primary and absolute filters from wall to wall and floor to ceiling and being pushed at about the same velocity at all levels which will continue to pass through the room at the same level as it entered, carrying with it all airborne particles light enough to be carried by the air stream. Those particles too heavy to be supported in the air stream will fall at some angle to a surface, such as a table top or floor. Inasmuch as there are no circular currents or dormant areas in the room, any particle that once reaches a lower level will remain at that level or fall even further until it has reached the floor or has flowed out the exhaust.

In a conventional type room where clean air enters from the ceiling through small openings and is exhausted out through small exhausts registers, circular currents and quiet areas are set up with air bounding off each wall and the floor, not to mention tables and equipment. With this method, airborne particles can continue to recirculate and, therefore, have a greater chance of ending up inside the equipment that must be kept clean.

To say that no contamination can enter the room is wrong because anytime people or equipment enter a dust-controlled area, contamination will enter. It is the control of this contamination that is the prime importance because the air entering the room by either method (laminar or conventional) can be rigidly controlled. Therefore, moving any contamination out of the room as fast and direct as possible is required. A straight line is the shortest distance between two points. In laminar flow, the air flows in relatively a straight line through the room. 


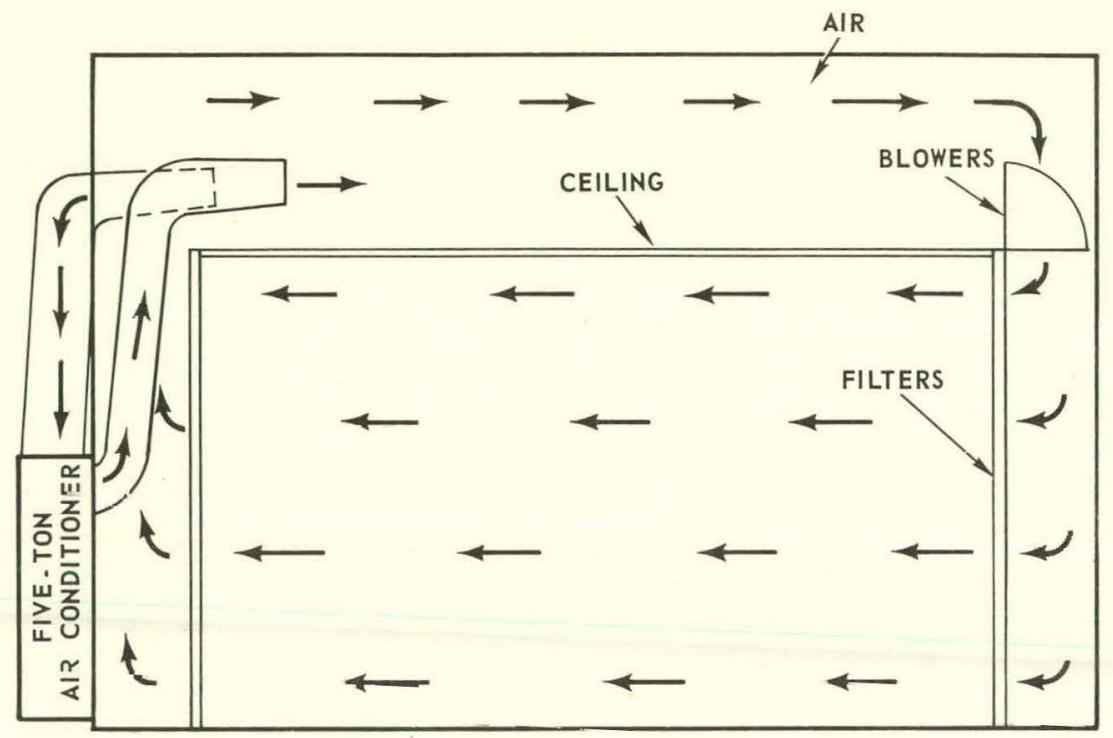

Figure 1. Air flow - side view

The clean room is being used primarily for miniature gyro work (Figure 2). Assembly, disassembly, and engineering testing are conducted in this room. This gyro is unique in that it does not have a housing until it is mated with another assembly. It, therefore, is necessary that, during a great deal of its setting up and testing, it be exposed. It is during this time that the utmost care must be given so as to not contaminate it with dust particles.

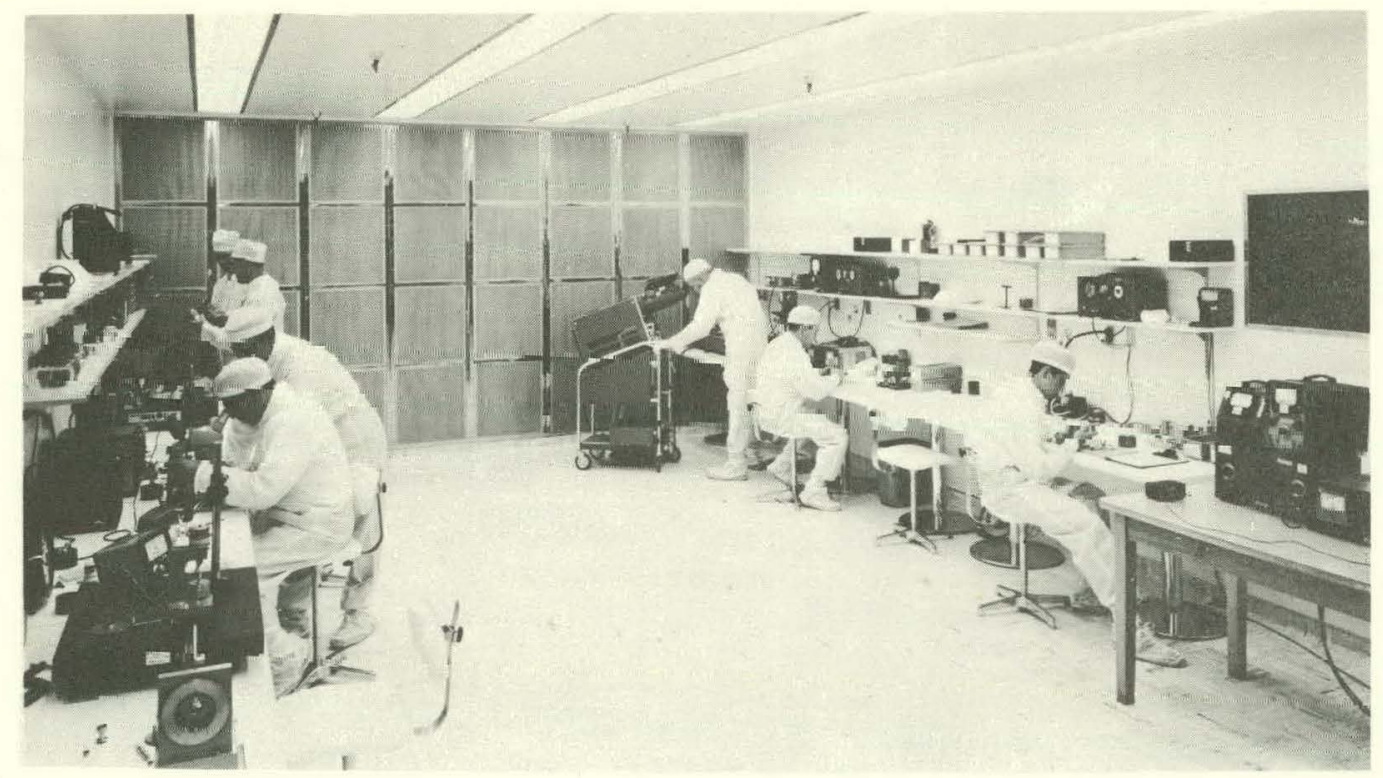

Figure 2. Clean room - interior view 
General Dynamics, Pomona Laminar Flow Clean Room

When General Dynamics, Pomona started looking for a clean room, several contractors were contacted and they presented their proposals; but, in every case, there was doubt in the minds of the committee as to whether or not it was what General Dynamics, Pomona wanted. We were trying to get as much as we could for the dollar spent and not be outdated by the time we had it completed. The proposal presented by Boyd Agnew of Agnew-Higgins, Inc appeared to do both. If all the items that Agnew claimed were true, then General Dynamics, Pomona could have the cleanest room for its size in the world. He was claiming that, although we were only specifying Class 2, his room would be Class 4. There would be little or no notice of moving air and, dollar for dollar, we couldn't beat it and maintain the class of room he was offering. The main question we had was "Has a room of this size, using the laminar flow concept, ever been built before?" It hadn't, and, although the room would be guaranteed, it still would be like buying a pig in a poke. The committee discussed the principle at great lengths and finally recommended the laminar flow concept over the others proposed (Figure 3). The room would have to have about $600 \mathrm{sq}$ ft--that is, a working area 17 feet wide by 35 feet long, and an antcroom about $9 \times 12$ feet. The tempraturc and humility would be as specified in Technical Osler 00-25-203. The room was to come equipped with 110-volt, 60-cycle power, regulated plant air--i.e., already filtered dry--fluorescent light fixtures that would give at least 150 foot-candles at table level, and a built-in vacuum cleaner system. The clean room air pressure would be positive in respect to the anteroom and it, in turn, positive in respect to the surrounding plant area. The floor was to be vinyl-covered with coved edges. The walls were to be white and smooth. All of these characteristics were agreed upon and, after 4 weeks, the General Dynamics, Pomona clean room was completed. It was very carefully cleaned and the air-circulating system turned on and allowed to clean down for 2 days. On the third day, every bench, chair, tool, and instrument to be used in the room was either washed or vacuumed before it was taken into the room. Two days later, the room was officially activated. Each person who entered the room wore dacron coveralls, surgical hat, and booties. The manufacturer had stated that this was not required, but General Dynamics, Pomona required it for two reasons: first, it was an ounce of prevention; second, the psychological effect on the workers shn11d he pooitive. One week later, Boyd Agner, in accordance with the contract, brought in a representative of the Royco Company and his equipment to run a dust particle count in the room to determine if the performance was as agreed upon. The largest count any place in the room was less than that required for a Class 4 room. As a matter of record, the average particle count for eight 15-minute observations in the range of 0.3 through 10 microns was 2850 total particles. This is far below the $10,000 \mathrm{maxi-}$ mum permissible in a Class 4 room. Even under the most adverse conditions, to be later explained, the largest particle size observed was only 1.6 microns. At the time the test was made, up to seven people were working in the room as well as entering, leaving, and moving about the room. One place the sampling was made was behind an oscilloscope that had its own fan for cooling. No noticeable rise in particle size or amount was registered. The test was witnessed by two General Dynamics, Pomona personnel at all times and during the last 45 minutes by three people, including Mr. A. Dulton, Chief Administrative Engineer for General Dynamics, Pomona, when it became obvious that no room of this size had ever proved to be so clcan.

\section{Staging the Room}

In a laminar flow room, you have the opportunity to stage the work if deemed necessary. By staging, I mean that the cleanest work shall be done by the filter supply wail and progressively less clean activities are placed down stream. Bearing cleaning, soldering, and handling incoming parts can be done next to the exhaust wall. Even with laminar flow characteristics and staging, some items cannot be tolerated in any clean room; for example, pencils and soft paper. We allow only hard paper and ballpoint pens. The room entrance is near the exhaust end, so, as one enters, he is washed with air while proceeding to his work area. In the work area, shelves have been specified so that drawers, boxes, and cabinets can be kept to a minimum. The reason for this is basic: the room is always clean, but storage areas are voids and dust collectors. 


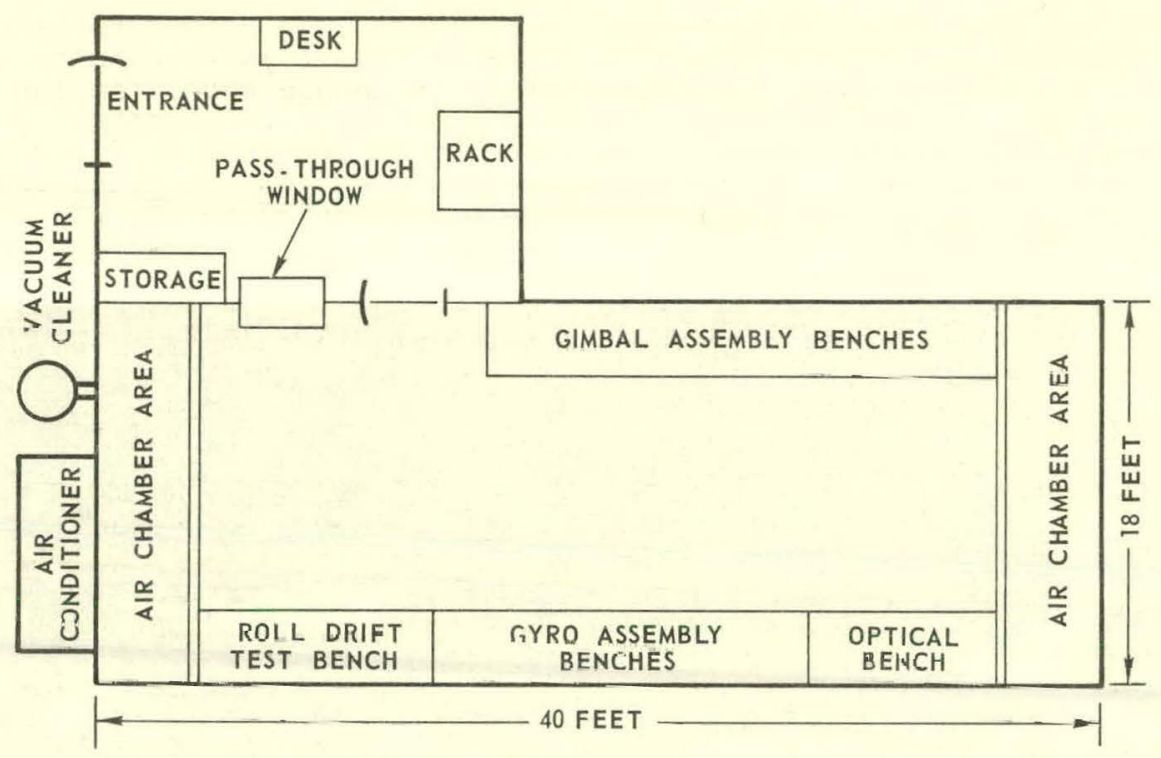

Figure 3, Clean room layout - top view

Laminar Flow Characteristics

So far, I have spoken of the room as laminar flow, but I should like to qualify this. When the room was first built with nothing in it to diffuse the air flow, a smoke test was run (Figure 4). The smoke appeared to climb on a platter of air and ride out the other end at the same level all the way. After the room was occupied with equipment and people, a similar test was run. The smoke did show some turbulence and diffusion, but as soon as it cleared the obstruction, it stayed in its final pattern until it reached the exhaust wall. Therefore, for simplification, let's refer to the room as a cross-flow clean room with laminar flow characteristics. Recently, the room was tested by various methods: smoke flow (Figure 5), particle count, bright light particle observation, and sterile slide collection. The test results are still being compiled, but the particle count was considered hetter than those taken last October. At their request, General Dynamics, Pomona permitted an outside agency to run these tests. As a matter of interest, the clean room has never been mopped since its activation. During the bright light portion, one individual was observed to be vigorously brushing his arms and legs and the particles could be seen flowing in virtually a straight line out the exhaust. A comment was made later that such a display would have closed a conventional type room for 2 weeks. The room was in use at the time, but, of course, no work was being done down stream of these gymnastics.

\section{Food for Thought}

Thinking ahead is important in the design of any room. Even so, we have already discovered that we didn't specify enough electrical outlets because the work load has grown beyond expectation. We did install conduit for DC power which we expect to complete if needed. In this type room, a db sound level must be specified. Do not overlook the fact that the air-circulating motors, sitting in the air stream, are a major heat generating source. Any of these items, although easily corrected in rooms of ordinary construction, can cause precious down time to correct in a clean room.

Usage will undoubtedly suggest desirable changes. As we gain experience with our room, we may relax the dacron coverull requirements and use smocks. I am sure that hats will be required for some time as will booties or some other method of 
keeping dust and dirt from being brought in on shoes. We expect to have a shoe cleaner in the near future and this will probably permit us to eliminate the booties. One suggestion under consideration is to change shoes leaving one pair in the clean room. I personally believe this could lead to personnel problems. At the present time, anyone entering the anteroom is required to first wipe his feet on a rough rubber mat. If one is going into the clean room, he must step on the sticky pad that is inside the anteroom before dressing in the clean room garb.

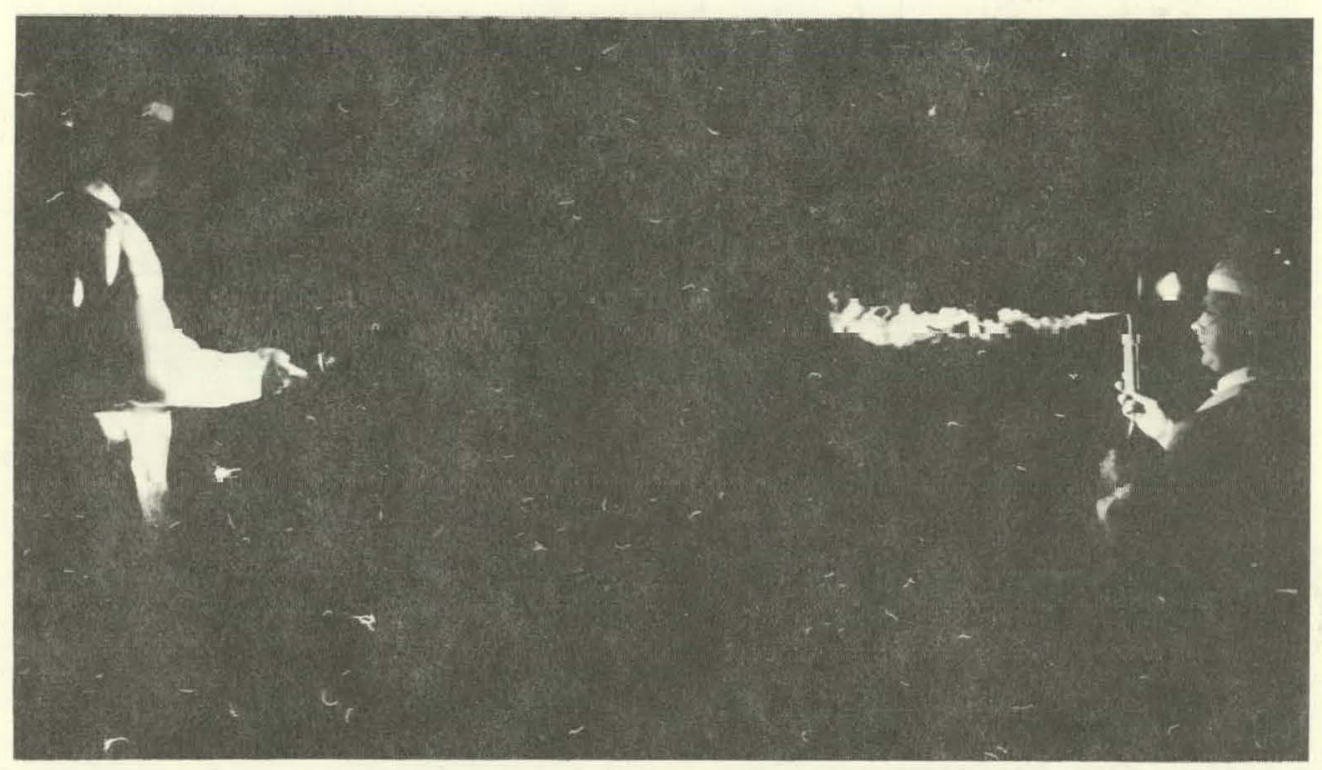

Figure 4. Laminar flow characteristics - unobstructed smoke pattern

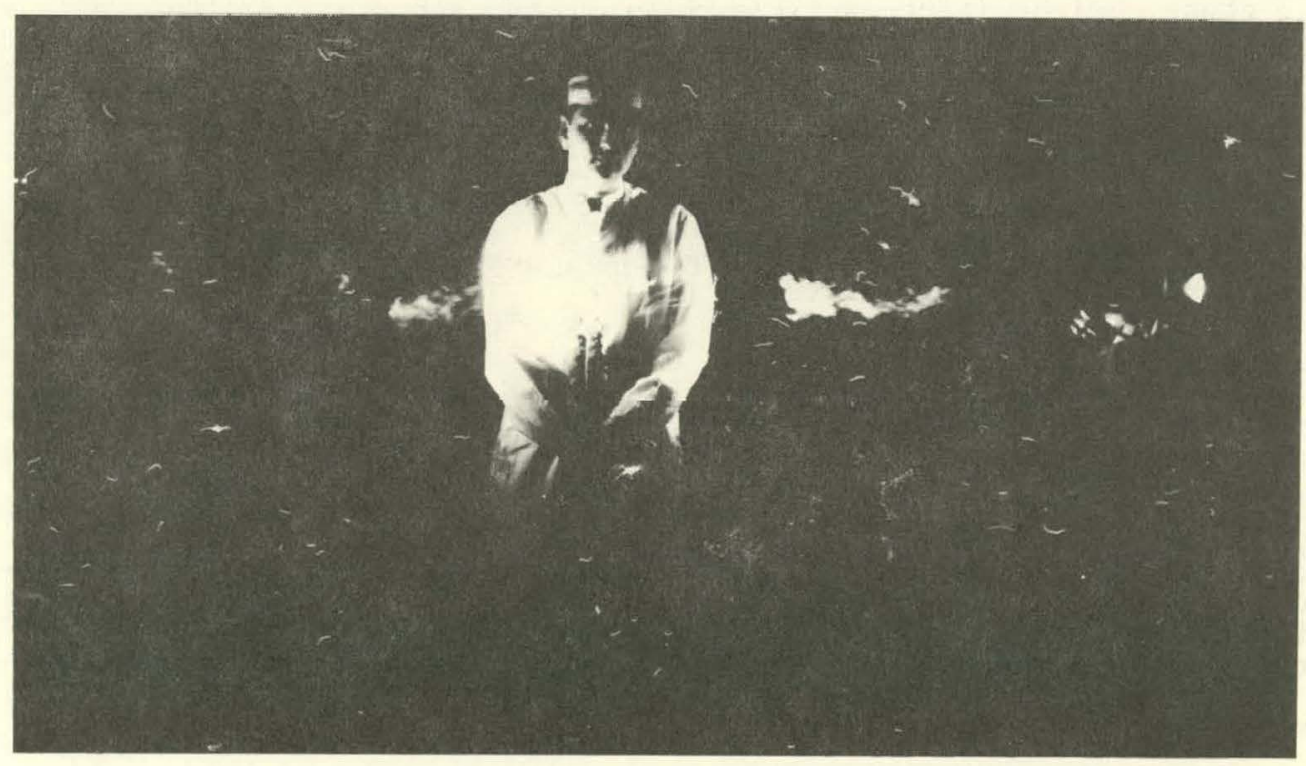

Figure 5. Laminar flow characteristics - obstructed smoke pattern 
The pass-through window, which I am sure is considered by all a requirement, can, by its location, be a problem. This should be near the observation window and accessible from the outside. There should also be an intercom station located there. The intercom should be of the type that does not require a person to leave his work area in the room to answer.

Design and Construction Features

The room was designed jointly by General Dynamics, Pomona personnel and those of the George $\mathrm{H}$. Waite Company. The latter were the construction contractors under the direction of $\mathrm{Mr}$. Pred Vinmont. The supply and return air-handling modules were manufactured and installed by Mr. Boyd Agnew of the Agnew-Higgins Company. The cost of the room was about $\$ 24,000.00$ or approximately $\$ 40.00$ per square foot of clean room area. Construction time was about 4 weeks (Figure 6).

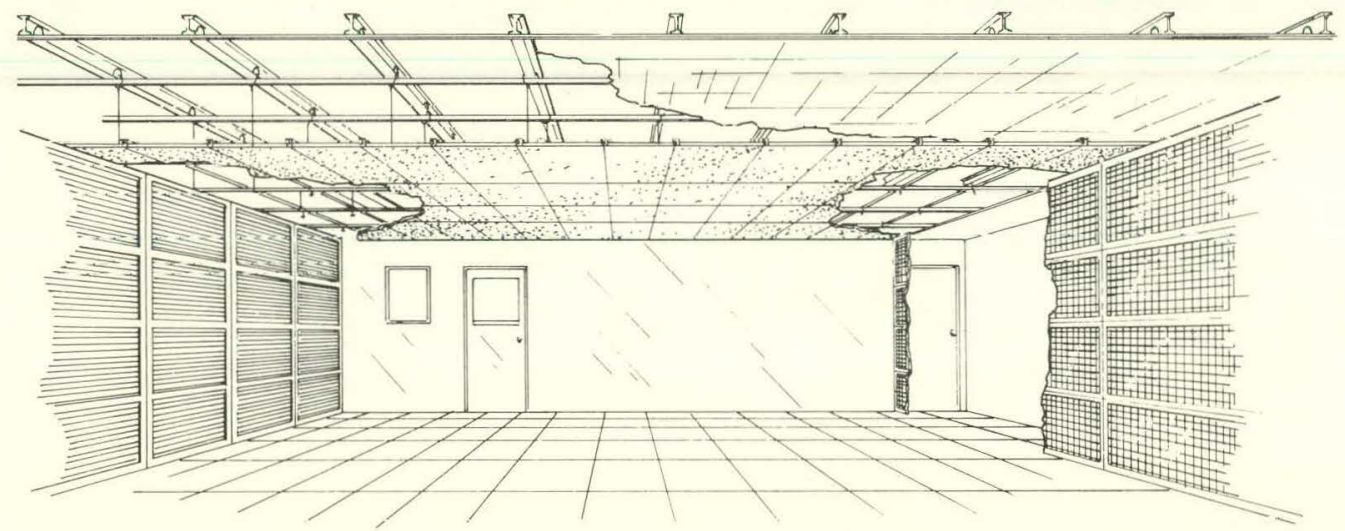

Figure 6. Clean room - structural cutaway

The room is basically of fireproof construction, consistent with plant-wide requirements. Usable space is $17 \times 35$ feet in the direction of air flow. The ceiling height is 8 feet 9 inches with a return plenum as wide as the room and 3 feet 3 inches high. The structure was erected on the existing building concrete floor. The walls are framed with 3-1/2-inch steel load bearing studs on 4-foot centers with intermediate light gauge spacer studs. The 12-foot high roof structure has light steel joists on 4-foot centers. Furring channels run perpendicular to the joists and support the suspended ceiling system including lighting and sprinklers as well as metal catwalks for servicing the lighting fixtures. Access to the ceiling plenum is through a small door above the air-circulating fans.

The walls and ceiling of both the antcroom and clean room are of $1 / 2$-inch sheetrock, puttied, taped, and sanded. Interior surfaces received a finish coat of top quality gloss white enamel. Exterior wall surfaces were painted to match existing rooms. The floor covering is vinyl tile, 1/16-inch thick in the clean room and 1/8-inch thick in the anteroom. The color is essentially white with a light green and faint black marble fleck.

Lighting fixtures are 8-foot long, three-lamp soft white fluorescent-type, flush-mounted with the ceiling with a lower removable solid sheet plastic diffuser. The lighting level measured upon completion of construction was more than 400 footcandles at bench level; this was far in excess of our specifications.

The air-flow system consists of the recirculation part and the conditioning part. In the former, eight 1/2-horsepower centrifugal fans extract air at the end of the ceiling plenum and discharge it vertically downward into a 24-inch wide space behind the filters. The air then passes through the filters and into the clean room, thence to the return wall. This consists of 80 louvres which have direction as well as volume adjustment blades. From a 2-foot wide plenum behind the return louvres, the air flows to the ceiling plenum completing the circuit. 
The average air velocity for the room cross section is about 1 mile per hour or 88 feet per minute. This, times the cross-sectional area of 148 square feet, gives a total air flow of about $13,000 \mathrm{cfm}$. This results in an air change every 30 seconds or 120 per hour.

The prefilters are 2-foot square sheets of 1/2-inch thick polyurethane expanded foam, secured directly to the final filters. The material is a product of Scott Paper Company of Los Angeles. The 32 absolute filters are $24 \times 24 \times 5-7 / 8$ inches, Cambridge Catalog No. 1A600-0, with Type CMl15 glass asbestos media. Access to these is by an exterior door.

The conditioning part consists of a Carrier packaged, nominal 5 ton, aircooled, direct expansion, refrigeration unit, along with a 2500 cfm up-flow airhandling unit and associated ducting. Air for this is extracted from and returned to the ceiling plenum via ducting arranged to prevent short circuiting. Two-stage electrical reheaters and a humidifier are included. The fan unit has a make-up or fresh air intake connection to provide ventilation air from the main building. Approximately $600 \mathrm{cfm}$ ventilation air is added to replace that purged by gravity dampers from the clean room to the anteroom and, thence, in the same manner, to the main building.

Tlie alr-handling unit, with associated controls, functions to provide a temperature of $72 \pm 2^{\circ} \mathrm{F}$ and $40^{\circ} \pm 10$ percent $\mathrm{RH}$. Also, its fan pressurizes the clean room above that of the anteroom which, in turn, is slightly above that of the building.

A central vacuum system has eight hose plug-in outlets, seven of which are in the clean room and one in the anteroom. Filtered, compressed air outlets and 115-volt convenience receptables are provided on approximately 8-foot centers. Provision is made for future DC electrical outlets at each work station.

\section{Room Maintenance and Operating Costs}

We have tabulated mnnthly costs frum our best records to date. First, electrical puwer for air conditioning, lighting and convenience receptacles--this is based on a unit cost of 6 mils per kilowatt hour and estimated consumptions. There are eight 1/2-horsepower circulating fans on continuously. The lighting totals 5100 watts for 12 hours per day. Consumption at receptacles is 3500 watts for 12 hours per day. The air-conditioning system cycles and is on a total of 8 hours per day. This is a 5-horsepower compressor, a 1/3-horsepower fan and two 4500-watt reheaters. This totals $\$ 84.00$ per month.

Anteroom daily damp-mop - Janitor $1 / 2$ hour per day

Clothing - Dacron overalls, hats, booties, gloves and

151.44

nylon wiping cloths

Sticky pad - 2 sheets per day

Prefilter malntenance - Vacuum weekly in place, remove, wash and dry every 90 days

Replace absolute and prefilters - No cost, as I will comment

0.00 on in a

No costs are shown for filler replacement as we cannot predict when this will be necessary. The filter manufacturer recommends filter removal when the pressure drop across them is twice that of the clean filters. The 0.7 inch of water reading on the draft gauge has not changed since installation about 1 November 1962. (The room was placed in operation on 6 october 1962). Obviously, there is no appreciable contamination build-up in the filters and this is very reasonable considering two factors. One is the cleanliness precautions exercised by the working personnel and the other is the double filtration of make-up air to the system. (Outdoor air is filtered at the building supply fan house and, in turn, the building air is passed through a filter in the clean room air-handling unit prior to introduction into the clean room system.) 
In conclusion, we expect that soon--if not already--General Dynamics, Pomona will lose the title of having the largest cross-flow clean room in the world, but we believe that, for some time, we will have one of the cleanest rooms in the world.

\section{QUESTIONS}

W. E. HARROLD, UNION CARBIDE NUCLEAR COMPANY: We have heard several diffcrent ideas about the number of foot-candles required and $I$ am sure this depends on what you are doing. You mentioned 400; I just wonder how this is worked out, and if actually you maintain 400 .

MR. GOSMA: Actuaily this just happened, and we haven't checked this in the 6 months the room has been in use. Lt. Austin yesterday said that he thought perhaps we had taken out some of the tubes. This has not been the case. We don't know what the reaction would be if we were to decrease our lighting level.

DON KOONI'Z, BELL LABORATORIES: I noticed in one of your slides you showed the room in operation. It appeared that most of the operations were carried on on a bcnch. If this is typical operation, could you tell me why you use a clean room and not a series of clean benches?

MR. FLINN: As I explained, this gyro is exposed, so with a clean ronm we can carry it around the room and not be restricted to a bench.

the gyro assemblies?

MR. FLINN: This would limit us. The way it is now, we can make tests the whole length of the room. We are not restricted. I think that the freedom that we are allowed from this setup is beneficial.

BERRY 0. JACOBSEN, PANTEX ORDNANCE PLANT: Do you shut this unit down over the weekend or do you let it run continuously?

MR. FLINN: We have never shut the unit down since October 6 (except that about $1 / 2$ hour per wcek we shut the room down to vacuum the prefilters in place).

A. L. LIEBERMAN, ARMUUR: Yuu indicatc that the pressure drop across the absolute filters has remained constant since you've had them. What is the cuulition of the prefilters when you maintain them?

MR. GOSMA: We have not been able to notice any dust on them. Evidently this vacuum cleaning weekly is taking care of anything that is present. About a month ago we took a couple of the shcets out and washed them in mild detergent and water and there was practically no evidence of any dirt being there.

dry?

C. W. COBLENTZ, NATIONAL BUREAU OF STANDARDS: Arc those prefilters oiled or sheets.

MR. GOSMA: They are dry. They are nothing but the expanded polyurethane

C. F. PHILLIFS, AFLC: What is the amount of your make-up air again please?

MR. GOSMA: Approximately 600 cubic feet per minute. The air-handling unit handles 2500 cubic feet per minute, but 600 is make-up which is purged from the clean room into the anteroom by gravity dampers and in this same manner on out through the building.

J. G. GROSCH, LOCKHEED MISSILES: We have a cross-flow room too; it might be the world's largest now for a while, but we do shut down on the weekend. We use only the plant air-conditioned source for the air-conditioning air, and it's turned off for the weekend. We left the room running one weekend, and we had a terrific heat build-up. It took about 4 or 5 hours to bring down the temperature created by the lights and everything. We close the whole thing down on the weekend, and in about 2 hours it is back on specifj.cation. 
MR. FLINN: We do not leave our lights on. One of the main reasons we have not shut down is that we have been running some 12 hours a day, 6 days a week.

H. E. MINER, AFLC: What was your reason for having 400 foot-candles? We have been using 100 foot-candles average.

MR. GOSMA: We specified 150 foot-candles minimum at bench level, the contractor overdid it in his design and we ended with the 400 .

MR. MINER: Have you figured out the expense of keeping the 400 ?

MR: GOSMA: No, we haven' $t$, but it is appreciable because the room is in operation 6 days a week and 12 hours a day.

MR. MINER: Have your employees complained of that increased lighting? I mean for their eyes.

MR. FLINN: When the fellows first went into the room, they had been working in a very small, congested "coal mine." When they went into the clean room, they did complain of snow blindness and such things. We decided that everybody was going to continue on for 2 weeks, and then we would see what complaints they had. These complaints no longer exist.

M. W. MCKENZIE, MARTIN COMPANY: I would like to make a comment about 400 foot-candles. Actually, right inside of a window on a sunshiny day, there will be about 500 foot-candles which will taper off to about 25 foot-candles within a living room. Most people read with much less light than they need. As long as it is economical, one can go up to about 500 foot-candles, and this is actually better and more efficient for the people working. The reason that 100 has been established in the past is that in the early days indirect or incandescent light caused heat problems and was also quite expensive. If you will take a light meter and read and adjust the light, you will find that your own eyes, not knowing what you have selected, will come nearer selecting up around 400 or 500 foot-candles than they ever will 100 to 150 foot-candles.

LT. FRITH, USAF: Have you ever tried any of the tote boxes that Don Kountz talked about inside your room for moving the 1tems from one bench to the other?

MR. FLINN: No, we have never done this. I think a certain type of people work on small instruments in clean rooms, and these people don't like to be restricted.

LT. AUSTIN, MAAMA: During the several times that $I$ have been to your room I got the effect of tunnel vision when $I$ was in the room. I feel this was because of the high intensity of light. I don't know if anybody else has experienced what tunnel vision is, but you lose perception on the outsides.

D. W. BALLARD, SANDIA CORPORATION: I have some experience on an installation at Bulova watch Company, where Sandia has about 150 linear feet of laminar flow work stations. We do use containers to transport a small electromechanical timer between operations. Unfortunately these containers get dirty. We found after a while that it would have been to our advantage to have had a whole clean room because every time we took the timer and put it in the container to move it to the next operation we introduced dirt from the cap. Unless these containers are kept extremely clean, they probably do more harm than good. 


\section{CLEAN BENCH}

Stewart W. Timmerman

MAAMA

An outgrowth of the original 1 aminar flow ruun developed by Sandia Corporation is llse clean bench or clean work station. This bench produces a superclean work area without the expense imposed by the construction of a complete room. Trius to the introduction of the clean work otatiun, a superior cleanliness level was achieved by using dust-controlled hoods. These hoods had two major disadvantages: (1) they restricted the workers' freedom of movement, and (2) the air-flow patterns did not eliminate contamination which might be generated within the unit. The primary function of the air flow was to exclude outside contaminants from the work area. Contaminants once inside the hood were not moved out of the work area immediately, but moved about inside the hood at random.

In developing a new dust-controlled hood, the design objectives were directed toward correcting these deficiencies. The new design must not restrict the worker's movement and it must have a very rapid recovery rate. The rapid recovery rate suggested bathing the work area with clean air. The nonrestricting requirement necessitated an open face bench. It logically followed that such a design would operate on principles similar to those employed in a laminar flow room. By placing a superinterception filter as close as possible to the work place, it was possible to bathe the work area in superclean laminar flow air. A self-contained air-handling systern was built around this idea. Air intakes were placed below the working surface and a bluwer was installed inside the bench. This blower pressurized a plenum chamber immediately behind the filter, forcing the air through the filter and producing laminar flow across the working surface. Since the unit was to have the capability of operating outside of a clean room, prefilters were added to the incoming air to eliminate large size particles and prolong the life of the superinterception filter. The atmosphere produced by this bench is potentially as clean as that developed by the laminar flow room. Care must be exercised, however, when using the bench in an uncontrolled area. Since filters are percentage devices they will pass a greater number of particles when used in filtering dirtier atmospheres. It is also necessary to protect the work area with an overhead surface to prevent large particles from falling out onto the bench. The use of the bench will almost eliminate the problem of a critical size particle landing in a critical area. The laminar flow produced will, give any particle generated in the bench only one pass at the component. Special work techniques to prevent transfer contamination are still necessary and, in fact, are especially important when the bench is used in an uncontrolled area.

The level of cleanliness achieved by a clean work station is in the range of 100 particles per cubic foot, 0.5 micron and larger. The level is so low that it is almost impossible to get a particle count on an automatic counter. This presents a problem when checking to determine if the clean work station is performing satisfactorily. Also, since the air flow is laminar, the counter will monitor only the streamline in which the intake is placed. There could be a great deal of contamination in another streamline and the counter would be unable to pick it up. Two tests are necessary to ascertain if the work station is providing a clean atmosphere. These tests are the leak test and the air-flow test. To perform the leak test, we introduce smoke into the intake of the bench and scan the filters with a smoke photometer to check for leaks. The photometer will react quickly to the presence of smoke and a leaky seal or ruptured filter passing this smoke can readily be detected. The other test is a velocity check. The velocity across the filter is scanned with a velometer to determine if the velocity of the air flow is adequate. If the bench passes both of these tests, then it can be deduced that it will perform satisfactorily. We have found that the sealing of the filter is quite critical and therefore it is very important to perform the leak test when receiving a new unit or changing a filter. 
One of the additional benefits that can be derived by using clean work stations is the capacity of the units to clean up the room. One 6-foot bench will filter 1200 cubic feet of air per minute. A clean room utilizing approximately 20 percent of its floor area with clean work stations can expect over 100 room air changes per hour due to the operation of the clean work stations. Such recirculation and refiltration of air through clean work stations should cause the room contamination level to approach the contamination level of the clean work station.

Another additional benefit that can be derived by using the clean work stations is increased production line flexibility. Most of the components requiring a controlled environment for manufacture or overhaul have only one or two critical operations as far as dust control is concerned. In the past, the tendency has been to overhaul this component in a room which would meet the most critical requirement. This has caused us to use expensive floor area for the majority of operations where a lesser degree of cleanliness, and a cheaper area, would have been satisfactory. By utilizing clean work stations, the overhaul may be accomplished in a standard room. Clean work stations will then be placed in the production line at the point where the critical operations take place.

Critics of the clean work station have argued that laminar flow only exists in the nurdisturbed air flow and that the work piece and worker produce turbulence which will retain contaminants within the unit. They also insist that the turbulence causcd by the worker's arms extending from outside the working area into the working area will produce turbulence which will carry outside contaminants irito the bench.

In order to prove or disprove this theory, our group has been conducting airflow tests at olmsted Air Force Base. These tests indicate that it is possible to disturb the laminar flow with a work piece. Any turbulented flow region formed, however, does not present a problem since only superclean air is in this region. Our test shows that this turbulence does not move contaminants upstream but continues to move them out of the work area. In many cases laminar flow is reformed behind the piece as soon as stream irregularities are dampened. Any contamination generated at the work piece will still be swept out of the work area. In an effort to determine if it were possible for contaminants to be carried into the work area, we generated highiy contaminated smoke close to the edge of the bench. Even when the worker attempted to carry these contaminants into the work area with his hand, the superclean air flow moved it away from his hand very quickly. We only succeeded in introducing the se contaminants an appreciable distance into the bench by giving the smoke a velocity toward the filter (by actually pointing the smoke generator upstream).

In a further effort to eliminate any possible introduction of contaminants, we added an air sink to the forward edge of the bench. This sink consists of a slot across the forward edge which draws off air at that point. Wilh the 3 inl. in operation, the possibility of the introduction of contaminants is further reduced. We are still studying the problem of the introduction of contaminants and the air sink is but one of the alternatives under study. It appears at this point, however, that it may not be necessary to resort to its use. Our latest air-flow tests indicate that the bench without the air sink resists the introduction of contaminants satisfactorily.

I have a short film taken several weeks ago which shows a clean work station with and without the air sink in use. The first few shots demonstrate the alr flow around the work piece. The later shots show the worker in an attempt to force contaminants upstream. We are having difficulty getting photogenic smoke in the quantities we need. We either get too much or not enough. You will notice that there is some unevenness in the density of the smoke as it comes from the smoke generator. This is due to a puffing action by our generator. In spite of this, I think these films are very enlightening.

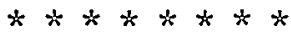

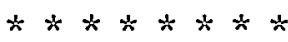

I think that we can see from this short film that the clean work station will give us the protection that we need from outside contamination, and with proper filter installation and work techniques, we will achieve a satisfactory environment for our critical components. 
In conclusion, we feel that the clean work station will:

1. Provide an economical technique to obtain very low contamination levels.

2. Enable the Air Force to upgrade rooms.

3. Give the Air Force increased production line flexibility.

\section{QUESTIONS}

MR. HAROLD HOLLINGSWORTH, AIRESEARCH MANUFACTURING COMPANY: Have you any information on mobile work stations which could be used on large items which could not be put into a work bench area?

MR. D. W. BALLARD, SANDIA CORPORATION: Mr. Marsh, in the next presentation, will show you a hood that we built which can eurround operaling tables or any large uuit with a clean air mass coming straight down.

I'd like to point out a couple of things which we have learned on extensive use of clean work stations througli our work with Bulova Watch Co.: (1) Watchmakers have a deplorable habit of putting their elbows up on the table. To encourage them not to do this, we put in skin trays on the critical watch-making operations, trays that slide out below the work bench and these keep the worker's elbows out of the clean air flow. (2) Another suggestion I might make is that ancillary equipment be kept on a small table to the side rather than under the hood itself. We put a small wire rack for tools near the air exit to keep the tools from disturbing the air flow.

MR. E. O. FOSTER, AUTONETICS: Have you ever considered using titanium tetrachloride for your smoke?

MR. TIMMERMAN: No, we will have to try that. 


\title{
ADAPTABILITY OF LAMINAR AIR FLOW FOR CONTAMINATION CONTROL
}

\author{
R. C. Marsh \\ Sandia Corporation
}

Introduction

The air-flow principle utilized in the laminar flow clean rooms and clean benches may be adapted to a wide variety of operations requiring cleanliness. However, it is not possible to design a universal work station suitable for all operations. Each must be designed to accomplish the particular operation of interest. Mr. Whitfield has already demonstrated that laminar air flow can be directed as a vertical flow, horizontal flow, or a combination of both. The primary requirements for contamination control units are: (1) that the space to be kept clean have walls or sides to maintain the laminar flow, and (2) that the air inlet and exit to the space each have an area equal to that of the cross section of the confined space. On the basis of these basic requirements a number of work station configurations can be designed.

This paper describes several special purpose devices which have been developed to control airborne contamination. The extension of these devices to similar opora tions is also described.

\section{Precision Cleaning Applications}

Two work stations have been developed to provide a clean environment around cleaning equipment. Precision cleaning processes are sensitive to airborne contamination for two reasons. First, the high purity solvents or other cleaning media must be kept clean during handling, pouring, and exposure during the cleaning process. Second, the freshly cleaned parts or assemblies must be kept clean until they are dried and protected in some manner.

\section{Deionized Water Washer}

A laminar flow hood was built over a deionized water washing unit which is used for precision cleaning. This unit is basically a Barnsted Transistor Washer which is designed to provide high purity distilled and deionized water to five wash tanks. However, because of this open wash tank arrangement, contamination can fall into the high purity water. The laminar flow hood constructed over the washer is shown in Figures 1 and 2 . A single 2 foot by 2 foot absolute filter is located horizontally above the washer. The hood contains its own blower and prefilter. Its lucite sides were constructed to confine the clean air and maintain the laminar flow.

The advantages gained from this unit are: (1) the water in the wash tanks maintains its purity regardless of the ambient dust conditions in the room, and (2) the area above the tanks is ultraclean, allowing parts to be dried and handled without subsequent recontamination from the air.

This basic design could be applied to a wide variety of operations or equipment requiring cleanliness. 


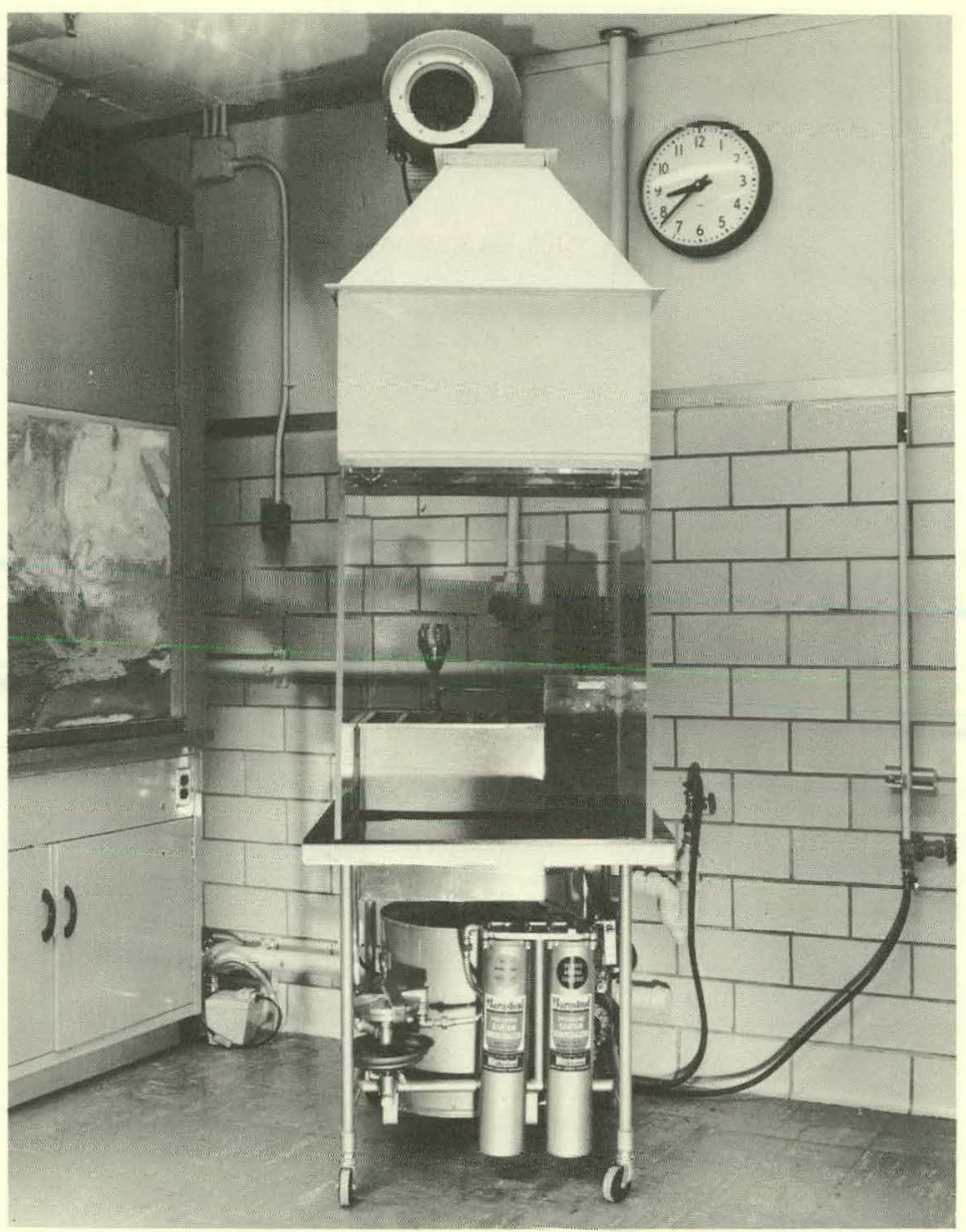

Figure 1

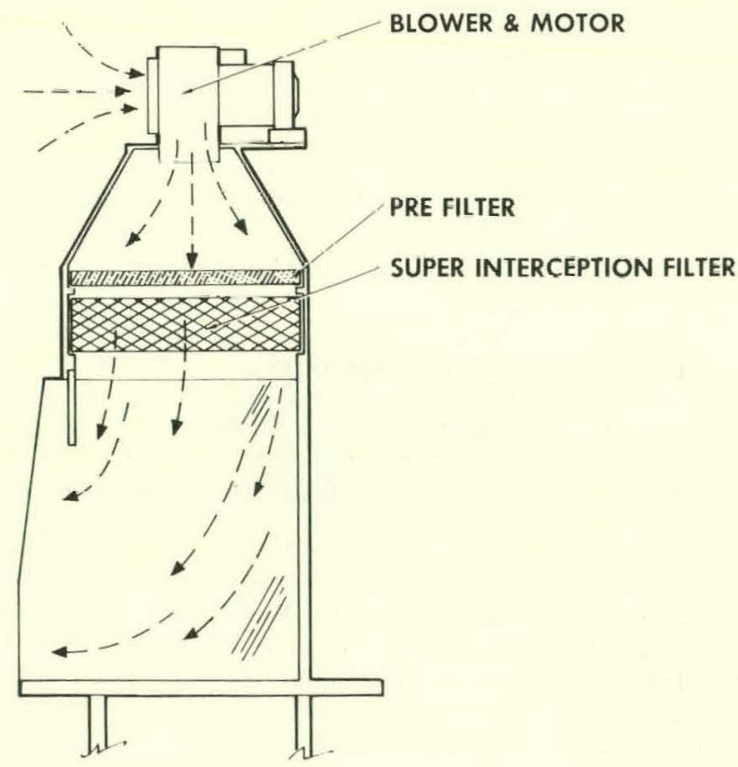

Figure 2. Clean air hood 
In most cleaning processes, it is not feasible to pass air over the process and out toward the operator or into the room because of the cleaning solvents used. Instead, solvent vapors with toxic properties must be handled with a positive exhaust system.

Consequently, a work station was designed to provide the working area with clean air and yet provide a positive exhaust to eliminate any unwanted vapors. This unit again has an absolute filter mounted horizontally over the work space. The work surface itself, however, is an open grating which allows the air to be exhausted through the work surface and out of the room. Figure 3 illustrates the principles of this hood. Two

blowers are used, one to provide clean air through the filter, and one to exhaust the air through the grating work surface. By adjusting the exhaust blower with a damper, the system may be balanced so that no air moves through the Front opening, or so that air moves elther lillu llie livid oi out from the hood. In any mode of operation, the space inside the hood is 1solated from the environment in the room because of the laminar air flow within the hood. Any mixing which occurs at the front opening is confined to a small region extending about 4 inches inside the hood.

The principal advantage of this work station is that the work space is continuously provided with ultraclean air while any vapors or unwanted contamination are exhaustéd from the hood and blown outside the room. The hood was primarily designed to be used with an ultrasonic cleaner mounted into the grating. Such a cleaning station would meet the most exacting requirements for precision cleaning and could be used inside the clean room without adding contamination to the room.

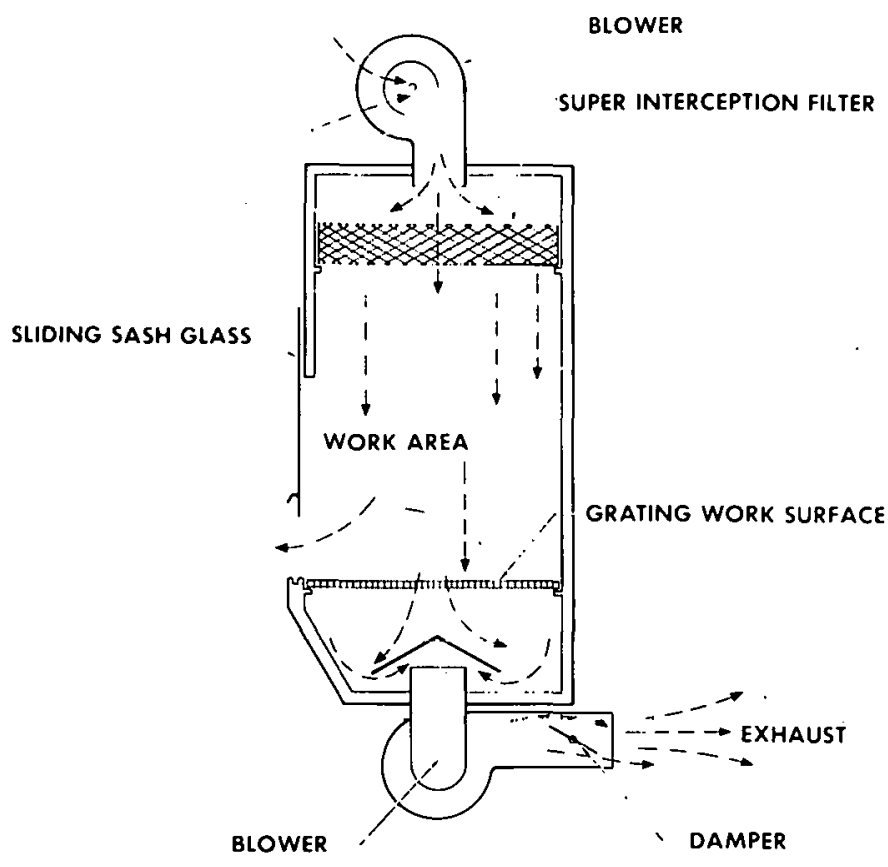

This hood is applicable to a number of other operations which require cleanliness as we 11 as positive exhaust.

\section{Medical Applications}

The medical field is another area requiring high standards of cleanliness. A great deal of time and effort has been expended over the last decade to control the level of bacteria present in the air in all types of medical facilities, including operating rooms. This has been necessary since airborne bacteria create a high $1 \mathrm{n}-$ fection rate in both surgical and other hospital facilities. The majority of these harmful microbiological contaminants are of a size which can be easily removed from the air by the superinterception or absolute filters. For example, the chief organism responsible for postoperative infection is hemolytic staphlococcus aureus (the "Staph Germ"). This germ, approximately 0.5 micron in diameter, will not readily drop out of the air but is easily captured by an absolute filter. During an operation, one person will likely release thousands of these germs which, if not removed from the room, may contact an open wound or incision and create an infection which is not amenable to antibiotic treatment. 
The capability of laminar air flow to reduce microbiological contamination has been partially investigated. For example, a dog was operated upon in the Sandia clean room under extremely unsterile conditions. This operation was a colon resection in which the contents of the bowel were exposed to the air in the clean room. Throughout the entire operation, about one-half hour, culture plates containing a blood-agar nutrient were exposed at various places in the operating area.

The results of the test showed that contamination only existed downstream from the dog and the doctors. There was no lateral movement of the bacteria, and the air at the site of the operation remained sterile. Furthermore, the areas where contamination ordinarily exists in a conventional operating room were majntained at a much lower contamination level. This may be explained by the dilution effect produced by the high rate of air flow. A superclean operating room, built on the principles of the Whitfield Clean Room, promises spectacular improvements in future operating environments.

The possibility of very clean air and the isolation properties of laminar air flow should be advantageous to other medical applications such as contagion wards, isolation for allergic patients, pharmaceutical research and preparation, and raising germ-free animals.

\section{Down-Flow Curtain Unit}

A small experimental device for localized control of contamination was built and is currently being evaluated for medical applications by the Lovelace Foundation in Albuquerque. The device, shown in Figure 4, consists of two absolute filters supported horizontally overhead, and an air supply unit. A plastic drape extends down from the filters to maintain the laminar flow. Four 15-watt ultraviolet lamps are located in the plenum behind the filters to sterilize the air and prevent any build-up of viable material on the filters.

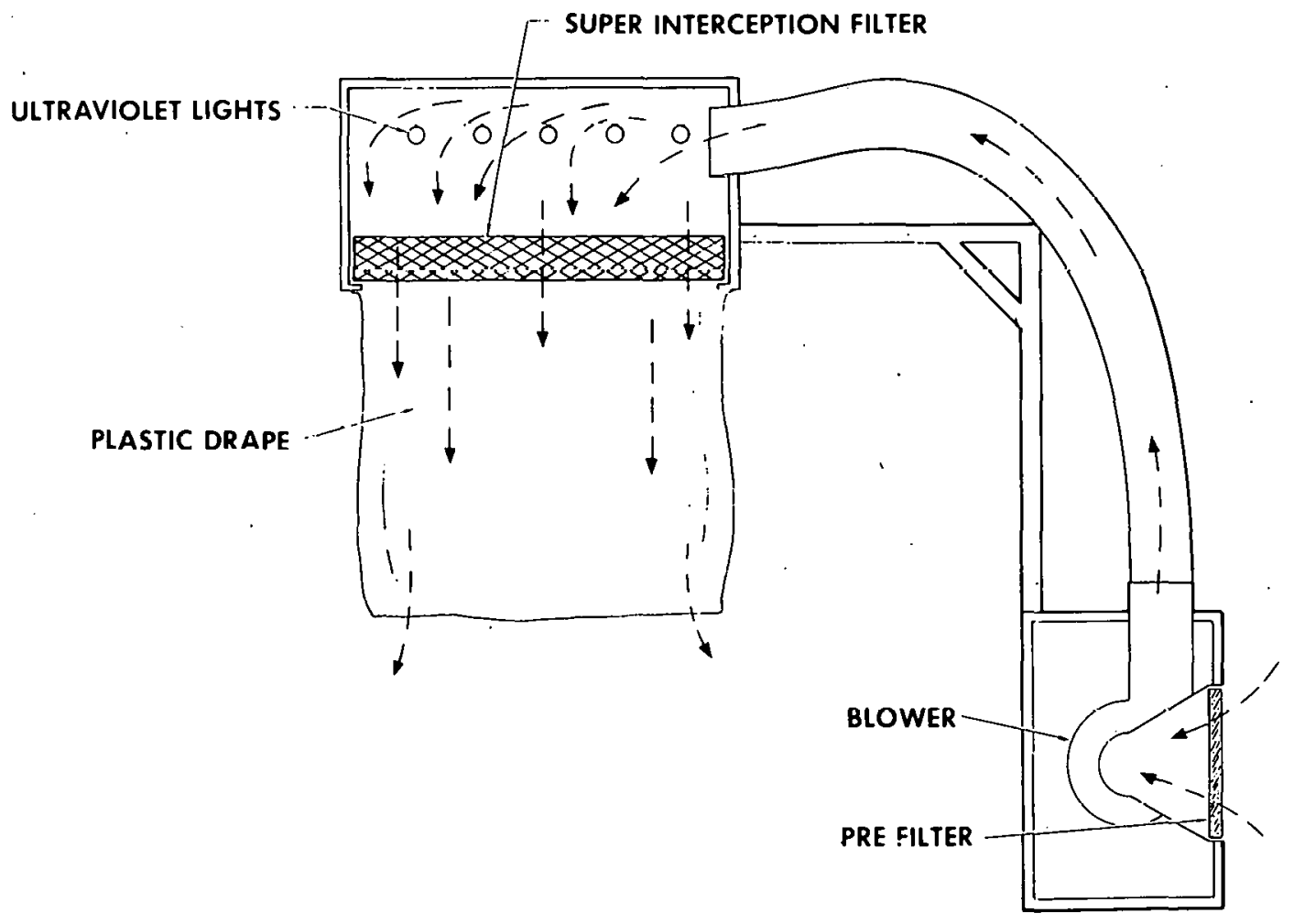

Figure 4. Overhead laminar flow unit 
A number of other applications of laminar flow have been considered and are being developed.

\section{Mobile Clean Room}

Often a temporary clean environment is needed under field conditions, as in field repair of sensitive components or equipment, final assembly at on-site locations or emergency medical operating facilities. Also, since a clean facility is often needed only temporarily at a given plant location, a permanent installation is not justified.

A mobile clean room to fit this type of need is being developed. The proposed design is shown in Figure 5. The trailer-mounted room will be coupled to an auxiliary air supply and power source unit. The air supply will feed through an overhead plenum and a bank of absolute filters in the ceiling. The air will flow vertically through the room and grating floor and back to the air supply unit. The present design is for a central highly controlled section with laminar flow and two lesser controlled sections on each end.

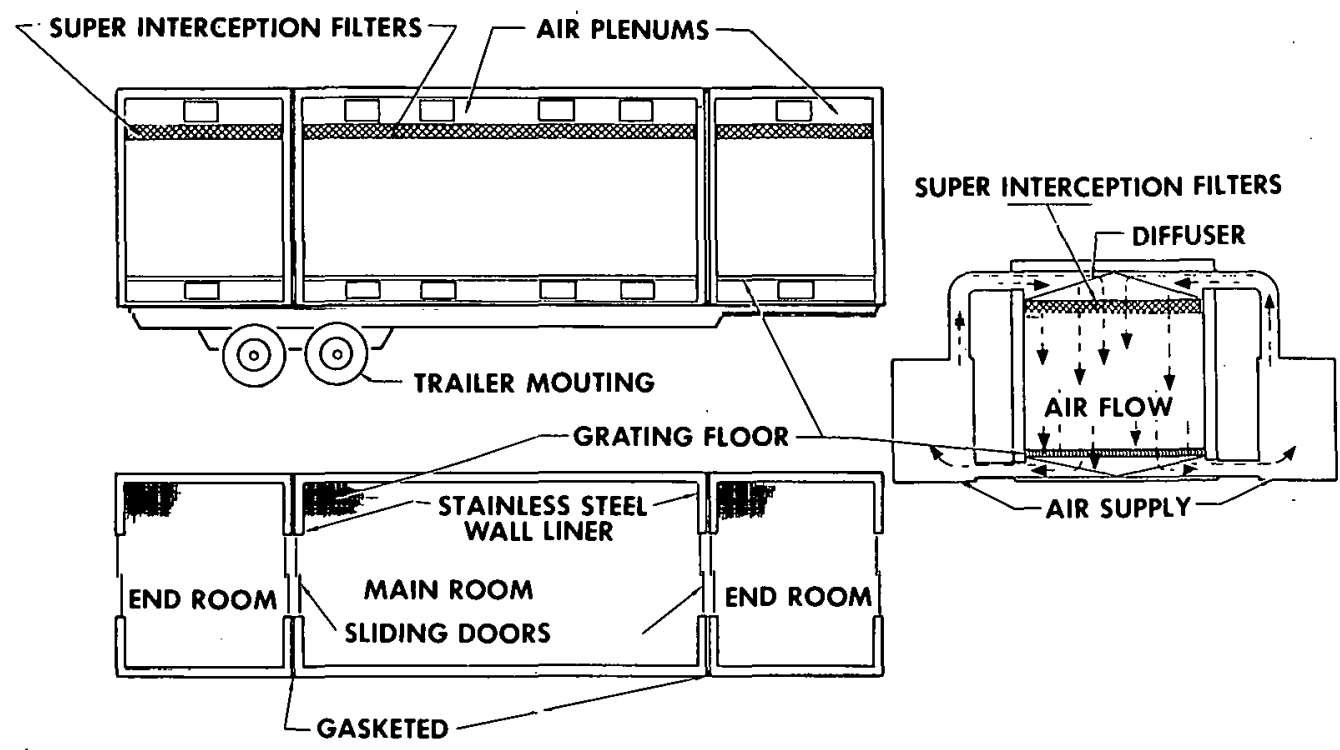

Figure 5. Portable laminar flow room

The advantages of such a unit are: (1) a high level of cleanliness possible independent of the field conditions, (2) the immediate clean down capability of the design, and (3) the utility of such a unit.

Down-Flow Curtained Unit

The small down-flow, curtained unit described under the medical applications may be expanded to encompass large objects such as missile cleaning stands, rocket assemblies, gyro test stands, etc. Here, isolation from the ambient room conditions can be achieved by simply constructing a horizontal, overhead filter bank and a surrounding flexible curtain. A portable unit of this type would have tremendous versatility. 


\section{Automated Color TV Line}

Another unique example of how laminar air flow can be utilized is an approach used by the Rawlings Corporation for controlling airborne contamination of color TV tubes processed on an automatic assembly line. The process of coating the se color TV tubes with light sensitive phosphor is extremely sensitive to airborne contamination. This entire process is completely automated and handled by complex machinery. To control contamination, a laminar flow hood and enclosure is being constructed over the entire 500-foot length of the automated line.

\section{Various-Methods of Achieving Contamination Control}

From the discussions presented thus far in this session, one can see that the clean room designer has a number of choices in designing a clean facility. His choice is based upon a number of factors such as economics, product requirements, type of operation, existing equipment, and permanency of the production line.

Figure 6 outlines the various approaches possible. This chart is divided into two sections; existing facilities and new construction. Stated simply, the chart points out "use what you already have if it is adequate or build new facilities which hest suit your needs."

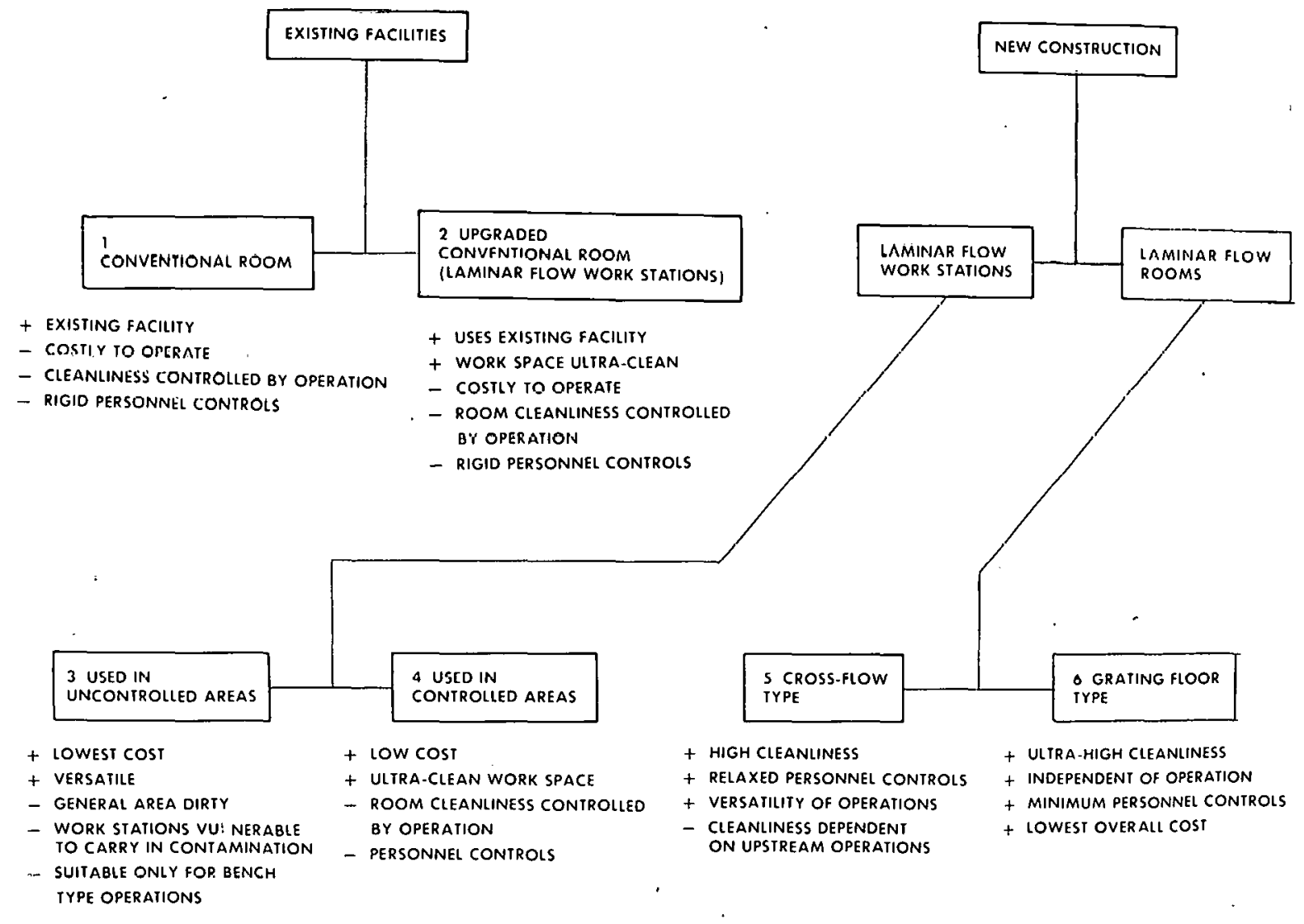

Figure 6. Types of controlled facilities

\section{Existing Facilities}

The tremendous acreage of clean rooms now in operation across the country represents a staggering investment in money and space. In a great many instances, these facilities are adequate as they are now operated. However, more exacting 
cleanliness requirements and the severe operating restrictions and personnel controls that are required often dictate upgrading of these facilities. Existing clean rooms may be easily upgraded by replacing work benches in the room with laminar flow work stations. The stations themselves provide an ultraclean work area and also recirculate room air in large quantities to give the entire room a self-cleaning capacity. The contamination level of the room is thus reduced substantially: depending upon the number of work stations in the room.

New Facilities

If no facilities are available or if it is decided that upgrading e: sting facilities is not justified, new construction must be considered. In new construction, laminar air flow should be designed into the facility. Here again several methods can be utilized.

1. Laminar flow work stations can be used in otherwise uncontro:led areas to provide control only inside the work area.

2. Laminar flow work stations can be used in controlled areas having tight walls, limiled acces3, improved housekesping; and filtered air supply. The work space is again highly controlled and the surrounding area will be controlled, depending upon the quality of the area and the number of work stations, sed.

3. Laminar flow rooms can be used to highly control an entire room area. Here either the cross-flow design or the grating floor design may be used. The grating floor design provides the highest level of control for an entire room.

Advantages and Limitations

Each of these approaches has associated with it a number of advantages and limitations.

In cases where an existing clean room is adequate there is a tremendous advantage in being able to use already existing facilities. However, a number of severe limitatuns should be notad: the conventional clean room is very costly to operate; the air-handling equipment must be run continuously; a continual clean-up or janitorial program is required; costly clean room garments must be bought and maintained; and the output from the clean room workers is severely reduced by time lost in gaining access to the area, and movements and operations which can be done in the clean room are severely limited. Record keeping, communications, parts flow, and access by engineering personnel are other serious problems. Since the cleanliness level of the room is dependent upon the nature of the operation in the room, many processes closely related to clean room operations must be kept out of the room. Also, because the cleanliness of the room depends upon the nature of the operation, a costly dust monitoring program is usually required.

Upgrading these conventional clean rooms with laminar flow work stations reduces some of these problems. The work space itself is ultraclean and independent of other operations in the room. Also, the general area is given some self-cleaning capacity. However, rigid personnel controls are still necessary to maintain the general room cleaniiness.

Using work stations in an uncontrolled area provides an ultraclean work space for a minimum cost. Also, the versatility of being able to move the work stations around to desired locations is important. However, the major limitation is that only the work station is controlled and the surrounding area may be quite dirty. Since everything which is brought into the work station carries in a certain amount of contamination, the critical object on the bench must be protected in some manner before it can be transported from the station. However, personnel control, access to the room, record keeping and communication problems are almost nonexistent.

Using work stations in'controlled areas provides an ultraclean work space and also allows the entire area to be cleaned up by the air from the work stations. Although this is an easy way to clean up an area, a number of controls (particularly on the personnel) are required.

The cross-flow-type laminar flow clean room is unique from several standpoints. The design provides areas near the filter wall which are ultraclean and independent of operations further down the room. This allows dust-producing operations (record 
keeping, etc.) to be done in the room immediately accessible to the clean room workers. However, the cleanliness of a large portion of the room is dependent upon upstream activity, and a continuous or frequent dust-monitoring program will normally be required. Personnel controls in the entire room may be greatly relaxed due to the self-cleaning capability of the room, but are still required to some extent. This type of room is a compromise of the down-flow design.

The grating-floor-type laminar flow rooms provide a high degree of control of an entire room. Each area within the room itself is isolated from the rest of the room and independent of other activities throughout the room. A minimum of personnel controls are required. Access to the room is essentially unrestricted. "Dirty" operations may be placed inside the room without affecting the cleanliness of other areas, or dirty operations may be kept outside of the clean room without limiting the accessibility to the clean room workers. This allows the size of the controlled area to be substantially reduced. Only those operations which require cleanliness need be inside the room. Elimination of air showers, controlled change rooms, lunch rooms, rest rooms, hallways, air-locks and paper-work rooms drastically reduce the amount of controlled space required. Also, her.a11se the room is independent of the operation, dust monitoring becomes simply a periodic equipment check rather than a continuous program. Maintenance of the room is minimized and the air-handling equipment need only be operated during the work period.

In considering the over-all cost of constructing and operating a clean facility, all of the factors pointed out in the preceding discussion should be considered.

\section{Cleanliness Considerations}

A clean room is designed to achieve airborne contamination control. Other benefits which are gained are really by-products of the clean room operation. Many rooms have been built which in fact do not achieve this control because of faulty design or because of the influence of the operation in the room. Many clean room operators have been led to believe that the by-products of the room, such as worker control and psychological conditioning of the worker, are justification for the clean room expense. Here an anomaly arises. The major expense of the facility is spent for sophisticated air-handling equipment and filtration and provisions for reducing the amount of contamination brought into the room on people and equipment, yet the performance of the room is judged by psychological concepts rather than by how much control is actually achieved over the airborne contamination.

Figure 7 shows the various cleanliness levels which one may expect from the various methods of obtaining airborne contamination control. The ease with which a very clean facility can be obtained using laminar air flow is an important factor in deciding which approach to take.

\section{Conclusions}

Our conclusions, based on the work which has been done at Sandia over the past two years, are:

1. Using laminar air flow, control over airborne contamination can be achieved both simply and economically to a point where airborne contamination is insignificant. Operational contamination levels of at least two orders of magnitude lower than that obtainable in conventional clean rooms can be maintained by the laminar flow design.

2. This control can be achieved independent of the activity within given areas.

3. The over-all cost of achieving and maintaining airborne contamination control by laminar air flow means will be substantially cheaper than the cost of conventional means. 


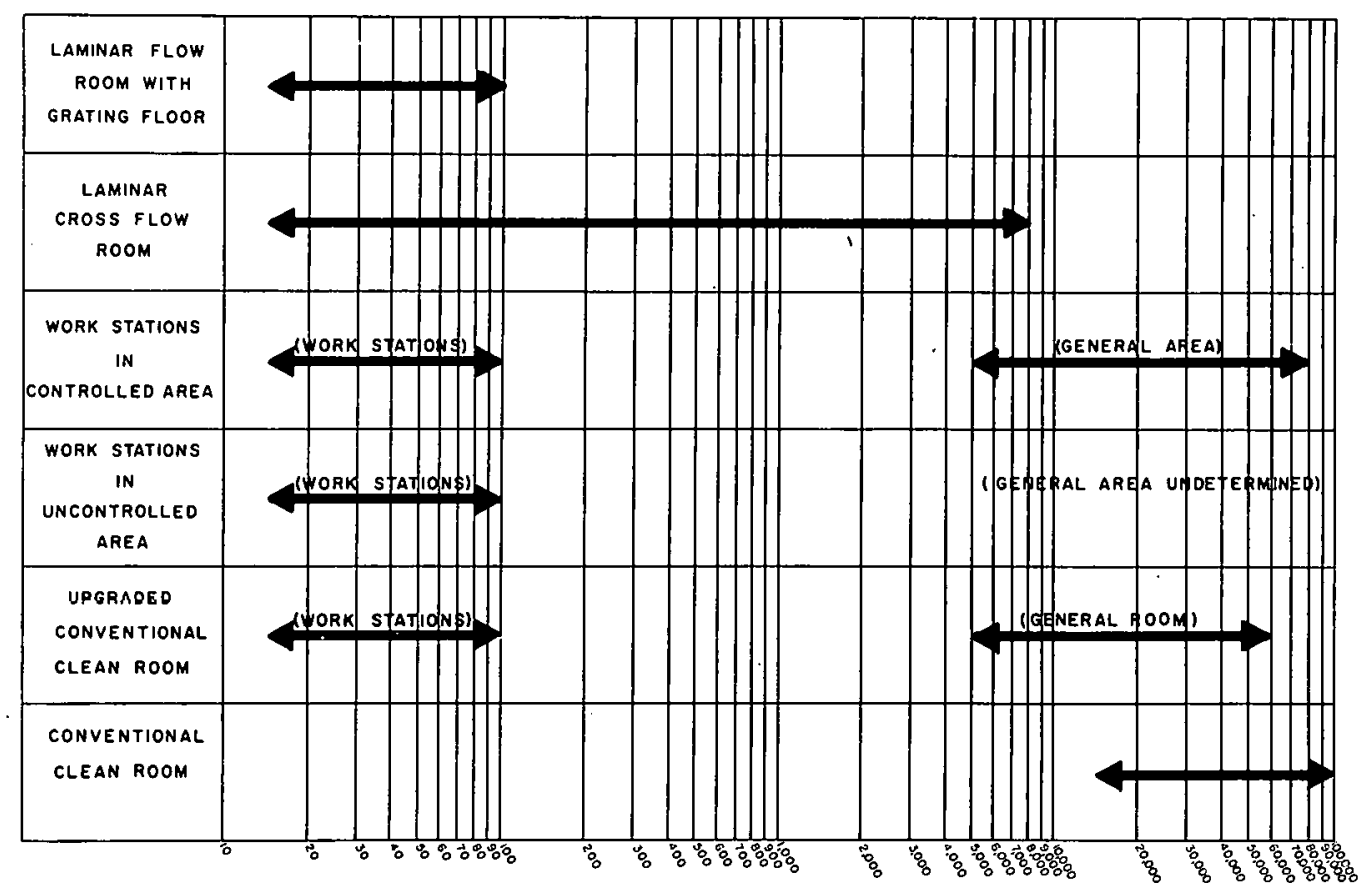

PARTICLES PER CUBIC FOOT EQUAL TO \& LARGER THAN 0.5 MICRON

Figure 7. Cleanliness levels possible with various clean room approaches

\section{QUESTIONS}

ROBERT A. RANDALL, SANDIA CORPORATION: I was wondering whether you could tell us something about the noise level in work stations. Is normal conversation possible?

MR. MARSH: This is a problem which designers of clean work stations are attacking. A number of them have achieved a noise level which is quite acceptable to conversation. 'Some work stations which have been built do have high noise levels; the problem is to find the right kind of blower and the right kind of acoustical baffling within the rear chamber.

ROBERT S. RUNKLE, NATIONAL INSTITUTE OF HEALTH: Have you any suggestions about lighting with the grated floor rooms?

MR. MARSH: Yes, we have. First of all, you could design a small light fixture that would spread over a large area, a fixture small enough that it could be mounted below the filter bank and thus create a minimum of disturbance. The laminar flow pattern would then be established before it reached the level of the work space. Lighting could also be mounted in the walls with diffuser arrangements.

ALBERT S. GATES, JR., NATIONAL INSTITUTE OF HEALTH: The grating floor is a costly and technically difficult part of the room. Have you looked into the possibility of reducing the total area of the grating? Maybe you could have grating strips and do as well as you are doing now. 
MR. MARSH: We haven't investigated this. If the air exit space is less than its entrance area, then you tend to get away from parallel flow lines and to encounter the possibility of turbulences. In an undisturbed room you could perhaps control the flow lines, but, once you put the objects in the room, there would be turbulence problems. We don't think the grating floor causes any serious problems. The floor can be supported at any number of different points. Closespaced grating is available on which heavy equipment can be rolled, and this grating is not too uncomfortable for working personnel. You can get grating with a large bearing surface.

G. C. MCDONALD, SANDIA CORPORATION: It seems to me that a man who has a conventional clean room that might have dirty pools of contaminated materials on the floors has a particular problem. I wonder if he could simply use the filter and blower on a caster installation and move a half dozen of them in during a dirty operation and remove them afterwards, thus achleve sume upgrading of his present facilities.

MR. MARSH: Yes, this would be one way of upgrading a present facility'. Critical work could be done right in front of this facllicy. Wurk stations can be moved into a tight room of standard office construction, and cleanliness can thus be provided by work stations.

F. W. VAN LUIK, JR., GENERAI ELECTRIC COMPANY: Have you done any work with respect to the minimum face velocities? One hundred feet per minute puts a lot of air through the room if you are forced to use hoods and throw away 60 percent of your total air because of contamination problems.

MR. MARSH: We have not investigated lower velocities. Üsing luwer rates, you reduce your response time; lower air flows can maintain cleanliness, but the rate at which contamination is carried out would be lessened.

J. G. GROSCH, LOCKHEED MISSILE AND SPACE COMPANY: Coming back to the AgnewHiggins concept of cross-flow rooms. We have 17 blowers of approximately 1\%2horsepower each providing the air movement. Do you anticipate any contamination of the air as a result of the motors?

MR. MARSH: I should think a more logical design would be to put the motors outside the ducting. 'lhe blower of course leinains in the duct, but the motor could be removed. The contamination contributed by the blowers serves primarily to contaminate the final filters.

EDWARD F. CASEY, ROCKETDYNE: With regard to your plastic curtain--we have enclosed 10,000-ton ball valves on our Fl facility, and this is working out quite wel1. We are going to enclose rocket engines completely. Another application has been working very well in our propulsion ficld lab. We use benches there when we draw samples of lox and fuel. We do this in an open area.

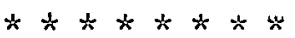

Mr. J. A. Paulhamus then demonstrated the operation of the laminar flow hood illustrated in Figure 8 . 


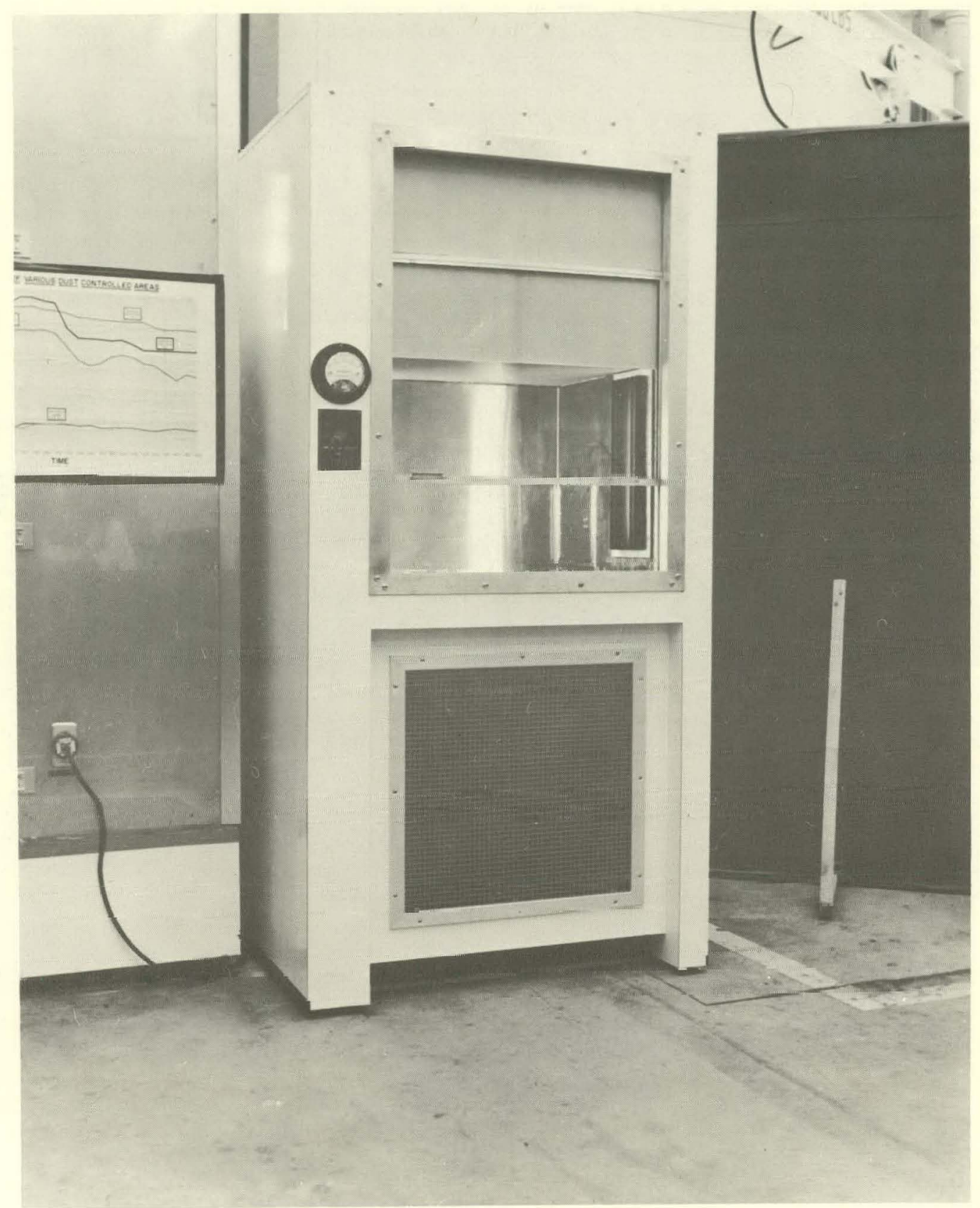

Figure 8 
SECOND DAY

Afternoon Session 


\section{IN'I'RUDUCTORY REMARKS}

Colonel Charles E. Fay, Jr.

Field Command, Defense Atomic Support Agency

This afternoon session will be devoted to a consideration of a proposal for a Federal Standard. I would like to turn the proceedings over to Mr. Ballard of Sandia Corporation who will explain where we are and where we go from here. 


\title{
SPECIAL SANDIA-PREPARED PROPOSAL
}

\author{
D. W. Ballard \\ Sandia Corporation
}

I would like to acknowledge the outstanding help and cooperation that we at Sandia Corporation have had in arranging this conference. As many of you know, a meeting of this sort requires a lot of preparation. First of all, I would like to give credit for many of the arrangements, the meals and so forth, to FC/DASA. I would like to recognize the fine assistance that AEC/ALO has given us. I would also like to express my appreciation for the assistance that we have received from top management here at Sandia Corporation.

As I look over this nearly full auditorium, it is hard to realize that only 6 months ago Gordon King and I were talking about holding an informal round-table discussion on clean room standards with a few key people from other Federal agencies. We talked at that time of perhaps a dozen invited attendees. This figure mushroomed to close to 175 , and I am sure that we could have doubled even this figure had we opened the doors to all equipment manufacturers and nondefense users of clean rooms who wished to attend. We are grateful for the impressive quality as well as the number of attendees at this Conference. It is obvious that we have people here who hold high positions in their agencies and companies.

We have underestimated the extreme interest and concern of many individuals and companies in developing dynamic Federal Standards for clean rooms, and the latest newcomer on the scene, clean work stations. I would just like to mention two other examples of our glaring underestimates:

1. We at Sandia, have had an unprecedented demand for copies of the three basic research reports that we published on the application of laminar air-flow principles to clean rooms. Our original thoughts were that 300 copies would suffice, whereas we have already distributed through Sandia, Oak Ridge Information Center, and OTS (Washington) more than 2500 copies.

2. More than 750 interested people from several hundred agencies and industrial concerns have visited Sandia and toured our prototype Laminar flow clean. rooms and work stations. Needless to say, this fact alone has caused our security people plenty of grief and hard work. Fortunately, for your tour later this afternoon, we have moved some of our equipment to the Sphere of Science which is located outside the classified area.

Because of our responsibilities as an AEC design agency, as explained by Mr. Hopkins yesterday, and encouraged by the high degree of interest that you gentlemen and the agencies or firms you represent had demonstrated, Sandia felt obligated to serve as a catalyst for the preparation of a Federal Standard that all of us could use with confidence. We discussed this need with our friends in $\mathrm{AEC} / \mathrm{ALO}$ and $\mathrm{AEC}$ in Washington. At AEC's request, the General Services Administration assigned the development of a Federal Standard to the Atomic Energy Commission with the Sandia Corporation designated as the preparing activity.

This Conference was planned to help implement the preparation of a workable and up-to-date Federal standard. By now, I am sure you gentlemen are full of technical details that have been pumped into you over the past day and a half. I will assure you that I will not give you any additional technical facts in my presentation, but it will be necessary to summarize certain key points as covered in our straw-man standard which will be circulated shortly to each of you. 
Before getting into the proposed standard, it might be well to take a few minutes to answer some general questions already expressed by some of you:

1. Why a standard rather than a specification?

The Defense Standardization Manual (M-200), which was used throughout as the "Bible" in the preparation of our straw-man standard, differentiates between Standards and Specifications:

\section{Standards}

Primarily to serve the needs of designers

Prepared to control variety

Broad and only essential performance requirements

Limited in details of "how-to-accomplish"

Function in procurement by reference in specifications

\section{Specifications}

Primarily for procurement purposes

Specific with respect to performance requirements

Detailed with respect to construction, packaging, and marking

Detailed in presenting "how-to-accomplish" information

\section{Standards are prepared:}

a. As the best solutions for recurring design and engineering problems

b. To provide the designer with cssential requirements normally necessary for intelligent selection and application.

As the assigned preparing activity for a Federal Standard, we feel the current needs in the clean room field lie in the area of broad performance standards rather than detailed procurement specifications. We feel it is impractical (and may be indeed impossible) to come up at this date with all possible combinations of detailed requirements for clean rooms and clean work stations. It is obvious from discussions yesterday afternoon that there are many personal preferences for detailed requirements in even areas such as lighting.

If we can't agree on broad performance criteria, we probably never would on minor details, construction, etc. Therefore, our straw man is a proposed Federal standard rather than a proposed Federal Specification.

2. Another question is why a Federal Standard? Why not an AEC Standard or a Sandia standard?

We feel (and are sure you agree) that clean room requirements are of prime interest to nearly all Federal agencies, military services, and prime industrial contractors. Our needs are strikingly alike (in spite of a few thousand words to the contrary) only varying in degrees of cleanliness and detailed operating re-

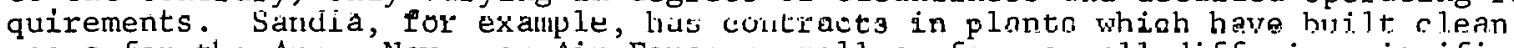
rooms for the Army, Navy, or Air Force as well as for us--all differing signifjcantly in controls, monitoring requirements, and the like--and all built with our dollars.

Acceptance of a workable Federal standard by all agencies would make good sense in a field that is being criticized in many of the technical publications for its costly ambiguity.

3. A third question logically asked is, "Why did we choose to use the "working group media" as the means for promulgating a Federal standard?"

We feel that time is of the essence and that Federal clean room standards are long overdue. It has been conservatively estimated that $\$ 1,000,000$ per week of the taxpayer dollars are going into new or upgraded clean room construction. We feel that tremendous strides have taken place in the "science" of clean room design and this data and guidance is badly needed by all of us. The need for expedited action was the reason a "working group" was selected. Section 3-200 of the Defense Standardization Manual states that "use of working groups provides the means for expediting coordination for the exceptional cases." We feel a coordinated and workable Federal standard is possible within 3 months if the working group approach is properly used, and if each of us objectively studies and comments constructively to his representatives on the working group. 
It might be well at this time to cover the membership of the working group that has been designated to develop the Federal Standard. As provided by Section 2 of the Defense Standardization Manual, Sandia Corporation as the preparing activity has asked that qualified representatives for the working group be designated by concerned agencies. As also provided in Paragraph 3-203 of the Manual, the preparing activity has designated $\mathrm{Mr}$. J. Gordon King of the Advanced Manufacturing Development Division of Sandia Corporation as Chairman of the working group.

The following persons have been designated as members of the working group and have indicated their willingness to serve. I would like each of these distinguished gentlemen to stand as I call his name so that you can recognize him in the future. Their names and mailing addresses will be distributed in a few minutes along with copies of the straw-man standard, so there is no need for you to write the names down in your notebooks.

In alphabetical order by last names we have:

Mr. Thomas R. Casberg, Office of Assistant Secretary of Defense (Installations and Logistics), Pentagon

Mr. Edward M. Do, Aerospace Division, Boeing Company

Lt. Col. B. L. Forkner, Field Command/DASA

Mr. J. W. Hodges, Army Missile Command, Redstone Arsena1

Mr. Harold Hollingsworth, AiResearch Manufacturing Company, Garrett Corporation Mr. Lloyd C. Kersey, AEC/Albuquerque Operations Office

Mr. Don E. Koontz, Bell Telephone Labs, Murray Hil1, New Jersey

Mr. Chris Logiss, Livermore Laboratory, Sandia Corporation

Mr. A. L. Lieberman, Armour Research Foundation

Mr. William E. B. Mason, Lewis Research Center, NASA

Mr. James R. Mildon, Lear-Sigler Inc.

Mr. Paul K. Miller, Standardization Division, General Services Administration Colonel I. R, Perkin, n1msted Air Forro Base, U.3. Mlr Force

Mr. E. C. Shadewald, U.S. Naval Air Station, San Diego

Mr. J. Gordon King, Sandia Corporation, Albuquerque, Chairman of Working Group

Mr. Jay A. Paulhamus of Sandia Corporation who will serve as Secretary for the Working Group

In addition to the named members of the working group, Mr. King has asked Willis Whitfield to serve as a technical advisor, and Mr. Frank Camperell FC/DASA will serve as technical advisor on standards.

I feel we are very fortunatc in securing the services of such a knowledgëable and responsible working group. It is a strong, well-balanced group of experts and the number of 16 is about right for efficient coordination. of course, Mr. King could add additional members to the working group as he sees fit.

Several members of the working group hold important offices in key technical societies such as the American Society for Testing and Materials (ASTM), the American Association for Contamination Control (AACC), and the Aerospace Industries Standards Association (AISA). Thus we have provided for valuable liaison with technical societies interested in the field of airborne contamination control. We have also provided four representatives outside the Federal agencies, not counting the two from Sandia Corporation.

Now, let us take a few minutcs and look at the straw-man proposed standard that was prepared for your review and for the specific consideration of the working group. This proposed standard represents the dedicated effort of a small study group composed of AEC/ALO, FC/DASA, and Sandia Corporation representatives. Special credit is due Mr. Frank Camperel1, Chief, Standardization Branch, FC/DASA for his professional assistance in keeping us on the straight and narrow with respect to conformance to the military guidelines for standards preparation; Mr. Chris Logiss of Sandia Corporation for his technical contributions; and $\mathrm{Mr}$. Lloyd Kersey of 
AEC/ALO for his valuable assistance in obtaining our assignment from GSA. Field Command, DASA had the draft typed and 450 copies reproduced in record time, and for this we are especially grateful. Sufficient extra copies should be on hand to provide the necessary supply for coordination of comments by the respective agencies.

I would like to highlight the most important parts of the straw-man standard. As you can see from the size and table of contents, there is a lot more meat than straw in the draft standard. Each section was worked and then reworked to lead the reader logically from an introduction of subject through a rather extensive nonmandatory appendix section (from pages 33 through 44).

There are three fundamental and essential factors in the straw-man standard that I wish to highlight at this time:

1. Airborne particle count is recognized as the most meaningful parameter for defining the controls on clean rooms and the most discriminating need for categorizing clean rooms. This factor is inherent in the definition of a clean room as given in the first paragraph of the Foreword (page II): "A space in which airborne contamination, and if needed, temperature and humidily are controlled to a far higher degree than conventional air-conditioned areas." Note that temperature and humidity controls are not the primary or discriminating environments for defining clean rooms; nor are other commonly used controls such as use of protective garments, air locks, lighting requirements, and special construction features such as rounded corners and stainless-steel tables the primary criteria for defining clean rooms. A clean room means airborne contamination control first; the other controls may or may not be added as the end use of the room dictates.

2. The proposed standard defines four classes of clean rooms (Page 7). The classifications are based solely on four maximum levels of airborne particle count, using minimum particle sizes of one-half a micron for counting. For Class A rooms (the most highly controlled clean rooms) only particles one-half micron or larger are counted, whereas Class $B, C$, and $D$ clean rooms are defined by maximum number of larger particles ( 5 microns or larger) as well as maximum number of small particles. Moreover, in Section 5.5.1, particle counting methods are enumerated to ensure uniform monitoring, and, consequently, uniform room classifications.

3. If the standard stopped with the classification of four clean rooms, I am sure all of us would be frustrated. There is a basic need for some "how-to-accomplish" information that can be translated into upgrading actions for current clean rooms and specifications for new construction. This third essential factor in the strawman standard is provided by recognition of the many possibilities that the laminar air-flow principle offers the designer of clean rooms. Pages 16 through 31 enumerate the essential performance requirements for laminar flow clean rooms and clean work stations. In addition, on Page 35 of the Appendix, the Standard recognizes the possibilities for upgrading the many exlsting conventional facilities by the nse of laminar flow work stations.

standard:

Let us recap then the three fundamental points covered by the "sllaw-maiil"

1. Airborne particle control (or dust control) is recognized and specified as the most significant factor for defining and classifying clean rooms.

2. Four classes of clean rooms are defined using maximum particle count as the criteria for categorizing.

3. "How-to-accomplish" information is given that will enable the designer to build new clean rooms and/or clean work stations to class A requirements by utilizing laminar flow principles or will permit the designer to upgrade conventional. existing facilities to Class B or C requirements by employing laminar-flow work stations. Table IV on Page 43 summarizes quite clearly the various methods for achieving desired clean room classifications. I recommend your close study of this table.

In addition to these three fundamental factors, there are several other key points worth highlighting for your review: 
On Page II the standard recognizes and defines the two distinct approaches to the design and operation of clean rooms and states that both approaches are covered in the document. Hence, only one standard, not two.

Page 2, paragraph 3.2, recognizes and defines a new concept of clean work stations utilizing the proven effective laminar flow principle.

Page 3, paragraph 3.3, defines laminar air flow, which has been the topic of many papers at this conference.

Page 4, paragraph 3.7, defines superinterception filters, which are later specified on Page 18 as, the final filters for all laminar flow clean rooms and work stations.

Page 13, paragraph 5.5.1, provides for the use of counting equipment employing light-scattering principles for particle sizes from 0.5 to 5 microns and microscopic counting of filtered particles for sizes larger than 5 microns.

Page 17, paragraph 5.7, a through $\underline{f}$, provides six vital requirements for the designer to follow in order to utilize the laminar flow principle to full advantage.

We also believe you will find the sketches shown on Pàges $20,24,28,29,30$, and 31 extremely useful in explaining the laminar flow principle and its variations to your associates when you return to your respective installations.

Gentlemen I sincerely request that each of you study this straw-man standard carefully and objectively. We feel it is a definitive standard badly needed; we feel it is up to date in terms of the state of the art; we feel it is a fair standard for the designer, the manufacturer, and the general public or the taxpayers. These three groups couldn't ask for anything less, now it is up to us to produce. 